\author{
SANDIA REPORT \\ SAND2008-3264 \\ Unlimited Release \\ May 2008
}

\title{
Evaluation of the Geotech Smart24 Data Acquisition System with Active Fortezza Crypto Card Data Signing and Authentication
}

Darren M. Hart

Prepared by

Sandia National Laboratories

Albuquerque, New Mexico 87185 and Livermore, California 94550

Sandia is a multiprogram laboratory operated by Sandia Corporation, a Lockheed Martin Company, for the United States Department of Energy's

National Nuclear Security Administration under Contract DE-AC04-94AL85000.

Approved for public release; further dissemination unlimited. 
Issued by Sandia National Laboratories, operated for the United States Department of Energy by Sandia Corporation.

NOTICE: This report was prepared as an account of work sponsored by an agency of the United States Government. Neither the United States Government, nor any agency thereof, nor any of their employees, nor any of their contractors, subcontractors, or their employees, make any warranty, express or implied, or assume any legal liability or responsibility for the accuracy, completeness, or usefulness of any information, apparatus, product, or process disclosed, or represent that its use would not infringe privately owned rights. Reference herein to any specific commercial product, process, or service by trade name, trademark, manufacturer, or otherwise, does not necessarily constitute or imply its endorsement, recommendation, or favoring by the United States Government, any agency thereof, or any of their contractors or subcontractors. The views and opinions expressed herein do not necessarily state or reflect those of the United States Government, any agency thereof, or any of their contractors.

Printed in the United States of America. This report has been reproduced directly from the best available copy.

Available to DOE and DOE contractors from

U.S. Department of Energy

Office of Scientific and Technical Information

P.O. Box 62

Oak Ridge, TN 37831

Telephone: $\quad$ (865) 576-8401

Facsimile: (865) 576-5728

E-Mail: $\quad$ reports@adonis.osti.gov

Online ordering: http://www.osti.gov/bridge

Available to the public from

U.S. Department of Commerce

National Technical Information Service

5285 Port Royal Rd.

Springfield, VA 22161

Telephone:

(800) 553-6847

Facsimile:

(703) 605-6900

E-Mail:

orders@ntis.fedworld.gov

Online order:

http://www.ntis.gov/help/ordermethods.asp?loc=7-4-0\#online

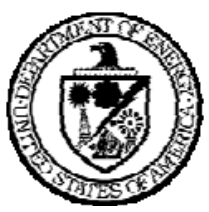


SAND2008-3264

Unlimited Release

May 2008

\title{
Evaluation of the Geotech Smart24 Data Acquisition System with Active Fortezza Crypto Card Data Signing and Authentication
}

\author{
Darren M. Hart \\ Ground-based Monitoring R and E \\ Sandia National Laboratories \\ P.O. Box 5800 \\ Albuquerque, New Mexico 87185
}

\begin{abstract}
Sandia National Laboratories has tested and evaluated Geotech Smart24 data acquisition system with active Fortezza crypto card data signing and authentication. The test results included in this report were in response to static and tonal-dynamic input signals. Most test methodologies used were based on IEEE Standards 1057 for Digitizing Waveform Recorders and 1241 for Analog to Digital Converters; others were designed by Sandia specifically for infrasound application evaluation and for supplementary criteria not addressed in the IEEE standards.
\end{abstract}


Table of Contents

1 EXECUTIVE SUMMARY 7

1.1 SMART24 w/ForTEZZA 20SPS AND 20VPP ADC BOARD- DigitizER EVALUATION SUMMARY:...... 7

1.2 SMART24 W/FORTEZZA 40SPS AND 20VPP ADC BOARD - DigITIZER EVALUATION SUMMARY:..... 8

1.3 SMART24 W/FORTEZZA 20SPS AND 40VPP ADC BOARD - DIGITIZER EVALUATION SUMMARY:..... 8

1.4 SMART24 W/FORTEZZA 40SPS AND 40VPP ADC BOARD - DigITIZER EVALUATION SUMMARY:..... 9

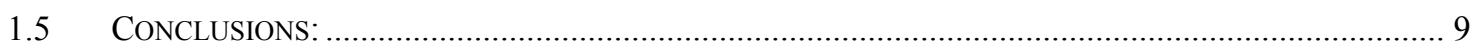

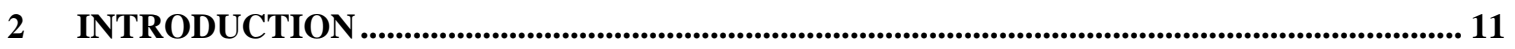

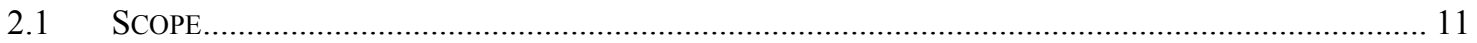

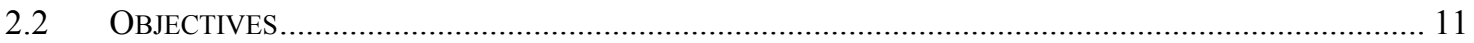

3 DWR TEST AND EVALUATION PROGRAM .................................................................................. 11

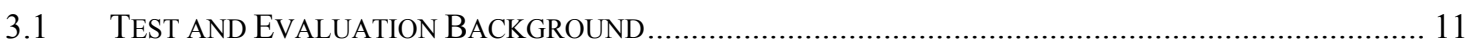

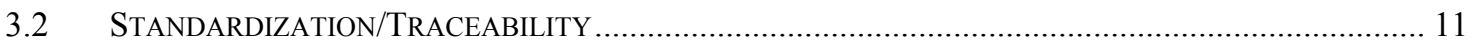

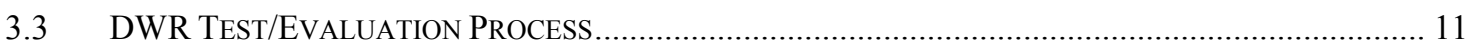

3.4 TEST CONFIGURATION AND SYSTEM SPECIFICATIONS .................................................................. 12

4 DWR - SMART24 TESTS …............................................................................................................. 12

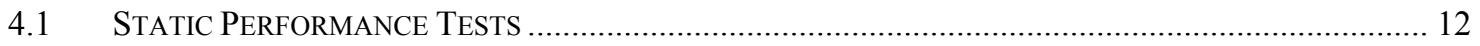

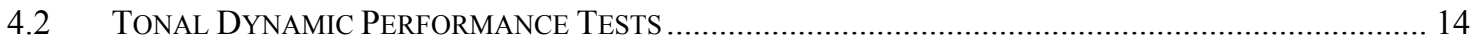

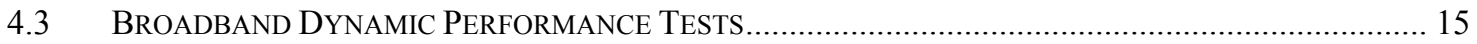

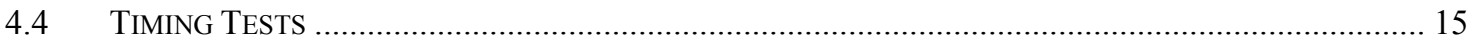

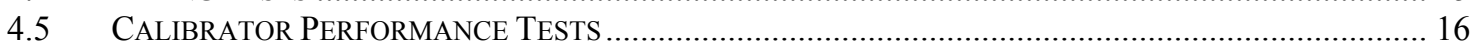

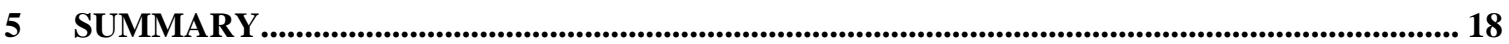

5.1 SMART24 w/FORTEZZA 20SPS AND 20VPP ADC BOARD- DigITIZER EVALUATION SUMMARY:.... 18

5.2 SMART24 W/FORTEZZA 40SPS AND 20VPP ADC BOARD - DiGITIZER EVALUATION SUMMARY:... 19

5.3 SMART24 W/FORTEZZA 20SPS AND 40VPP ADC BOARD - DigITIZER EVALUATION SUMMARY:... 19

5.4 SMART24 W/FORTEZZA 40SPS AND 40VPP ADC BOARD - DigitiZER EVALUATION SUMMARY:... 20

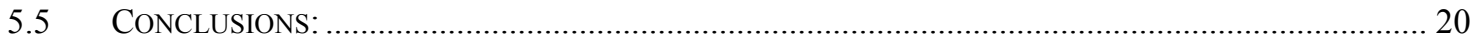

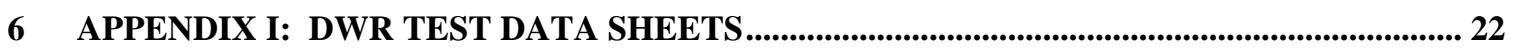

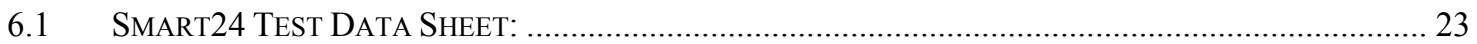

6.2 SMART24 TeSt DATA SHEET: 20 VPP ADC TEST - STATIC/DCA ………................................ 25

6.3 SMART24 TEST DATA SHEET: 20 VPP ADC TEST - STATIC/ITN/MPDR ………......................... 26

6.4 SMART24 TEST DATA SHEET: 20 VPP ADC TEST - STATIC/ITN/MPDR …................................. 29

6.5 SMART24 TEST DATA SHEET: 20 VPP ADC TEST - DYNAMIC TONAL/THD .............................. 32

6.6 SMART24 TEST DATA SHEET: 20 VPP ADC TEST - DyNAMIC TONAL/CTK ................................ 34

6.7 SMART24 TEST DATA SHEET: 20 VPP ADC TEST - DyNAMIC BROADBAND/RTF/ABW ............. 35

6.8 SMART24 TeST DATA SHEET: 20 VPP ADC TEST - TIMING/TTA ................................................. 38

6.9 SMART24 TEST DATA SHEET: 20 VPP ADC TEST - CALIBRATOR/CAT/CFT .............................. 40

6.10 SMART24 TeSt DATA SHEET: 20 VPP ADC TEST - CALIBRATOR/CAT/CFT .............................. 41

6.11 SMART24 TEST DATA SHEET: 20 VPP ADC TEST - CALIBRATOR/CHD/CLB ............................ 42

6.12 SMART24 TeSt DATA SHEET: 20 VPP ADC TEST - CAliBRATOR/CHD/CLB ............................ 44

6.13 SMART24 TeSt DATA SHEET: 40 VPP ADC TEST - STATIC/DCA ……...................................... 46

6.14 SMART24 TEST DATA SHEET: 40 VPP ADC TEST - STATIC/ITN/MPDR ……............................. 47

6.15 SMART24 TEST DATA SHEET: 40 VPP ADC TEST - STATIC/ITN/MPDR …................................... 50

6.16 SMART24 TeSt DATA SHEET: 40 VPP ADC TEST - DYNAMIC TONAL/THD ............................... 53

6.17 SMART24 TEST DATA SHEET: 40 VPP ADC TEST - DyNAMIC TONAL/CTK ................................. 55

6.18 SMART24 TEST DATA SHEET: 40 VPP ADC TEST - DYNAMIC BROADBAND/RTF/ABW ............ 56

6.19 SMART24 TeSt DATA SHEET: 40 VPP ADC TEST - TIMING/TTA ............................................... 59 
6.20 SMART24 TeST DATA SHEET: 40 VPP ADC TEST - CALIBRATOR/CAT/CFT ............................61

6.21 SMART24 TEST DATA SHEET: 40 VPP ADC TEST - CALIBRATOR/CAT/CFT ............................62

6.22 SMART24 TEST DATA SHEET: 40 VPP ADC TEST - CALIBRATOR/CHD/CLB ............................63 63

6.23 SMART24 TEST DATA SHEET: 40 VPP ADC TEST - CALIBRATOR/CHD/CLB ..........................65

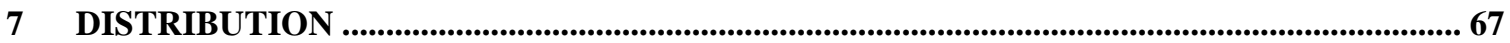




\section{Executive Summary}

\section{Objective:}

The objective of this work was to evaluate the overall technical performance of the Geotech Smart24 digitizer with a Fortezza PCMCIA crypto card actively implementing the signing of data packets. The results of this evaluation were compared to relevant specifications provided within manufacturer's documentation notes. The tests performed were chosen to demonstrate different performance aspects of the digitizer under test. The performance aspects tested include determining noise floor, least significant bit (LSB), dynamic range, cross-talk, relative channel-to-channel timing, time-tag accuracy, analog bandwidth and calibrator performance.

\section{Description:}

The SMART24 digitizers under evaluation were manufactured by Geotech Instruments, LLC of Dallas, TX. The SMART24 was designed to be a high resolution 24-bit data acquisition system, configured for 1channel or 3-channel operation. Smart24 digitizers were designed to have the capability to be configured to collect data from either an infrasound or seismic application. An additional requirement for some installations is to have the capability to sign outgoing data packets. The Smart24 digitizer supports the use of a Fortezza Crypto PCMCIA Card for the purpose of data signing and authentication. For an infrasound application, the likely Smart 24 configuration would be $20 \mathrm{Vpp}$ ADC Board, LSB of 1.6355e-06 V/count, one active channel and sampled at 20 samples-per-second (sps). While for a seismic application the configuration would likely be $40 \mathrm{Vpp}$ ADC Board, LSB of 3.271e-6 V/count, three active channels and sampled at $40 \mathrm{sps}$. Digitizer testing focused on characterization of one unit serial number s1224. It is expected that other Geotech Smart24 with Fortezza PCMCIA crypto cards will perform in a like manner.

The central recording facility at FACT uses the Geotech GeoHub software suite running on a standard PC for acquisition and data archiving of the test data. The GeoHub system was designed for network and array operators to allow greater control in data acquisition, data concentration and distribution for data archiving via its flexible communication protocol. The basic data transmission path from the data loggers to database starts at the Smart24 with a RJ45 Ethernet connection to the FACT internal LAN. The PC running the GeoHub software was also connected to the same LAN. The Smart24 and GeoHub communicate via fixed IP addresses. All test data were acquired in near real-time in CSS 3.0 flat-file database records in S4 format.

Testing was performed in a seismic vault for temperature stability. The Smart24 tested were set to the gain of 1 , required for seismic or infrasound applications.

\subsection{Smart24 w/Fortezza 20sps and 20Vpp ADC Board- Digitizer Evaluation Summary:}

Static Performance:

Smart $24 \mathrm{w} /$ Fortezza DC accuracy errors were within $0.52 \%$ for standard \pm 1 volt scale. DC offset was less than 23 microvolts. The input terminated noise was less than 0.88 counts RMS for the 0.02 to $10 \mathrm{~Hz}$ application band. The Maximum Potential Dynamic Range was better than $133.7 \mathrm{~dB}$.

\section{Tonal Dynamic Performance:}

The Smart24 w/Fortezza Total Harmonic Distortion (THD) was better than -121.8 dB. Crosstalk between channels was better than $-122 \mathrm{~dB}$.

Broadband Dynamic Performance:

Smart24 w/Fortezza channel to channel timing was better than 1.1 microseconds for the 0.02 to $10 \mathrm{~Hz}$ band. Bandwidth measured $-3 \mathrm{~dB}$ at $8.5 \mathrm{~Hz}$ with a relative attenuation of $-112 \mathrm{~dB}$ at the Nyquist.

\section{Timing Performance:}


The Smart24 w/Fortezza time-tagged the data with respect to the digitizer input to better than 18.0 microseconds.

Calibrator Performance:

The Smart24 w/Fortezza produced sinusoids of variable amplitudes for a fixed frequency of $1 \mathrm{~Hz}$ within $0.3 \%$ of the programmed voltage values. By varying the frequency for a fixed amplitude of 1 volt the Smart $24 \mathrm{w} /$ Fortezza produced sinusoids with frequencies that matched the programmed frequency values. The Smart24 calibrator's signal generator has a THD of $-80.6 \mathrm{~dB}$ for a $1 \mathrm{~Hz} 1$ volt sinusoid when output in sensor mode. The Smart24 calibrator when in loopback mode (instead of sensor output mode) has a measured Calibrator Loopback THD (CLB) of $-81.6 \mathrm{~dB}$.

\subsection{Smart24 w/Fortezza 40sps and 20Vpp ADC Board - Digitizer Evaluation Summary:}

Static Performance:

Smart $24 \mathrm{w} /$ Fortezza DC accuracy errors were within $0.52 \%$ for standard \pm 1 volt scale. DC offset was less than 24.7 microvolts. The input terminated noise was less than 1.13 counts RMS for the 0.02 to $20 \mathrm{~Hz}$ application band. The Maximum Potential Dynamic Range was better than $131.6 \mathrm{~dB}$.

\section{Tonal Dynamic Performance:}

The Smart24 w/Fortezza Total Harmonic Distortion (THD) was better than -121.2 dB. Crosstalk between channels was better than $-120 \mathrm{~dB}$.

Broadband Dynamic Performance:

Smart24 w/Fortezza channel to channel timing was better than 1.1 microseconds for the 0.02 to $20 \mathrm{~Hz}$ band. Bandwidth measured $-3 \mathrm{~dB}$ at $17.1 \mathrm{~Hz}$ with a relative attenuation of $-117 \mathrm{~dB}$ at the Nyquist.

Timing Performance:

The Smart24 w/Fortezza time-tagged the data with respect to the digitizer input to better than 19.0 microseconds.

\section{Calibrator Performance:}

The Smart24 w/Fortezza produced sinusoids of variable amplitudes for a fixed frequency of $1 \mathrm{~Hz}$ within $0.3 \%$ of the programmed voltage values. By varying the frequency with a fixed amplitude of 1 volt the Smart $24 \mathrm{w} /$ Fortezza produced sinusoids with frequencies that matched the programmed frequency values. The Smart24 calibrator's signal generator has a THD of $-79.6 \mathrm{~dB}$ for a $1 \mathrm{~Hz} 1$ volt sinusoid when output in sensor mode. The Smart24 calibrator when in loopback mode (instead of sensor output mode) has a measured Calibrator Loopback THD (CLB) of $-79.0 \mathrm{~dB}$.

\subsection{Smart24 w/Fortezza 20sps and 40Vpp ADC Board - Digitizer Evaluation Summary:}

Static Performance:

Smart $24 \mathrm{w} /$ Fortezza DC accuracy errors were within $0.37 \%$ for standard \pm 1 volt scale. DC offset was less than 99 microvolts. The input terminated noise was less than 0.79 counts RMS for the 0.02 to $10 \mathrm{~Hz}$ application band. The Maximum Potential Dynamic Range was better than $134.7 \mathrm{~dB}$.

Tonal Dynamic Performance:

The Smart24 w/Fortezza Total Harmonic Distortion (THD) was better than -124.6 dB. Crosstalk between channels was better than $-122.7 \mathrm{~dB}$.

Broadband Dynamic Performance:

Smart24 w/Fortezza channel to channel timing was better than 4.4 microseconds for the 0.02 to $10 \mathrm{~Hz}$ band. Bandwidth measured $-3 \mathrm{~dB}$ at $8.6 \mathrm{~Hz}$ with a relative attenuation of better than $-113 \mathrm{~dB}$ at the Nyquist.

Timing Performance: 
The Smart24 w/Fortezza time-tagged the data with respect to the digitizer input to better than 8 microseconds.

Calibrator Performance:

The Smart24 w/Fortezza produced sinusoids of variable amplitudes for a fixed frequency of $1 \mathrm{~Hz}$ within $0.3 \%$ of the programmed voltage values. By varying the frequency with a fixed amplitude of 1 volt the Smart $24 \mathrm{w} /$ Fortezza produced sinusoids with frequencies that matched the programmed frequency values. The Smart24 calibrator's signal generator has a THD of $-79.6 \mathrm{~dB}$ for a $1 \mathrm{~Hz} 1$ volt sinusoid when output in sensor mode. The Smart24 calibrator when in loopback mode (instead of sensor output mode) has a measured Calibrator Loopback THD (CLB) of $-77.3 \mathrm{~dB}$.

\subsection{Smart24 w/Fortezza 40sps and 40Vpp ADC Board - Digitizer Evaluation Summary:}

Static Performance:

Smart $24 \mathrm{w} /$ Fortezza DC accuracy errors were within $0.37 \%$ for standard \pm 1 volt scale. DC offset was less than 99 microvolts. The input terminated noise was less than 0.97 counts RMS for the 0.02 to $20 \mathrm{~Hz}$ application band. The Maximum Potential Dynamic Range was better than $133.0 \mathrm{~dB}$.

\section{Tonal Dynamic Performance:}

The Smart24 w/Fortezza Total Harmonic Distortion (THD) was better than -125.4 dB. Crosstalk between channels was better than $-121.4 \mathrm{~dB}$.

Broadband Dynamic Performance:

Smart24 w/Fortezza channel to channel timing was better than 0.41 microseconds for the 0.02 to $20 \mathrm{~Hz}$ band. Bandwidth measured $-3 \mathrm{~dB}$ at $17.1 \mathrm{~Hz}$ with a relative attenuation of $-121 \mathrm{~dB}$ at the Nyquist.

\section{Timing Performance:}

The Smart24 w/Fortezza time-tagged the data with respect to the digitizer input to better than 7 microseconds.

\section{Calibrator Performance:}

The Smart24 w/Fortezza produced sinusoids of variable amplitudes for a fixed frequency of $1 \mathrm{~Hz}$ within $0.47 \%$ of the programmed voltage values. By varying the frequency with a fixed amplitude of 1 volt the Smart24 w/Fortezza produced sinusoids with frequencies that were within $0.0004 \%$ the programmed frequency values. The Smart2 4 calibrator's signal generator has a THD of $-79.0 \mathrm{~dB}$ for a $1 \mathrm{~Hz} 1 \mathrm{volt}$ sinusoid when output in sensor mode. The Smart24 calibrator when in loopback mode (instead of sensor output mode) has a measured Calibrator Loopback THD (CLB) of $-77.2 \mathrm{~dB}$.

\subsection{Conclusions:}

Results, where appropriate, are compared to Manufacturer specifications listed in Smart24 Series User Manual. Note: manufacturer's specifications taken at 50 sps.

The Smart24 digitizer with the 20Vpp ADC board had performance of 21.9-bits for the 0.02 to $10 \mathrm{~Hz}$ passband at 20 samples per second. The Smart24 digitizer with the 20Vpp ADC board had performance of 21.6 for the 0.02 to $20 \mathrm{~Hz}$ passband at 40 samples per second. The total harmonic distortion (THD) of $121 \mathrm{~dB}$ was below manufacturer specifications of $-110 \mathrm{~dB}$. The input terminated noise (ITN) was slightly higher, 1.3 counts RMS, than manufacturer specifications of 0.8 counts RMS. Dynamic range was found to $132 \mathrm{~dB}$ or greater. (Note: The RMS band not specified by manufacture and sampled at different rate.) The Channel-to-Channel timing skew was better than 1.1 microseconds, still greater than the manufacturer specified \pm 50 nanoseconds. The Data sample time-tag accuracy of better than 19 microseconds, was outside manufacturer's specifications of 10 microseconds, but meets International Monitoring System requirements. . The Analog bandwidth of $8.6 \mathrm{~Hz}$ was better than that listed by manufacturer as $80 \%$ of Nyquist. 
The Smart24 digitizer with the 40Vpp ADC board had performance of 22.1-bits for the 0.02 to $10 \mathrm{~Hz}$ passband at 20 samples per second. The Smart24 digitizer with the 40Vpp ADC board had performance of 21.8 for the 0.02 to $20 \mathrm{~Hz}$ passband at 40 samples per second.

The total harmonic distortion (THD) of $-124.6 \mathrm{~dB}$ was below manufacturer specifications of $-110 \mathrm{~dB}$. The input terminated noise (ITN) was slightly higher, 1.0 counts RMS, than manufacturer specifications of 0.8 counts RMS. Dynamic range was found to $133 \mathrm{~dB}$ or greater. (Note: RMS band not specified by manufacturer and sampled at different rate). The Channel-to-Channel timing skew was better than 4.4 microseconds, still greater than the manufacturer specified \pm 50 nanoseconds. The data sample time-tag accuracy of better than 8 microseconds, was within manufacturer's specifications of 10 microseconds. The analog bandwidth of $17.1 \mathrm{~Hz}$ was better than that listed by manufacturer as $80 \%$ of Nyquist. 


\section{Introduction}

\subsection{Scope}

This Evaluation Report defines the activities that were performed as part of the evaluation of the Geotech Smart24 configured with a Fortezza Crypto PCMCIA Card describes the results of the testing.

\subsection{Objectives}

The objective of this work was to evaluate the overall technical performance of the Geotech Smart24 digitizer while the Fortezza Card is enabled and signing data outbound data packets. Basic digitizer characterization includes determining LSB, DC offset, noise, dynamic range, time-tag accuracy, channelto-channel cross-talk, total harmonic distortion and the calibrator's performance. The results of this evaluation were compared to relevant application requirements or specifications of the Smart24 provided by the manufacturer.

\section{DWR Test and Evaluation Program}

\subsection{Test and Evaluation Background}

Sandia National Laboratories (SNL), Ground-based Monitoring R\&E Department has the capability of evaluating the performance of digitizing waveform recorders and analog-to-digital converters/highresolution digitizers for geophysical applications.

\subsection{Standardization/Traceability}

Most tests are based on the Institute of Electrical and Electronics Engineers (IEEE) Standard 1057

[Reference 1] for Digitizing Waveform Recorders and Standard 1241 for Analog to Digital Converters [Reference 2]. The analyses based on these standards were performed in the frequency domain or time domain as required. When appropriate, instrumentation calibration was traceable to the National Institute for Standards Technology (NIST).

\subsection{DWR Test/Evaluation Process}

\subsubsection{SMART24 Testing}

Testing of the Smart24 w/Fortezza, serial number s1224, digitizer was performed between October 2007 and February 2008, at the Sandia National Laboratories Facility for Acceptance, Calibration and Testing (FACT) Site, Albuquerque, NM. The unit arrived with one $20 \mathrm{Vpp}$ ADC board installed, serial number 1360. The ADC board has an input range of 20 Volts peak-to-peak (Vpp). To test the performance of a 40 Vpp ADC board, required Sandia provide one for testing. The $40 \mathrm{Vpp}$ ADC used for testing was serial number 1724 procured by Sandia November 2007.

The Smart24 allows up to four data customer profiles to be configured. We configured profile \#3 for testing at FACT. Configuration of the profile consisted of setting the peak-to-peak voltage, sample rate and channel naming convention. For both ADC boards tested at 20sps the data was labeled as c1s -channel 1 , $\mathrm{c} 2 \mathrm{~s}$ - channel 2 and $\mathrm{c} 3 \mathrm{~s}$ - channel 3; the 40 sps data was labeled as BDF - channel 1, c2p - channel 2 and $\mathrm{c} 3 \mathrm{p}$ - channel 3 .

\subsubsection{SMART24 General Digitizer Performance Tests}

The following tests were conducted on the Smart24 as described in the test plan: Test Definition and Test Procedures for the Evaluation of Digitizing Waveform Recorders [Reference 3].

The tests selected provide a high level of characterization for IMS when evaluating digitizers for seismic or acoustic applications.

Smart24 w/Fortezza 20Vpp / 40Vpp and 20sps / 40sps Configuration 
Static Performance Tests

DC Accuracy Nominal (DWR-DCA)

Input Terminated Noise (DWR-ITN)

Maximum Potential Dynamic Range (DWR-MPDR)

Tonal Dynamic Performance Tests

Total Harmonic Distortion (DWR-THD)

Crosstalk (DWR-CTK)

Broadband Dynamic Performance Tests

Analog Bandwidth (DWR-ABW)

Relative Transfer Function (DWR-RTF)

Timing Tests

Time-Tag Accuracy (DWR-TTA)

Calibrator Performance Tests

Sine Calibrator Amplitude (DWR-CAT)

Sine Calibrator Frequency (DWR-CFT)

Sine Calibrator THD (DWR-CHD)

Sine Calibrator Loop-Back (DWR-CLB)

\subsection{Test Configuration and System Specifications}

\subsubsection{Smart24 Digitizer Description and Test Configuration}

The SMART24 digitizers under evaluation were manufactured by Geotech Instruments, LLC of Dallas, TX. The SMART24 was designed to be a high resolution 24-bit data acquisition system. The SMART24 was configured to acquire a primary data stream at 40 samples per second (sps) and a secondary data stream at 20 sps. The system under test used the GeoHub ${ }^{\text {TM }}$ data acquisition software for the SMART24 digitizers. GeoHub operated on a PC running Windows XP and communicated with the SMART24 digitizers through an Ethernet connection. Data were acquired in real-time in CSS 3.0 flat-file records. Waveform data were archived in "s4" data format.

DWR testing was performed in a seismic vault for temperature stability.
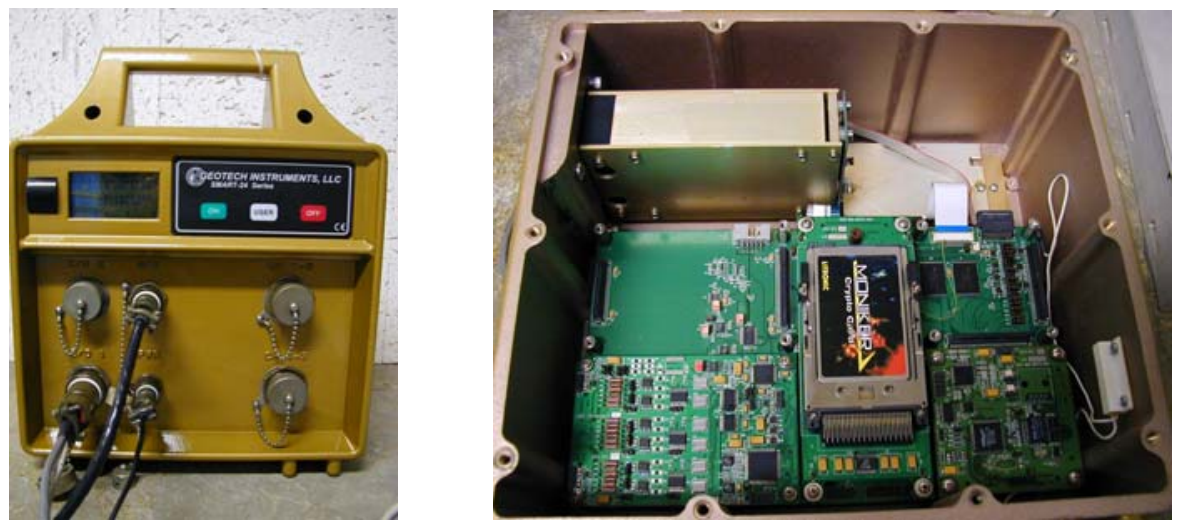

Figure 3.4.1 Smart24 w/Fortezza Card used for testing in FACT Vault. Illustrating the unit as viewed from the front and inside after removing back plate.

\section{DWR - SMART24 Tests}

\subsection{Static Performance Tests}

Static tests provide a constant or non time-varying stimulus to the DWR under evaluation. The purpose of these tests is to determine specific parameters such as: gain (accuracy at nominal, full-scale and overscale), DC offset, short-term and long-term stability, relationship to quantizing noise floor, and 
correlated/uncorrelated spurious signals. The results of these tests include measurement of dynamic range and resolution.

\subsubsection{Accuracy Standard (DWR-DCA)}

Purpose: The purpose of the DC accuracy test was to determine and verify the accuracy of the SMART24. The bit-weight (LSB) of a non-gain-ranged digitizer is its resolution.

Configuration: The SMART24 inputs were connected to a high precision +/- DC voltage source set to +/- 1 volt.

Evaluation: The DC gain (accuracy) of the SMART24, DC offset, bit-weight (LSB)/resolution and counts/volt were measured.

\section{Test Results:}

20 Vpp ADC board:

DWR Serial Number: ADC 1360 20sps DCA Test Data Sheet, Appendix I, Section 6.2. DWR Serial Number: ADC 1360 40sps DCA Test Data Sheet, Appendix I, Section 6.2. 40 Vpp ADC board:

DWR Serial Number: ADC 1724 20sps DCA Test Data Sheet, Appendix I, Section 6.13.

DWR Serial Number: ADC 1724 40sps DCA Test Data Sheet, Appendix I, Section 6.13.

\subsubsection{Input Terminated Noise (DWR-ITN)}

Purpose: The purpose of the input-terminated noise test was to verify the static parameters of the SMART24. These static parameters are dominated primarily by the random noise generated within the digitizer and from other components within the digitizer package.

Configuration: The SMART24 Port 1 inputs were terminated with 100 ohms external resistors.

Evaluation: A power density spectrum (PDS) of the input-terminated noise provided a measure of the noise floor of the SMART24. RMS noise in the 0.02 to $20 \mathrm{~Hz}$ bandwidth for 40 sps data, 0.02 to $10 \mathrm{~Hz}$ bandwidth for the 20 sps data, short term and long-term stability, relationship to quantizing noise floor and correlated and uncorrelated spurious signals were measured.

Test Results:

20 Vpp ADC board:

DWR Serial Number: ADC 1360 20sps ITN/MPDR Test Data Sheet, Appendix I, Section 6.3. DWR Serial Number: ADC 1360 40sps ITN/MPDR Test Data Sheet, Appendix I, Section 6.4. 40 Vpp ADC board:

DWR Serial Number: ADC 1724 20sps ITN/MPDR Test Data Sheet, Appendix I, Section 6.14. DWR Serial Number: ADC 1724 40sps ITN/MPDR Test Data Sheet, Appendix I, Section 6.15.

\subsubsection{Maximum Potential Dynamic Range (DWR-MPDR) Computation}

Calculating the RMS value of the full-scale sinusoid (20.0 Volts or 40.0 Volts) and dividing by the RMS value of the Input Terminated Noise (ITN) test data determined the Maximum Potential Dynamic Range (MPDR) of the SMART24. A bandwidth of 0.02 to $20 \mathrm{~Hz}$ was used for 40 sps data and 0.02 to $10 \mathrm{~Hz}$ was used for the 20 sps data.

\section{Test Results:}

20 Vpp ADC board:

DWR Serial Number: ADC 1360 20sps ITN/MPDR Test Data Sheet, Appendix I, Section 6.3. DWR Serial Number: ADC 1360 40sps ITN/MPDR Test Data Sheet, Appendix I, Section 6.4. 40 Vpp ADC board: 
DWR Serial Number: ADC 1724 20sps ITN/MPDR Test Data Sheet, Appendix I, Section 6.14. DWR Serial Number: ADC 1724 40sps ITN/MPDR Test Data Sheet, Appendix I, Section 6.15.

\subsection{Tonal Dynamic Performance Tests}

Tonal tests are dynamic tests that use sinusoids as stimuli. Sine waves are the most popular signals for evaluating analog-to-digital converter performance because of the ease of generation and mathematical analysis. The DWR under test is asynchronously sampled with respect to the signal source for all tonal tests.

Dynamic tests are those that provide a time-varying stimulus to the DWR under evaluation. The purpose of these tests is to determine the DWR performance when digitizing time-varying signals. Several tests are available to determine the DWR digitizer's self noise, deviation from ideal performance and conversion distortions.

\subsubsection{Total Harmonic Distortion (DWR-THD)}

Purpose: The purpose of the total harmonic distortion test was to verify the linearity and to identify sources of non-linearity of the SMART24.

Configuration: The SMART24 inputs were connected to an ultra-low-distortion oscillator. The amplitude of the oscillator was set to approximately one-half full scale. The $40 \mathrm{Vpp}$ ADC board had an input of approximately $20 \mathrm{Vpp}$ and the $20 \mathrm{Vpp}$ ADC board had an input of $10.0 \mathrm{Vpp}$. The oscillator was set to a frequency $(1.4 \mathrm{~Hz})$ unrelated to the sample rate and with at least nine harmonics observable.

Evaluation: A power density spectrum provided a measure of the non-linearity of the SMART24. THD was calculated by integrating the power density spectral peaks at the fundamental and all harmonics (up to nine) below the Nyquist frequency.

Test Results:

20 Vpp ADC board:

DWR Serial Number: ADC 1360 20sps THD Test Data Sheet, Appendix I, Section 6.5. DWR Serial Number: ADC 1360 40sps THD Test Data Sheet, Appendix I, Section 6.5. 40 Vpp ADC board:

DWR Serial Number: ADC 1724 20sps THD Test Data Sheet, Appendix I, Section 6.16. DWR Serial Number: ADC 1724 40sps THD Test Data Sheet, Appendix I, Section 6.16.

\subsubsection{Crosstalk (DWR-CTK)}

Purpose: The purpose of the crosstalk test was to determine the extent of crosstalk between channels on the multi-channel SMART24.

Configuration: The SMART24 channel under test was terminated with 50 ohms. All other SMART24 inputs were connected to a large amplitude (i.e. $20 \mathrm{Vpp}$ for $40 \mathrm{Vpp}$ ADC board and $10 \mathrm{Vpp}$ for $20 \mathrm{Vpp}$ ADC board) sinusoidal $(1.4 \mathrm{~Hz})$ test signal.

Evaluation: A power density spectrum provided a measure of crosstalk. The ratio of test signal to crosstalk signal was calculated using integrated power density spectra around the signal frequency.

Test Results:

20 Vpp ADC board:

DWR Serial Number: ADC 1360 20sps CTK Test Data Sheet, Appendix I, Section 6.6. DWR Serial Number: ADC 1360 40sps CTK Test Data Sheet, Appendix I, Section 6.6. 40 Vpp ADC board:

DWR Serial Number: ADC 1724 20sps CTK Test Data Sheet, Appendix I, Section 6.17. DWR Serial Number: ADC 1724 40sps CTK Test Data Sheet, Appendix I, Section 6.17. 


\subsection{Broadband Dynamic Performance Tests}

Broadband tests are dynamic tests that use Gaussian pseudo-random signal generators as stimuli.

Dynamic tests are those that provide a time-varying stimulus to the DWR under evaluation. The purpose of these tests is to determine the DWR performance when digitizing time-varying signals. Multitudes of tests are available to determine the DWR digitizer's self noise, deviation from ideal performance and conversion distortions.

\subsubsection{Relative Transfer Function (DWR-RTF)}

Purpose: The purpose of the relative transfer function test was to determine the relative phase between channels in the multi-channel SMART24.

Configuration: The SMART24 inputs were connected to a bandwidth-limited Gaussian signal generator. The signal generator output amplitude was set to approximately $20 \mathrm{Vpp}$ for the $40 \mathrm{Vpp}$ ADC board and set to approximately $10 \mathrm{Vpp}$ for the $20 \mathrm{Vpp}$ ADC board.

Evaluation: Coherence analysis computation provided a measure of relative phase. Channel-to-channel timing was calculated.

Test Results:

20 Vpp ADC board:

DWR Serial Number: ADC 1360 20sps RTF/ABW Test Data Sheet, Appendix I, Section 6.7. DWR Serial Number: ADC 1360 40sps RTF/ABW Test Data Sheet, Appendix I, Section 6.7. 20 Vpp ADC board:

DWR Serial Number: ADC 1724 20sps RTF/ABW Test Data Sheet, Appendix I, Section 6.18. DWR Serial Number: ADC 1724 40sps RTF/ABW Test Data Sheet, Appendix I, Section 6.18.

\subsubsection{Analog Bandwidth (DWR-ABW)}

Purpose: The purpose of the analog bandwidth test was to verify the bandwidth of the SMART24 digital FIR filter.

Configuration: The SMART24 inputs were connected to a bandwidth-limited Gaussian signal generator. The bandwidth of the signal generator was set to avoid aliasing the SMART24 and to maximize the power within the passband. The signal generator output amplitude was set to approximately $20 \mathrm{Vpp}$ for the 40 Vpp ADC board and set to approximately $10 \mathrm{Vpp}$ for the $20 \mathrm{Vpp}$ ADC board.

Evaluation: A power density spectrum provided a measure of the SMART24 digitizer bandwidth. The 3 $\mathrm{dB}$ point and relative attenuation at the Nyquist of the digital FIR filters were measured.

Test Results:

20 Vpp ADC board:

DWR Serial Number: ADC 1360 20sps RTF/ABW Test Data Sheet, Appendix I, Section 6.7. DWR Serial Number: ADC 1360 40sps RTF/ABW Test Data Sheet, Appendix I, Section 6.7. 40 Vpp ADC board:

DWR Serial Number: ADC 1724 20sps RTF/ABW Test Data Sheet, Appendix I, Section 6.18. DWR Serial Number: ADC 1724 40sps RTF/ABW Test Data Sheet, Appendix I, Section 6.18.

\subsection{Timing Tests}

Geophysical digitizing waveform recorders utilize a Universal Time Code (UTC) source, typically GPS, to time-tag the digitizer data samples. The HRD internal clock is usually synchronized to or phase-locked to this UTC receiver. Timing tests can determine the accuracy of this time-tag. 


\subsubsection{Time Tag Accuracy (DWR-TTA)}

Purpose: The purpose of the time tag accuracy test was to verify the ability of the SMART24 to accurately time-tag the data samples with respect to the digitizer inputs.

Configuration: One SMART24 input was connected to the One Pulse per Minute (PPM) output of an independent running GPS Timing Reference.

Evaluation: The time tags of the data from the SMART24 were analyzed for correct time on the minute transition for an hour crossing.

Test Results:

20 Vpp ADC board:

DWR Serial Number: ADC 1360 20sps TTA Test Data Sheet, Appendix I, Section 6.8. DWR Serial Number: ADC 1360 40sps TTA Test Data Sheet, Appendix I, Section 6.8. 40 Vpp ADC board:

DWR Serial Number: ADC 1724 20sps TTA Test Data Sheet, Appendix I, Section 6.19. DWR Serial Number: ADC 1724 40sps TTA Test Data Sheet, Appendix I, Section 6.19.

\subsection{Calibrator Performance Tests}

Digitizing Waveform Recorders frequently include a programmable voltage or current calibrator source to calibrate the internal DWR or drive a sensor calibration input. The calibrator may generate sinusoidal, step, white/pink noise, random binary telegraph (RBT) or a combination of these. The calibrator performance can be tested to determine parameters such as amplitude accuracy, frequency/duration, and distortion.

\subsubsection{Sine-calibrator Amplitude (DWR-CAT)}

Purpose: The purpose of the calibrator amplitude test is to determine and verify if the SMART24

accurately outputs the correct amplitude for sensor calibrations.

Configuration: The DWR calibrator output is connected to a signal source measurement system. The amplitude and frequency of the SMART24 calibrator are set to known levels. The frequency was fixed at 1 $\mathrm{Hz}$ and several different amplitude values were executed from the calibrator (i.e. 5, 1, 0.5, 0.1, 0.05 and $0.01)$.

Evaluation: Measured amplitudes are compared to the programmed amplitudes.

\section{Test Results:}

20 Vpp ADC board:

DWR Serial Number: ADC 1360 20sps DWR-CAT/CFT Test Data Sheet, Appendix I, Section 6.9. DWR Serial Number: ADC 1360 40sps DWR-CAT/CFT Test Data Sheet, Appendix I, Section 6.10. 40 Vpp ADC board:

DWR Serial Number: ADC 1724 20sps DWR-CAT/CFT Test Data Sheet, Appendix I, Section 6.20. DWR Serial Number: ADC 1724 40sps DWR-CAT/CFT Test Data Sheet, Appendix I, Section 6.21.

\subsubsection{Sine-Calibrator Frequency (DWR-CFT)}

Purpose: The purpose of the calibrator frequency test is to determine and verify if the SMART24 accurately outputs the correct frequency for sensor calibrations.

Configuration: The SMART24 Calibrator output is connected to a frequency counter. The calibrator is programmed to output sinusoids at a range of frequencies. The amplitude was fixed at 1 volt and several different frequencies were executed from the calibrator (i.e. 5, 1, 0.5, 0.1, and 0.05).

Evaluation: Measured frequencies are compared to the programmed frequencies. 
Test Results:

20 Vpp ADC board:

DWR Serial Number: ADC 1360 20sps DWR-CAT/CFT Test Data Sheet, Appendix I, Section 6.9. DWR Serial Number: ADC 1360 40sps DWR-CAT/CFT Test Data Sheet, Appendix I, Section 6.10. 40 Vpp ADC board:

DWR Serial Number: ADC 1724 20sps DWR-CAT/CFT Test Data Sheet, Appendix I, Section 6.20. DWR Serial Number: ADC 1724 40sps DWR-CAT/CFT Test Data Sheet, Appendix I, Section 6.21.

\subsubsection{Sine-Calibrator THD (DWR-CHD)}

Purpose: The purpose of the calibrator THD test is to determine and verify the linearity of the sensor calibration generator.

Configuration: The SMART24 calibrator output is connected to a signal source measurement system. The amplitude and frequency of the SMART24 calibrator are set to known levels.

Evaluation: A power density spectrum provides a measure of the linearity of the calibrator. THD is computed.

Test Results:

20 Vpp ADC board:

DWR Serial Number: ADC 1360 20sps DWR-CHD/CLB Test Data Sheet, Appendix I, Section 6.11. DWR Serial Number: ADC 1360 40sps DWR-CHD/CLB Test Data Sheet, Appendix I, Section 6.12. 40 Vpp ADC board:

DWR Serial Number: ADC 1724 20sps DWR-CHD/CLB Test Data Sheet, Appendix I, Section 6.22. DWR Serial Number: ADC 1724 40sps DWR-CHD/CLB Test Data Sheet, Appendix I, Section 6.23.

\subsubsection{Calibrator Loopback THD (DWR-CLB)}

Purpose: The purpose of the calibrator loop back THD test is to determine and verify the linearity of the combination of the sensor calibration generator and DWR.

Configuration: The DWR calibrator output is looped back to the DWR input. The amplitude and frequency of the DWR calibrator are set to known levels.

Evaluation: A power density spectrum provides a measure of the linearity of the calibrator. THD is computed. The THD using the DWR should be the same as the CHD test.

Test Results:

20 Vpp ADC board:

DWR Serial Number: ADC 1360 20sps DWR-CHD/CLB Test Data Sheet, Appendix I, Section 6.11. DWR Serial Number: ADC 1360 40sps DWR-CHD/CLB Test Data Sheet, Appendix I, Section 6.12. 40 Vpp ADC board:

DWR Serial Number: ADC 1724 20sps DWR-CHD/CLB Test Data Sheet, Appendix I, Section 6.22. DWR Serial Number: ADC 1724 40sps DWR-CHD/CLB Test Data Sheet, Appendix I, Section 6.23. 


\section{Summary}

\section{Objective:}

The objective of this work was to evaluate the overall technical performance of the Geotech Smart24 digitizer with a Fortezza PCMCIA crypto card actively implementing the signing of data packets. The results of this evaluation were compared to relevant specifications provided within manufacturer's documentation notes. The tests performed were chosen to demonstrate different performance aspects of the digitizer under test. The performance aspects tested include determining noise floor, least significant bit (LSB), dynamic range, cross-talk, relative channel-to-channel timing, time-tag accuracy, analog bandwidth and calibrator performance.

\section{Description:}

The SMART24 digitizers under evaluation were manufactured by Geotech Instruments, LLC of Dallas, TX. The SMART24 was designed to be a high resolution 24-bit data acquisition system, configured for 1channel or 3-channel operation. Smart24 digitizers were designed to have the capability to be configured to collect data from either an infrasound or seismic application. An additional requirement for some installations is to have the capability to sign outgoing data packets. The Smart24 digitizer supports the use of a Fortezza Crypto PCMCIA Card for the purpose of data signing and authentication. For an infrasound application, the likely Smart 24 configuration would be 20 Vpp ADC Board, LSB of $1.6355 \mathrm{e}-06 \mathrm{~V} /$ count, one active channel and sampled at 20 samples-per-second (sps). While for a seismic application the configuration would likely be $40 \mathrm{Vpp}$ ADC Board, LSB of 3.271e-6 V/count, three active channels and sampled at $40 \mathrm{sps}$. Digitizer testing focused on characterization of one unit serial number s1224. It is expected that other Geotech Smart24 with Fortezza PCMCIA crypto cards will perform in a like manner.

The central recording facility at FACT uses the Geotech GeoHub software suite running on a standard PC for acquisition and data archiving of the test data. The GeoHub system was designed for network and array operators to allow greater control in data acquisition, data concentration and distribution for data archiving via its flexible communication protocol. The basic data transmission path from the data loggers to database starts at the Smart24 with a RJ45 Ethernet connection to the FACT internal LAN. The PC running the GeoHub software was also connected to the same LAN. The Smart24 and GeoHub communicate via fixed IP addresses. All test data were acquired in near real-time in CSS 3.0 flat-file database records in S4 format.

Testing was performed in a seismic vault for temperature stability. The Smart24 tested were set to the gain of 1 , required for seismic or infrasound applications.

\subsection{Smart24 w/Fortezza 20sps and 20Vpp ADC Board- Digitizer Evaluation Summary:}

Static Performance:

Smart $24 \mathrm{w} /$ Fortezza DC accuracy errors were within $0.52 \%$ for standard \pm 1 volt scale. DC offset was less than 23 microvolts. The input terminated noise was less than 0.88 counts RMS for the 0.02 to $10 \mathrm{~Hz}$ application band. The Maximum Potential Dynamic Range was better than $133.7 \mathrm{~dB}$.

\section{Tonal Dynamic Performance:}

The Smart24 w/Fortezza Total Harmonic Distortion (THD) was better than $-121.8 \mathrm{~dB}$. Crosstalk between channels was better than $-122 \mathrm{~dB}$.

Broadband Dynamic Performance:

Smart24 w/Fortezza channel to channel timing was better than 1.1 microseconds for the 0.02 to $10 \mathrm{~Hz}$ band. Bandwidth measured $-3 \mathrm{~dB}$ at $8.5 \mathrm{~Hz}$ with a relative attenuation of $-112 \mathrm{~dB}$ at the Nyquist.

\section{Timing Performance:}

The Smart24 w/Fortezza time-tagged the data with respect to the digitizer input to better than 18.0 microseconds. 
Calibrator Performance:

The Smart24 w/Fortezza produced sinusoids of variable amplitudes for a fixed frequency of $1 \mathrm{~Hz}$ within $0.3 \%$ of the programmed voltage values. By varying the frequency for a fixed amplitude of 1 volt the Smart $24 \mathrm{w} /$ Fortezza produced sinusoids with frequencies that matched the programmed frequency values. The Smart2 4 calibrator's signal generator has a THD of $-80.6 \mathrm{~dB}$ for a $1 \mathrm{~Hz} 1$ volt sinusoid when output in sensor mode. The Smart24 calibrator when in loopback mode (instead of sensor output mode) has a measured Calibrator Loopback THD (CLB) of $-81.6 \mathrm{~dB}$.

\subsection{Smart24 w/Fortezza 40sps and 20Vpp ADC Board - Digitizer Evaluation Summary:}

Static Performance:

Smart $24 \mathrm{w} /$ Fortezza DC accuracy errors were within $0.52 \%$ for standard \pm 1 volt scale. DC offset was less than 24.7 microvolts. The input terminated noise was less than 1.13 counts RMS for the 0.02 to $20 \mathrm{~Hz}$ application band. The Maximum Potential Dynamic Range was better than $131.6 \mathrm{~dB}$.

Tonal Dynamic Performance:

The Smart24 w/Fortezza Total Harmonic Distortion (THD) was better than -121.2 dB. Crosstalk between channels was better than $-120 \mathrm{~dB}$.

Broadband Dynamic Performance:

Smart24 w/Fortezza channel to channel timing was better than 1.1 microseconds for the 0.02 to $20 \mathrm{~Hz}$ band. Bandwidth measured $-3 \mathrm{~dB}$ at $17.1 \mathrm{~Hz}$ with a relative attenuation of $-117 \mathrm{~dB}$ at the Nyquist.

Timing Performance:

The Smart24 w/Fortezza time-tagged the data with respect to the digitizer input to better than 19.0 microseconds.

Calibrator Performance:

The Smart24 w/Fortezza produced sinusoids of variable amplitudes for a fixed frequency of $1 \mathrm{~Hz}$ within $0.3 \%$ of the programmed voltage values. By varying the frequency with a fixed amplitude of 1 volt the Smart $24 \mathrm{w} /$ Fortezza produced sinusoids with frequencies that matched the programmed frequency values. The Smart24 calibrator's signal generator has a THD of $-79.6 \mathrm{~dB}$ for a $1 \mathrm{~Hz} 1$ volt sinusoid when output in sensor mode. The Smart24 calibrator when in loopback mode (instead of sensor output mode) has a measured Calibrator Loopback THD (CLB) of $-79.0 \mathrm{~dB}$.

\subsection{Smart24 w/Fortezza 20sps and 40Vpp ADC Board - Digitizer Evaluation Summary:}

Static Performance:

Smart $24 \mathrm{w} /$ Fortezza DC accuracy errors were within $0.37 \%$ for standard \pm 1 volt scale. DC offset was less than 99 microvolts. The input terminated noise was less than 0.79 counts RMS for the 0.02 to $10 \mathrm{~Hz}$ application band. The Maximum Potential Dynamic Range was better than $134.7 \mathrm{~dB}$.

Tonal Dynamic Performance:

The Smart24 w/Fortezza Total Harmonic Distortion (THD) was better than -124.6 dB. Crosstalk between channels was better than $-122.7 \mathrm{~dB}$.

Broadband Dynamic Performance:

Smart24 w/Fortezza channel to channel timing was better than 4.4 microseconds for the 0.02 to $10 \mathrm{~Hz}$ band. Bandwidth measured $-3 \mathrm{~dB}$ at $8.6 \mathrm{~Hz}$ with a relative attenuation of better than $-113 \mathrm{~dB}$ at the Nyquist.

Timing Performance:

The Smart24 w/Fortezza time-tagged the data with respect to the digitizer input to better than 8 microseconds. 
Calibrator Performance:

The Smart24 w/Fortezza produced sinusoids of variable amplitudes for a fixed frequency of $1 \mathrm{~Hz}$ within $0.3 \%$ of the programmed voltage values. By varying the frequency with a fixed amplitude of 1 volt the Smart $24 \mathrm{w} /$ Fortezza produced sinusoids with frequencies that matched the programmed frequency values. The Smart2 4 calibrator's signal generator has a THD of $-79.6 \mathrm{~dB}$ for a $1 \mathrm{~Hz} 1$ volt sinusoid when output in sensor mode. The Smart24 calibrator when in loopback mode (instead of sensor output mode) has a measured Calibrator Loopback THD (CLB) of $-77.3 \mathrm{~dB}$.

\subsection{Smart24 w/Fortezza 40sps and 40Vpp ADC Board - Digitizer Evaluation Summary:}

Static Performance:

Smart $24 \mathrm{w} /$ Fortezza DC accuracy errors were within $0.37 \%$ for standard \pm 1 volt scale. DC offset was less than 99 microvolts. The input terminated noise was less than 0.97 counts RMS for the 0.02 to $20 \mathrm{~Hz}$ application band. The Maximum Potential Dynamic Range was better than $133.0 \mathrm{~dB}$.

Tonal Dynamic Performance:

The Smart24 w/Fortezza Total Harmonic Distortion (THD) was better than -125.4 dB. Crosstalk between channels was better than $-121.4 \mathrm{~dB}$.

Broadband Dynamic Performance:

Smart24 w/Fortezza channel to channel timing was better than 0.41 microseconds for the 0.02 to $20 \mathrm{~Hz}$ band. Bandwidth measured $-3 \mathrm{~dB}$ at $17.1 \mathrm{~Hz}$ with a relative attenuation of $-121 \mathrm{~dB}$ at the Nyquist.

Timing Performance:

The Smart24 w/Fortezza time-tagged the data with respect to the digitizer input to better than 7 microseconds.

Calibrator Performance:

The Smart24 w/Fortezza produced sinusoids of variable amplitudes for a fixed frequency of $1 \mathrm{~Hz}$ within $0.47 \%$ of the programmed voltage values. By varying the frequency with a fixed amplitude of 1 volt the Smart $24 \mathrm{w} /$ Fortezza produced sinusoids with frequencies that were within $0.0004 \%$ the programmed frequency values. The Smart24 calibrator's signal generator has a THD of $-79.0 \mathrm{~dB}$ for a $1 \mathrm{~Hz} 1 \mathrm{volt}$ sinusoid when output in sensor mode. The Smart24 calibrator when in loopback mode (instead of sensor output mode) has a measured Calibrator Loopback THD (CLB) of $-77.2 \mathrm{~dB}$.

\subsection{Conclusions:}

Results, where appropriate, are compared to Manufacturer specifications listed in Smart24 Series User Manual. Note: manufacturer's specifications taken at $50 \mathrm{sps}$.

The Smart24 digitizer with the 20Vpp ADC board had performance of 21.9-bits for the 0.02 to $10 \mathrm{~Hz}$ passband at 20 samples per second. The Smart24 digitizer with the 20Vpp ADC board had performance of 21.6 for the 0.02 to $20 \mathrm{~Hz}$ passband at 40 samples per second. The total harmonic distortion (THD) of $121 \mathrm{~dB}$ was below manufacturer specifications of $-110 \mathrm{~dB}$. The input terminated noise (ITN) was slightly higher, 1.3 counts RMS, than manufacturer specifications of 0.8 counts RMS. Dynamic range was found to $132 \mathrm{~dB}$ or greater. (Note: The RMS band not specified by manufacture and sampled at different rate.) The Channel-to-Channel timing skew was better than 1.1 microseconds, still greater than the manufacturer specified \pm 50 nanoseconds. The Data sample time-tag accuracy of better than 19 microseconds, was outside manufacturer's specifications of 10 microseconds, but meets International Monitoring System requirements. The Analog bandwidth of $8.6 \mathrm{~Hz}$ was better than that listed by manufacturer as $80 \%$ of Nyquist.

The Smart24 digitizer with the 40Vpp ADC board had performance of 22.1-bits for the 0.02 to $10 \mathrm{~Hz}$ passband at 20 samples per second. The Smart24 digitizer with the 40Vpp ADC board had performance of 21.8 for the 0.02 to $20 \mathrm{~Hz}$ passband at 40 samples per second. 
The total harmonic distortion (THD) of $-124.6 \mathrm{~dB}$ was below manufacturer specifications of $-110 \mathrm{~dB}$. The input terminated noise (ITN) was slightly higher, 1.0 counts RMS, than manufacturer specifications of 0.8 counts RMS. Dynamic range was found to $133 \mathrm{~dB}$ or greater. (Note: RMS band not specified by manufacturer and sampled at different rate). The Channel-to-Channel timing skew was better than 4.4 microseconds, still greater than the manufacturer specified \pm 50 nanoseconds. The data sample time-tag accuracy of better than 8 microseconds, was within manufacturer's specifications of 10 microseconds. The analog bandwidth of $17.1 \mathrm{~Hz}$ was better than that listed by manufacturer as $80 \%$ of Nyquist.

\section{References:}

1. IEEE Standard for Digitizing Waveform Recorders, IEEE Std. 1057-1994.

2. IEEE Standard for Analog to Digital Converters, IEEE Std. 1241-2001.

3. Kromer, Richard P., Hart, Darren M. and J. Mark Harris (2007), 'Test Definition for the Evaluation of Digitizing Waveform Recorders, SAND2007-5037. 
6 Appendix I: DWR Test Data Sheets 


\subsection{Smart24 Test Data Sheet:}

Smart24 S/N: 1224

Firmware Revision: 1.38

Raw Data Format (CH 1-3): 24-bit Integer

Smart24 Sample Rate: 20sps and 40sps

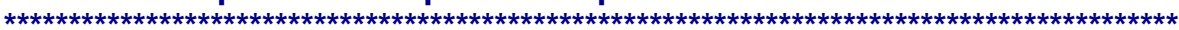

Test Description: Define Smart24 digitizer gain.

Manufacturer Specified Nominal Volts/Count Based on Geotech User Manual.

Nominal Volts/Count $-5 \mathrm{Vpp}: \quad \mathbf{0 . 4 0 8 8 8 7} \times \mathbf{1 0}^{-6}$

Nominal Volts/Count -20 Vpp: $\quad \mathbf{1 . 6 3 5 5 4 8} \times \mathbf{1 0}^{-6}$

Nominal Volts/Count - 40 Vpp: $\quad 3.271096 \times \mathbf{1 0}^{-6}$

Nominal Counts/Volt - 5 Vpp: 2445663

Nominal Counts/Volt - 20 Vpp: 611416

Nominal Volts/Count - 40 Vpp: 305708

\begin{tabular}{|c|c|c|c|}
\hline Characteristics & 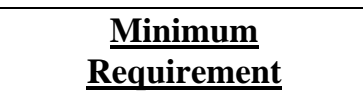 & $\underline{\text { Test Results }}$ & $\begin{array}{l}\text { Manufacture } \\
\text { Specifications }\end{array}$ \\
\hline Array Pass Band & IS :0.02-4 Hz & 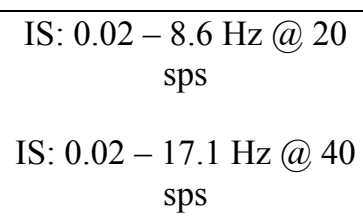 & $\begin{array}{c}\text { Approximately } 20 \% \text { of } \\
\text { Nyquist }\end{array}$ \\
\hline Sampling Rate & $\geq 10$ samples per second & $\begin{array}{l}20 \mathrm{sps} \\
40 \mathrm{sps}\end{array}$ & $\begin{array}{c}1,5,10,20,40,50 \\
100,125,200,250,500 \\
1000, \text { and } 2000 \mathrm{sps},\end{array}$ \\
\hline Resolution & N/A & $<1.1$ counts $\mathrm{RMS}$ noise & \\
\hline Dynamic range & $\geq 108 \mathrm{~dB}$ & $>132 \mathrm{~dB}$ & $>132$ \\
\hline Timing Accuracy & $\geq 1 \mathrm{~ms}^{1}$ & $\sim 18 \mu \mathrm{s}$ & $\pm 10 \mu \mathrm{s}$ \\
\hline Cross-talk & N/A & $<-120 \mathrm{~dB}$ & N/A \\
\hline $\begin{array}{l}\text { Relative timing between } \\
\text { channels }\end{array}$ & N/A & $<1.1 \mu \mathrm{s}$ & $\pm 50 \mathrm{~ns}$ \\
\hline Bit-weight Accuracy & $\mathrm{N} / \mathrm{A}$ & $\begin{array}{l}<0.8 \% \text { from } \\
\text { manufacture } \\
\text { specification }\end{array}$ & 1.635548 e-6 V/Count \\
\hline $\begin{array}{l}\text { Total Harmonic } \\
\text { Distortion }\end{array}$ & N/A & $<-121.8 \mathrm{~dB}$ & $<-110 \mathrm{~dB}$ \\
\hline
\end{tabular}

${ }^{1}$ relative timing between array elements.

Table 6.1 Smart24 - 20 Vpp ADC board; 20SPS and 40SPS Summary 


\begin{tabular}{|c|c|c|c|}
\hline$\underline{\text { Characteristics }}$ & $\begin{array}{l}\text { Minimum } \\
\text { Requirement }\end{array}$ & $\underline{\text { Test Results }}$ & $\begin{array}{l}\text { Manufacture } \\
\text { Specifications }\end{array}$ \\
\hline Array Pass Band & IS :0.02-4 Hz & 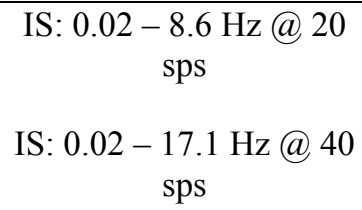 & $\begin{array}{c}\text { Approximately } 20 \% \text { of } \\
\text { Nyquist }\end{array}$ \\
\hline Sampling Rate & $\geq 10$ samples per second & $\begin{array}{l}20 \mathrm{sps} \\
40 \mathrm{sps}\end{array}$ & $\begin{array}{c}1,5,10,20,40,50 \\
100,125,200,250,500 \\
1000, \text { and } 2000 \mathrm{sps}\end{array}$ \\
\hline Resolution & $\mathrm{N} / \mathrm{A}$ & $<1.0$ counts RMS noise & \\
\hline Dynamic range & $\geq 108 \mathrm{~dB}$ & $>133 \mathrm{~dB}$ & $>132$ \\
\hline Timing Accuracy & $\geq 1 \mathrm{~ms}^{1}$ & $\sim 7 \mu \mathrm{s}$ & $\pm 10 \mu \mathrm{s}$ \\
\hline Cross-talk & N/A & $<-120 \mathrm{~dB}$ & $\mathrm{~N} / \mathrm{A}$ \\
\hline $\begin{array}{l}\text { Relative timing between } \\
\text { channels }\end{array}$ & $\mathrm{N} / \mathrm{A}$ & $<4.4 \mu \mathrm{s}$ & $\pm 50 \mathrm{~ns}$ \\
\hline Bit-weight Accuracy & N/A & $\begin{array}{l}<0.8 \% \text { from } \\
\text { manufacture } \\
\text { specification }\end{array}$ & 3.271096 e-6 V/Count \\
\hline $\begin{array}{l}\text { Total Harmonic } \\
\text { Distortion }\end{array}$ & N/A & $<-121.8 \mathrm{~dB}$ & $<-110 \mathrm{~dB}$ \\
\hline
\end{tabular}

${ }^{1}$ relative timing between array elements.

Table 6.2 Smart24 - 40 Vpp ADC board; 20SPS and 40SPS Summary 


\subsection{SMART24 Test Data Sheet: 20 Vpp ADC Test - Static/DCA}

Smart24 S/N: 1224

Firmware Revision: 1.38

Authentication: Enabled

CH 1-3: Single Three Channel 20 Vpp ADC Board - S/N 1360

Smart24 Sample Rate: 20sps and 40sps

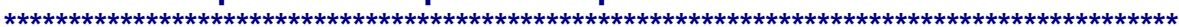

DCA Test Description: Measure DC Accuracy, and DC Full-Scale.

DCA- Manufacture Specified Volts/Count (CH 1-3): $1.635548 \times 10^{-6}$

\begin{tabular}{|c|c|c|c|c|c|c|}
\hline Channel & $\begin{array}{c}\text { Test Input } \\
\text { Volts }\end{array}$ & Counts/Volt & $\begin{array}{c}\mu \text { Volts/Coun } \\
\mathrm{t}\end{array}$ & $\begin{array}{c}\% \text { Deviation } \\
\text { from } \\
\text { Test Input } \\
\text { Voltage }\end{array}$ & $\begin{array}{c}\text { DC Offset } \\
\mu \text { Volts }\end{array}$ & $\begin{array}{c}\% \text { Deviation } \\
\text { from } \\
\text { Manufactures } \\
\text { LSB } \\
\text { Specification } \\
\mathrm{s}\end{array}$ \\
\hline $\mathrm{C} 1 \mathrm{~S}$ & 1.0000 & 605569 & 1.64862 & -0.523 & -14.8 & 0.80 \\
\hline $\mathrm{C} 2 \mathrm{~S}$ & 1.0000 & 608242 & 1.64408 & -0.248 & -24.7 & 0.52 \\
\hline $\mathrm{C} 3 \mathrm{~S}$ & 1.0000 & 607889 & 1.64503 & -0.306 & -1.6 & 0.58 \\
\hline
\end{tabular}

Table 6.2.1 DC Accuracy \pm 1 Volt Results for 20 sps.

\begin{tabular}{|c|c|c|c|c|c|c|}
\hline Channel & $\begin{array}{c}\text { Test Input } \\
\text { Volts }\end{array}$ & Counts/Volt & $\begin{array}{c}\mu \text { Volts/Coun } \\
\mathrm{t}\end{array}$ & $\begin{array}{c}\% \text { Deviation } \\
\text { from } \\
\text { Test Input } \\
\text { Voltage }\end{array}$ & $\begin{array}{c}\text { DC Offset } \\
\mu \text { Volts }\end{array}$ & $\begin{array}{c}\% \text { Deviation } \\
\text { from } \\
\text { Manufactures } \\
\text { LSB } \\
\text { Specification } \\
\mathrm{s}\end{array}$ \\
\hline BDF & 1.0000 & 606569 & 1.64861 & -0.523 & -14.8 & 0.80 \\
\hline C2P & 1.0000 & 608242 & 1.64408 & -0.248 & -23.0 & 0.52 \\
\hline C3P & 1.0000 & 607890 & 1.64503 & -0.306 & -1.6 & 0.58 \\
\hline
\end{tabular}

Table 6.2.2 DC Accuracy \pm 1 Volt Results for 40 sps.

Test Results: Tables 6.2.1-2 indicate that the Smart24 w/Fortezza Card accuracy of the measured LSB to \pm 1 Volt DC input is better than $0.52 \%$ and better than $0.80 \%$ of the manufactures specified LSB. 


\subsection{SMART24 Test Data Sheet: 20 Vpp ADC Test - Static/ITN/MPDR}

Smart24 S/N: 1224

Firmware Revision: 1.38

Authentication: Enabled

CH 1-3: Single Three Channel 20 Vpp ADC Board - S/N 1360

Smart24 Sample Rate: 20sps

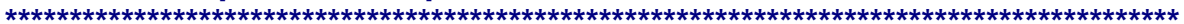

ITN Test Description: Measure Input Terminated Noise.

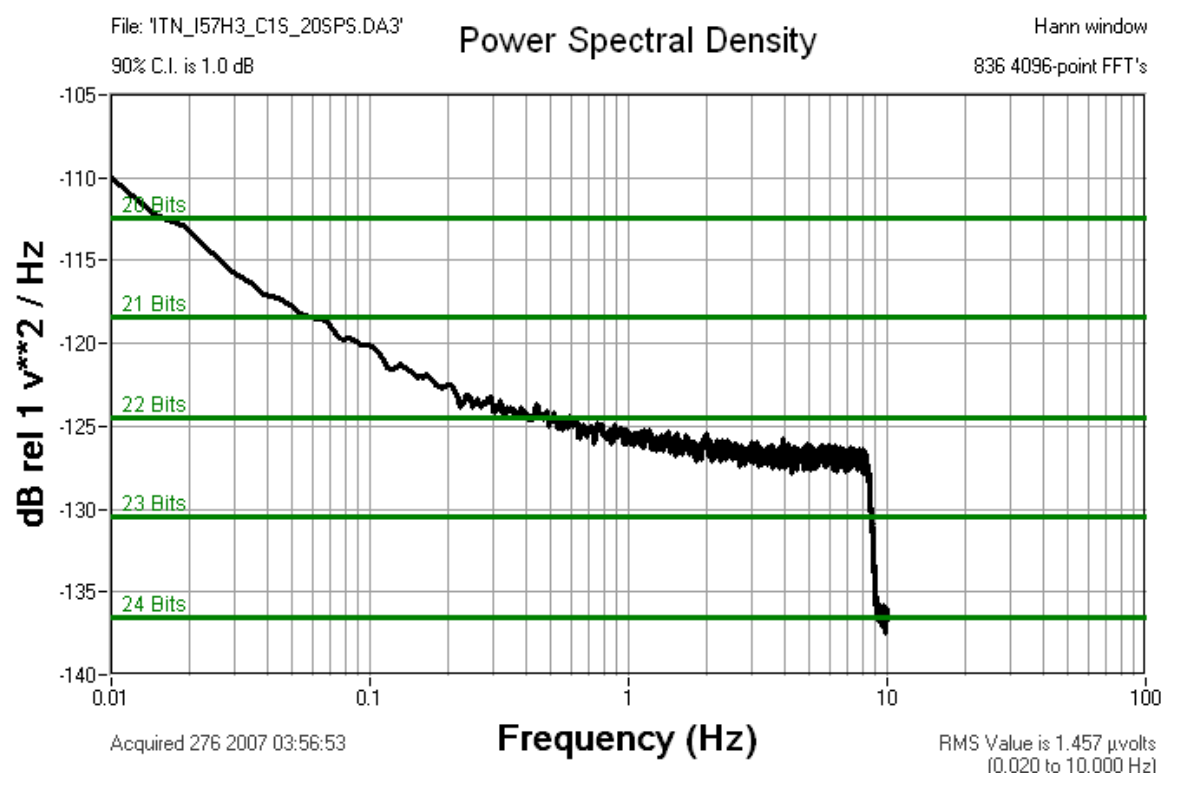

Figure 6.3.1 SMART24 Channel C1S Input Terminated Noise 


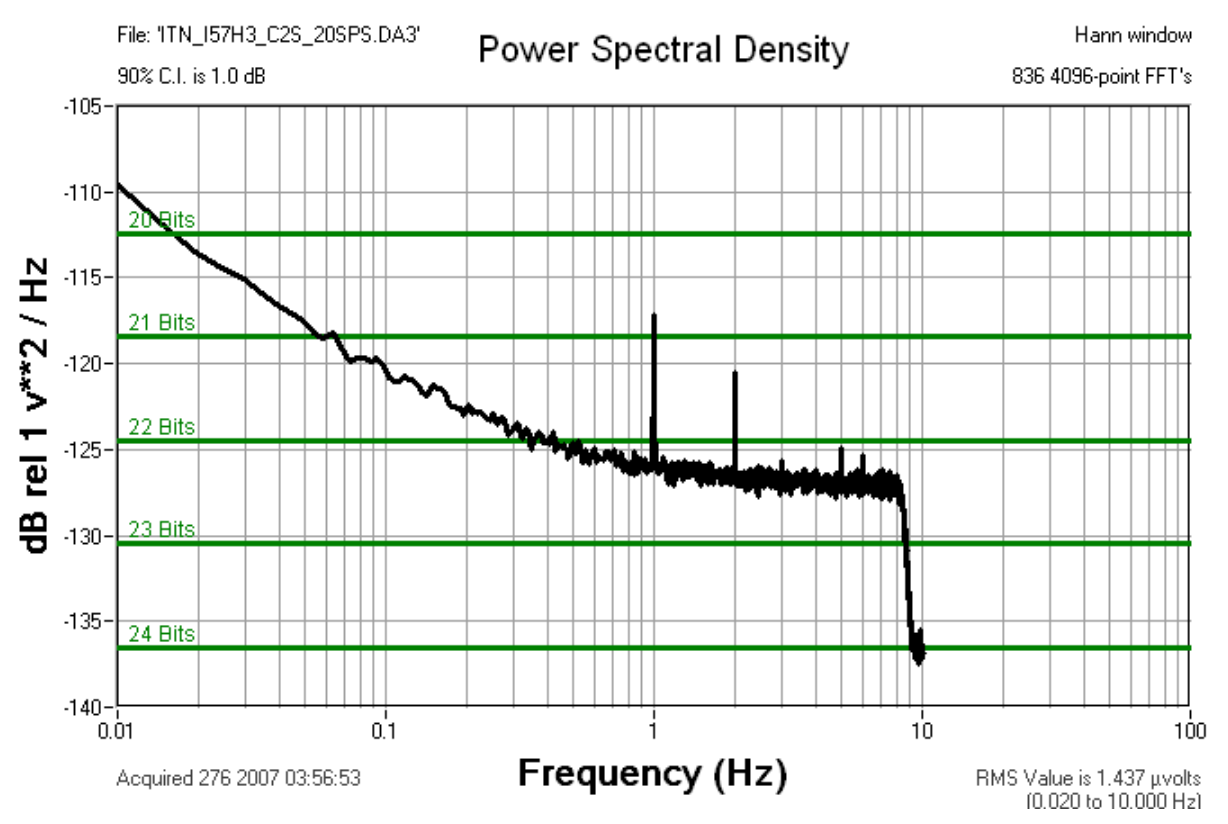

Figure 6.3.2 SMART24 Channel C2S Input Terminated Noise

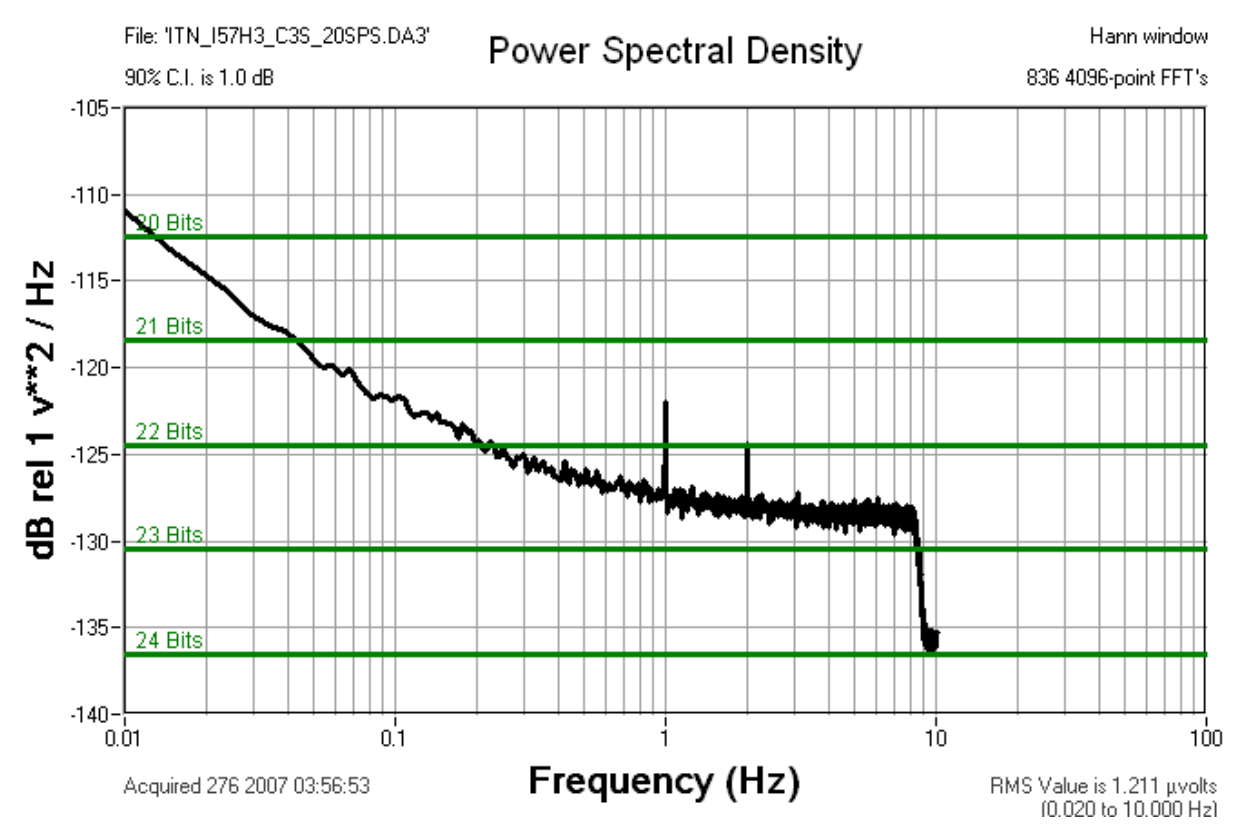

Figure 6.3.3 SMART24 Channel C3S Input Terminated Noise

\begin{tabular}{|c|c|c|}
\hline Channel & $\begin{array}{c}\text { RMS Noise } \mu \mathrm{V} \\
0.02 \text { to } 10 \mathrm{~Hz}\end{array}$ & Counts RMS \\
\hline $\mathrm{C} 1 \mathrm{~S}$ & 1.457 & 0.884 \\
\hline $\mathrm{C} 2 \mathrm{~S}$ & 1.437 & 0.874 \\
\hline
\end{tabular}




\begin{tabular}{|l|l|l|}
\hline $\mathrm{C} 3 \mathrm{~S}$ & 1.211 & 0.736 \\
\hline
\end{tabular}

Table 6.3.1 SMART24 20sps RMS Noise

Test Results: Figures 6.3.1-3 and Table 6.3.1 indicate that the SMART24 has $<1.5$ counts RMS noise.

MPDR Test Description: Compute Maximum Potential Dynamic Range, using the RMS noise estimate in microvolts from ITN Test and theoretical RMS full-scale in volts.

\begin{tabular}{|c|c|c|c|}
\hline Channel & $\begin{array}{c}\text { RMS Noise } \mu \mathrm{V} \\
0.02 \text { to } 10 \mathrm{~Hz}\end{array}$ & $\begin{array}{c}\text { RMS } \\
\text { Full-Scale Volts }\end{array}$ & MPDR (dB) \\
\hline C1S & 1.457 & 7.07 & 133.7 \\
\hline C2S & 1.437 & 7.07 & 133.8 \\
\hline C3S & 1.211 & 7.07 & 135.3 \\
\hline
\end{tabular}

Table 6.3.2 SMART24 20sps MPDR

Test Results: Table 6.3.2 indicates that the SMART24 Maximum Potential Dynamic Range is greater than $133.7 \mathrm{~dB}$. 


\subsection{SMART24 Test Data Sheet: 20 Vpp ADC Test - Static/ITN/MPDR}

Smart24 S/N: 1224

Firmware Revision: 1.38

Authentication: Enabled

CH 1-3: Single Three Channel 20 Vpp ADC Board - S/N 1360

Smart24 Sample Rate: 40sps

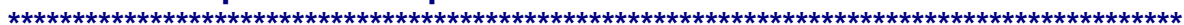

ITN Test Description: Measure Input Terminated Noise.

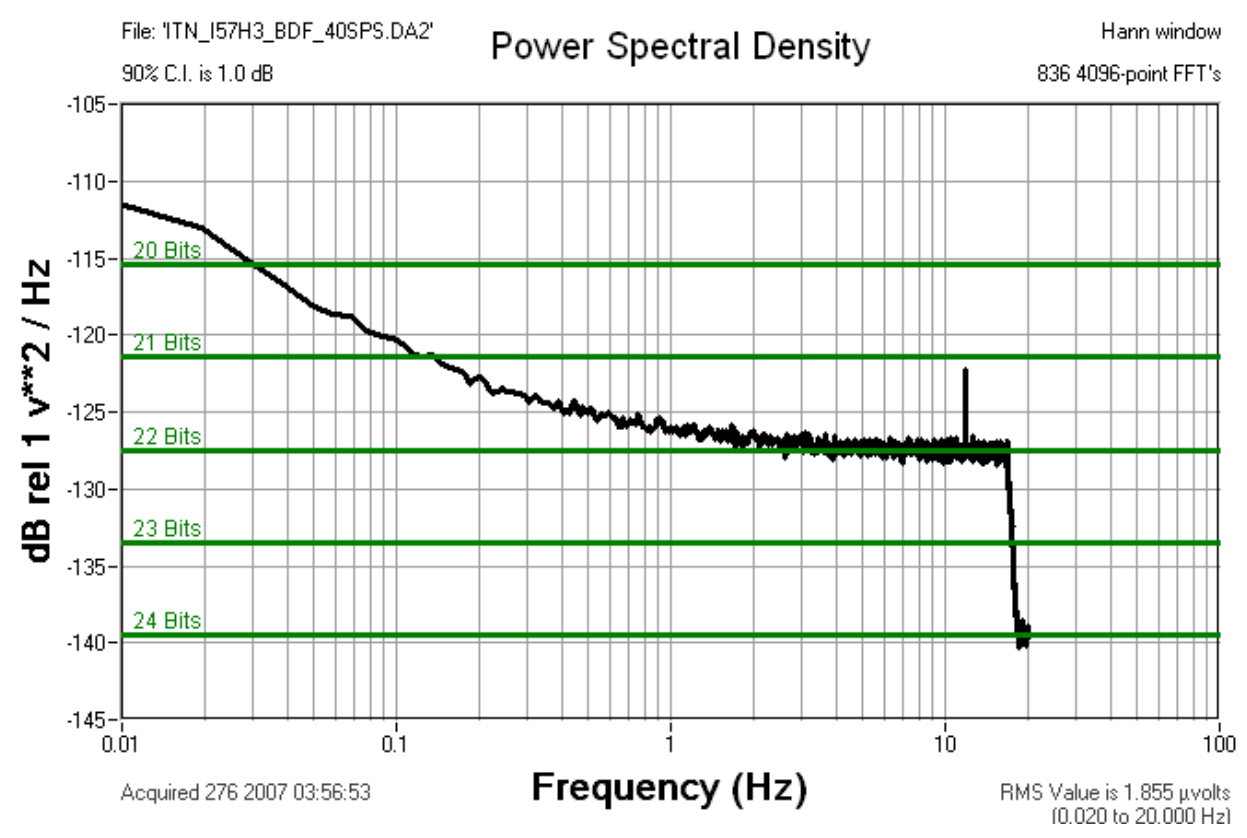

Figure 6.4.1 SMART24 Channel BDF Input Terminated Noise 


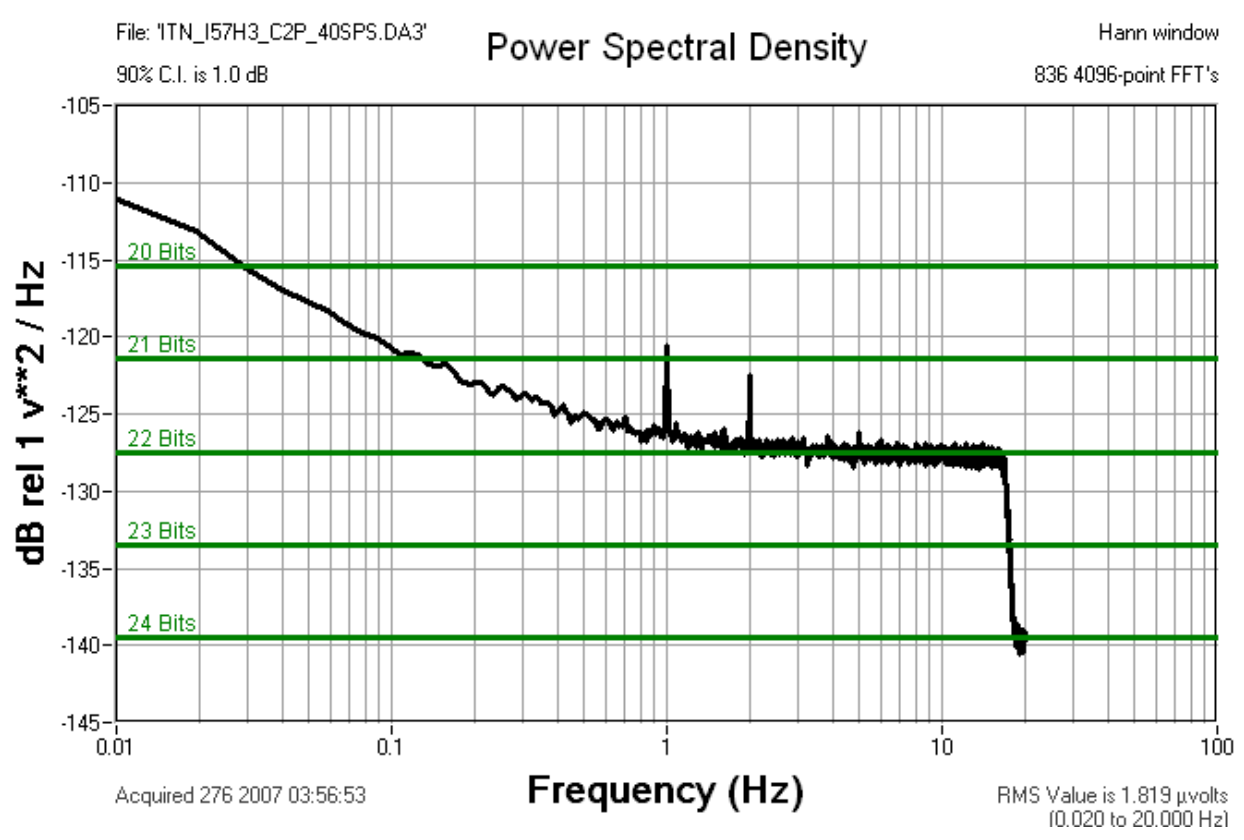

Figure 6.4.2 SMART24 Channel C2P Input Terminated Noise

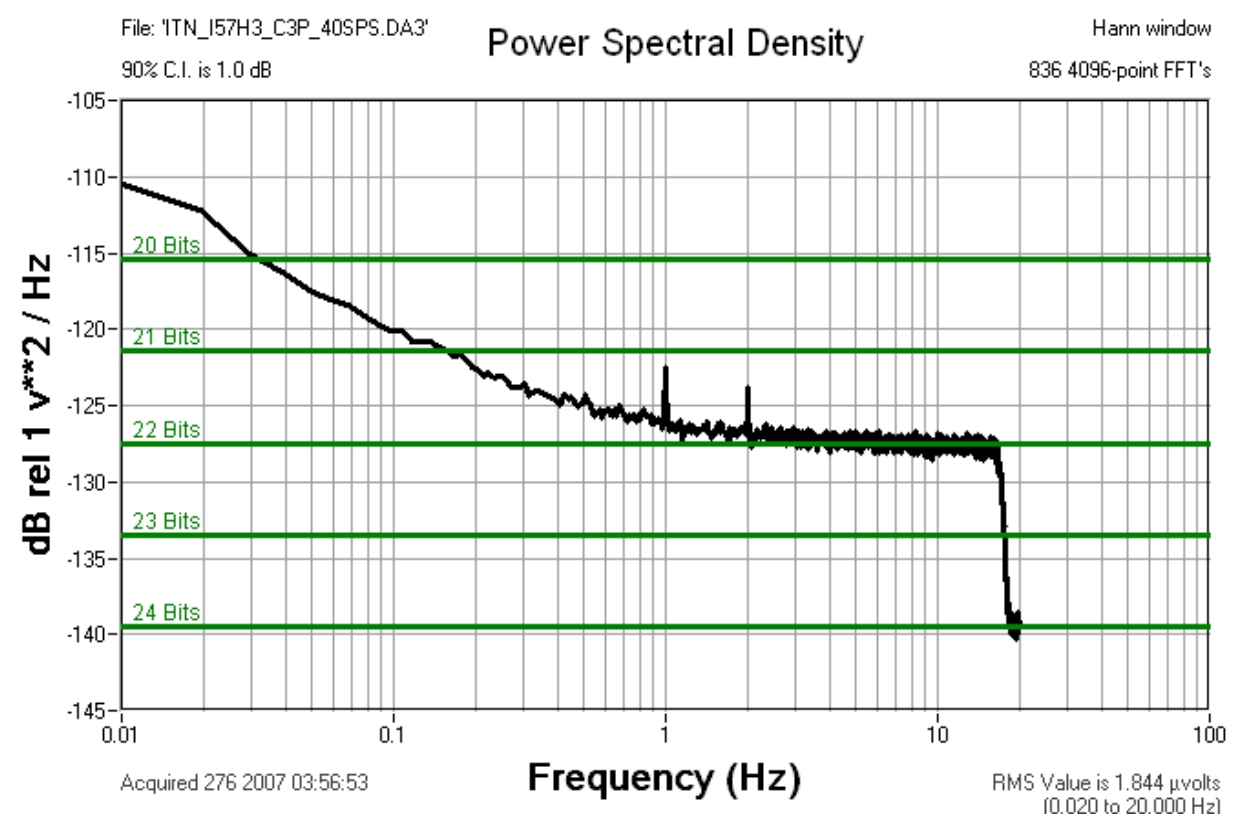

Figure 6.4.3 SMART24 Channel C3P Input Terminated Noise

\begin{tabular}{|c|c|c|}
\hline Channel & $\begin{array}{c}\text { RMS Noise } \mu \mathrm{V} \\
0.02 \text { to } 20 \mathrm{~Hz}\end{array}$ & Counts RMS \\
\hline BDF & 1.855 & 1.125 \\
\hline
\end{tabular}




\begin{tabular}{|l|l|l|}
\hline C2P & 1.819 & 1.106 \\
\hline C3P & 1.844 & 1.121 \\
\hline
\end{tabular}

Table 6.4.1 SMART24 40sps RMS Noise

Test Results: Figures 6.4.1-3 and Table 6.4.1 indicate that the SMART24 has $<1.9$ counts RMS noise.

MPDR Test Description: Compute Maximum Potential Dynamic Range, using the RMS noise estimate in microvolts from ITN Test and theoretical RMS full-scale in volts

\begin{tabular}{|c|c|c|c|}
\hline Channel & $\begin{array}{c}\text { RMS Noise } \mu \mathrm{V} \\
0.02 \text { to } 20 \mathrm{~Hz}\end{array}$ & $\begin{array}{c}\text { RMS } \\
\text { Full-Scale Volts }\end{array}$ & MPDR \\
\hline BDF & 1.855 & 7.07 & 131.6 \\
\hline C2P & 1.819 & 7.07 & 131.8 \\
\hline C3P & 1.844 & 7.07 & 131.7 \\
\hline
\end{tabular}

Table 6.4.2 SMART24 40sps MPDR

Test Results: Table 6.4.2 indicates that the SMART24 Maximum Potential Dynamic Range is greater than 131.6 dB. 


\subsection{SMART24 Test Data Sheet: 20 Vpp ADC Test - Dynamic Tonal/THD}

Smart24 S/N: 1224

Firmware Revision: 1.38

Authentication: Enabled

CH 1-3: Single Three Channel 20 Vpp ADC Board - S/N 1360

Smart24 Sample Rate: 20 sps and 40sps

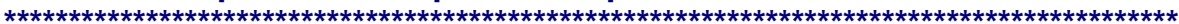

THD Test Description: Measure the linearity of the SMART24 using Total Harmonic Distortion.

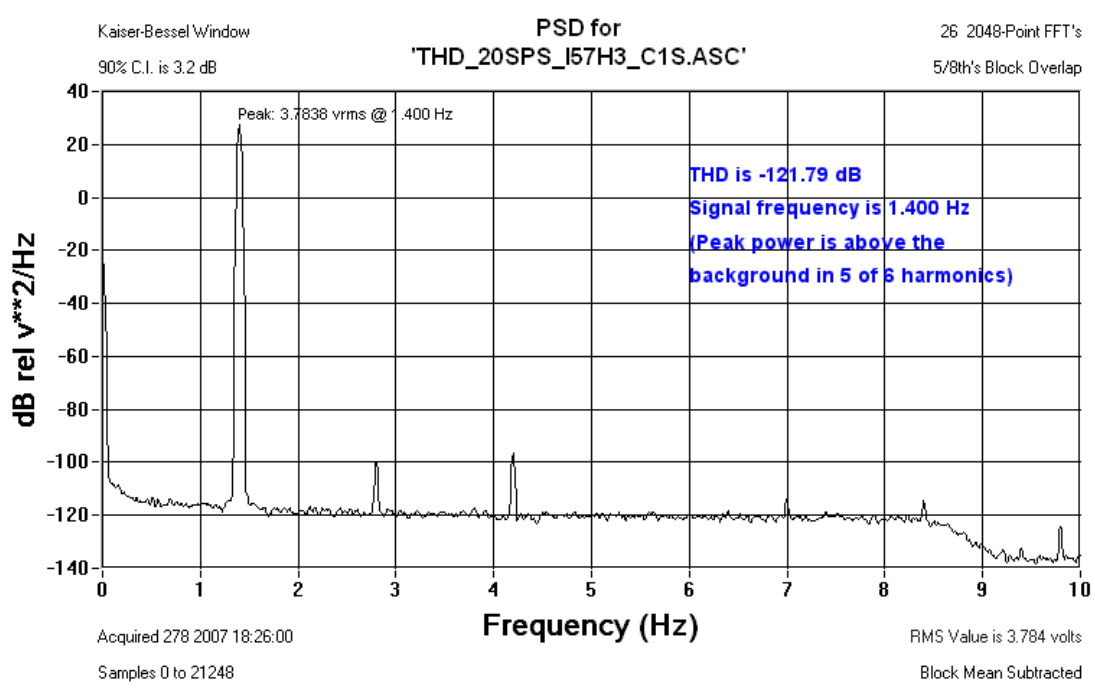

Figure 6.5.1 SMART24 20sps Total Harmonic Distortion

\begin{tabular}{|c|c|}
\hline Channel & THD (dB) \\
\hline C1S & -121.79 \\
\hline C2S & -122.45 \\
\hline C3S & -123.74 \\
\hline
\end{tabular}

Table 6.5.1 SMART24 THD

Test Results: Table 6.5.1 indicates that the SMART24 Total Harmonic Distortion is better than $121.8 \mathrm{~dB}$ for 20 sps acquisition rate. 


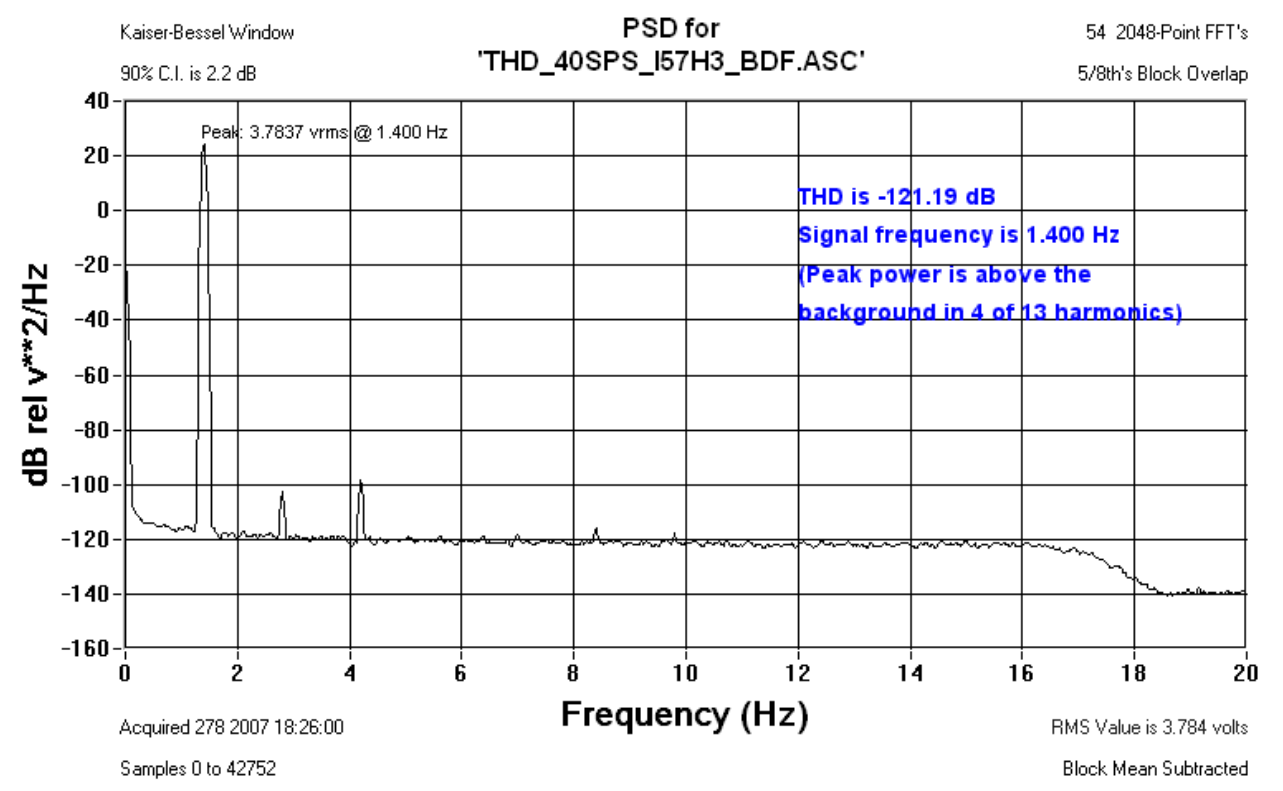

Figure 6.5.2 SMART24 40sps Total Harmonic Distortion

\begin{tabular}{|c|c|}
\hline Channel & THD (dB) \\
\hline BDF & -121.19 \\
\hline C2P & -121.98 \\
\hline C3P & -123.98 \\
\hline
\end{tabular}

Table 6.5.2 SMART24 40sps THD

Test Results: Table 6.5.2 indicates that the SMART24 Total Harmonic Distortion is better than $121.2 \mathrm{~dB}$ for 40 sps acquisition rate. 


\subsection{SMART24 Test Data Sheet: 20 Vpp ADC Test - Dynamic Tonal/CTK}

Smart24 S/N: 1224

Firmware Revision: 1.38

Authentication: Enabled

CH 1-3: Single Three Channel 20 Vpp ADC Board - S/N 1360

Smart24 Sample Rate: 20 sps and 40 sps

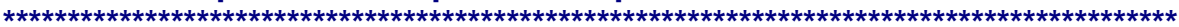

CTK Test Description: Measure the amount of SMART24 channel-to-channel crosstalk.

\begin{tabular}{|c|c|c|c|}
\hline Channel & RMS Input & RMS Crosstalk & $\begin{array}{c}\text { Crosstalk } \\
(\mathrm{dB})\end{array}$ \\
\hline $\mathrm{C} 1 \mathrm{~S}$ & $1.9 \mathrm{~V}$ & $1.5 \mu \mathrm{V}$ & -122.0 \\
\hline $\mathrm{C} 2 \mathrm{~S}$ & $1.9 \mathrm{~V}$ & $1.5 \mu \mathrm{V}$ & -122.1 \\
\hline $\mathrm{C} 3 \mathrm{~S}$ & $1.9 \mathrm{~V}$ & $1.4 \mu \mathrm{V}$ & -122.5 \\
\hline
\end{tabular}

Table 6.6.1 SMART24 20 sps Crosstalk

\begin{tabular}{|c|c|c|c|}
\hline Channel & RMS Input & RMS Crosstalk & $\begin{array}{c}\text { Crosstalk } \\
(\mathrm{dB})\end{array}$ \\
\hline BDF & $1.9 \mathrm{~V}$ & $1.88 \mu \mathrm{V}$ & -120.1 \\
\hline $\mathrm{C} 2 \mathrm{P}$ & $1.9 \mathrm{~V}$ & $1.87 \mu \mathrm{V}$ & -120.1 \\
\hline $\mathrm{C} 3 \mathrm{P}$ & $1.9 \mathrm{~V}$ & $1.90 \mu \mathrm{V}$ & -120.0 \\
\hline
\end{tabular}

Table 6.6.2 SMART24 40 sps Crosstalk

Test Results: Table 6.6.1 indicates that the SMART24 20sps crosstalk is better than $-122 \mathrm{~dB}$ and the Smart 24 40sps is better than $-120 \mathrm{~dB}$. 


\subsection{SMART24 Test Data Sheet: 20 Vpp ADC Test - Dynamic Broadband/RTFIABW}

Smart24 S/N: 1224

Firmware Revision: 1.38

Authentication: Enabled

CH 1-3: Single Three Channel 20 Vpp ADC Board - S/N 1360

Smart24 Sample Rate: 20 sps and 40 sps

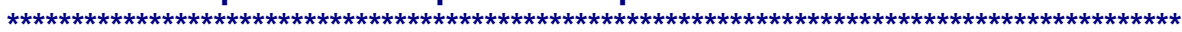

RTF/ABW Test Description: Measure SMART24 channel-to-channel relative phase and compute channel-to-channel timing difference. Measure the bandwidth/corner frequency ( $-3 \mathrm{~dB}$ point) and attenuation at the Nyquist $(20 \mathrm{~Hz})$.

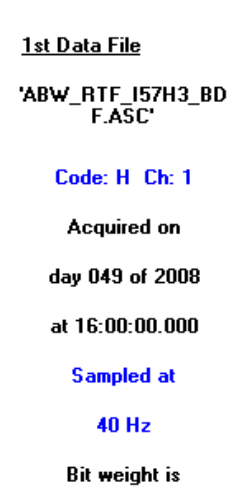

1.6400e-6 volts

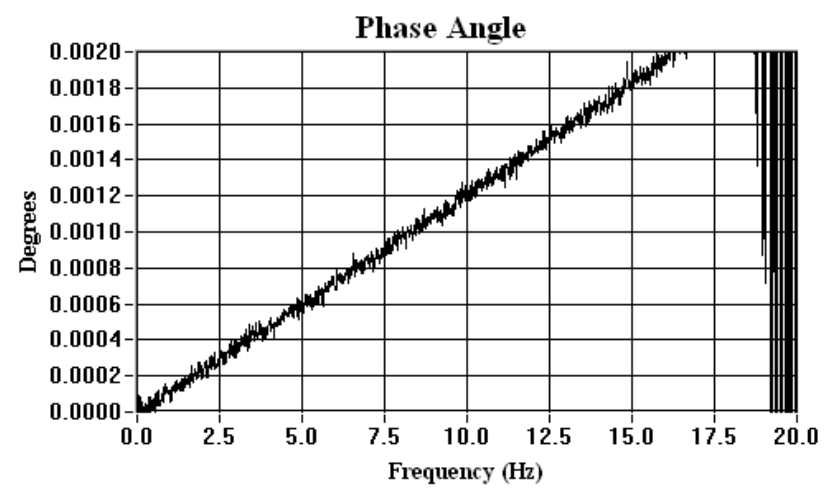

185 4096-point FFT's

Hann window, block mean subtracted

\author{
2nd Data File \\ 'ABW_RTF_157H3_C2 \\ P.AS' $\mathbf{C}^{\prime}$ \\ Code: H Ch: 2 \\ Acquired on \\ day 049 of 2008 \\ at 16:00:00.000 \\ Sampled at \\ $40 \mathrm{~Hz}$ \\ Bit weight is
}

$1.6400 \mathrm{e}-6$ volts

Figure 6.7.1 Coherence analysis results for SMART24 40 sps Channel Relative Phase/Skew

\begin{tabular}{|c|c|c|}
\hline Channel & $\begin{array}{c}\text { Relative Phase } \\
\text { (degrees) } \\
@, 5 \mathrm{~Hz}\end{array}$ & $\begin{array}{c}\text { Channel Skew } \\
(\mu \text { seconds })\end{array}$ \\
\hline C1S-C2S & 0.00057 & 0.32 \\
\hline C1S-C3S & 0.0020 & 1.11 \\
\hline C2S-C3S & 0.0014 & 0.78 \\
\hline
\end{tabular}

Table 6.7.1 SMART24 20 sps Channel Relative Phase/Skew

\begin{tabular}{|c|c|c|}
\hline Channel & $\begin{array}{c}\text { Relative Phase } \\
\text { (degrees) } \\
\text { @ 10 Hz }\end{array}$ & $\begin{array}{c}\text { Channel Skew } \\
\text { (Microseconds) }\end{array}$ \\
\hline $\begin{array}{c}\text { BDF- } \\
\text { C2P }\end{array}$ & 0.0012 & 0.33 \\
\hline $\begin{array}{c}\text { BDF- } \\
\text { C3P }\end{array}$ & 0.0014 & 1.11 \\
\hline C2P-C3P & 0.0027 & 0.75 \\
\hline
\end{tabular}

Table 6.7.2 SMART24 40 sps Channel Relative Phase/Skew

Test Results: Table 6.7.1-2 indicates that the SMART24 has less than $1.1 \mu$ seconds of channel to channel skew at 20 sps or 40 sps. 


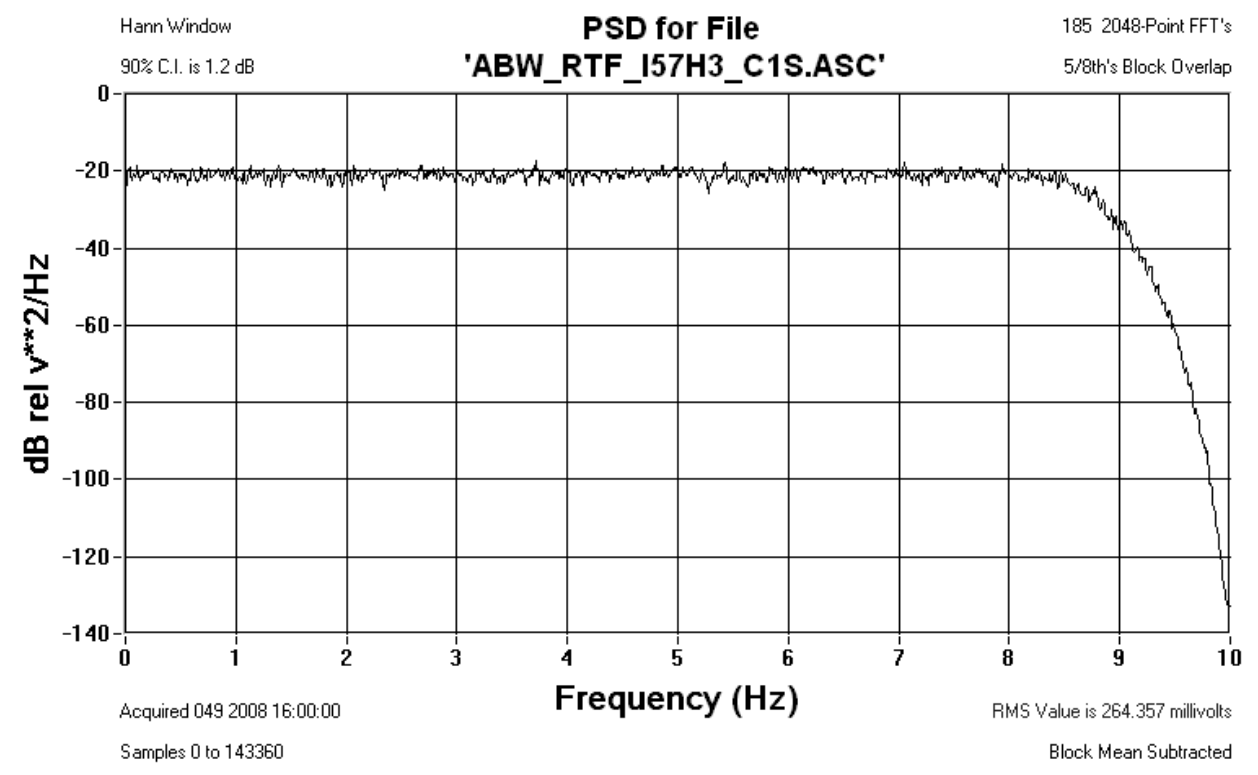

Figure 6.7.1 Response of the SMART24 to Broadband Noise

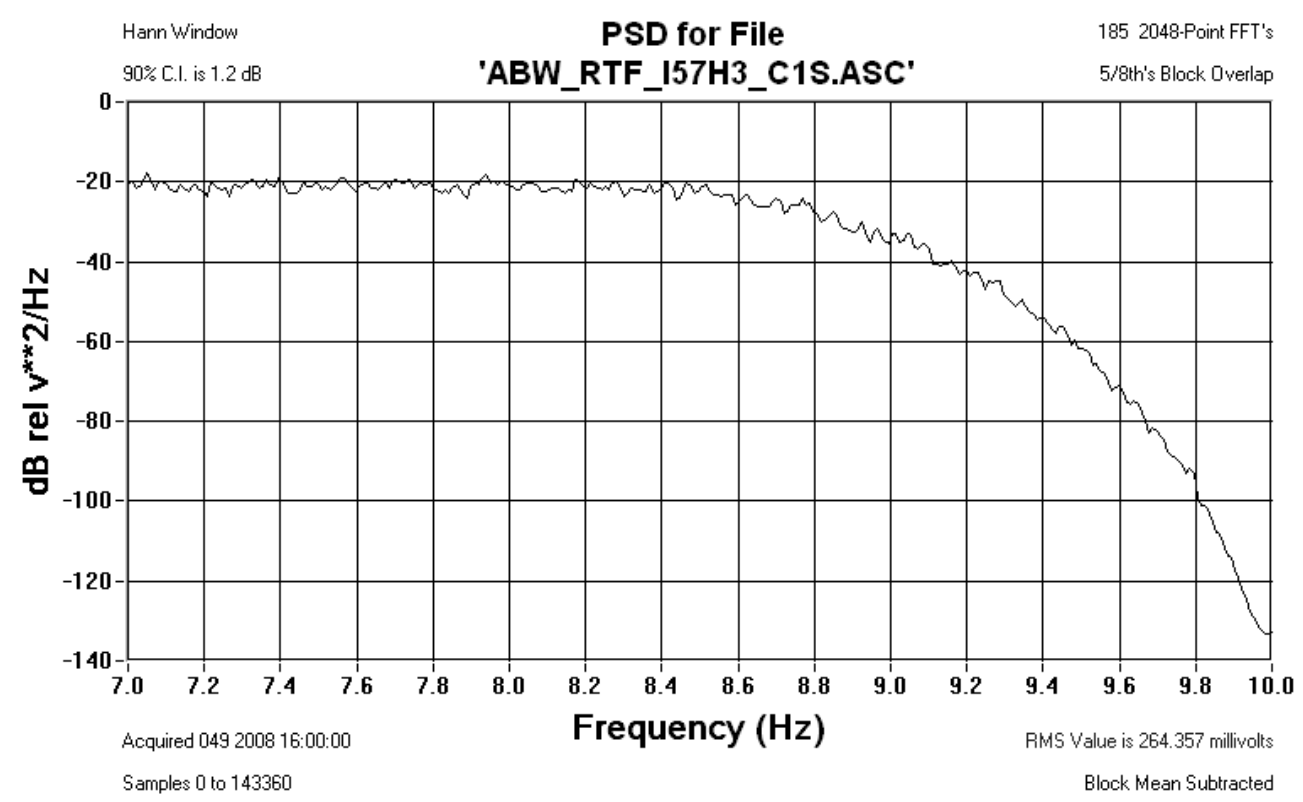

Figure 6.7.2 Response of the SMART24 to Broadband Noise 


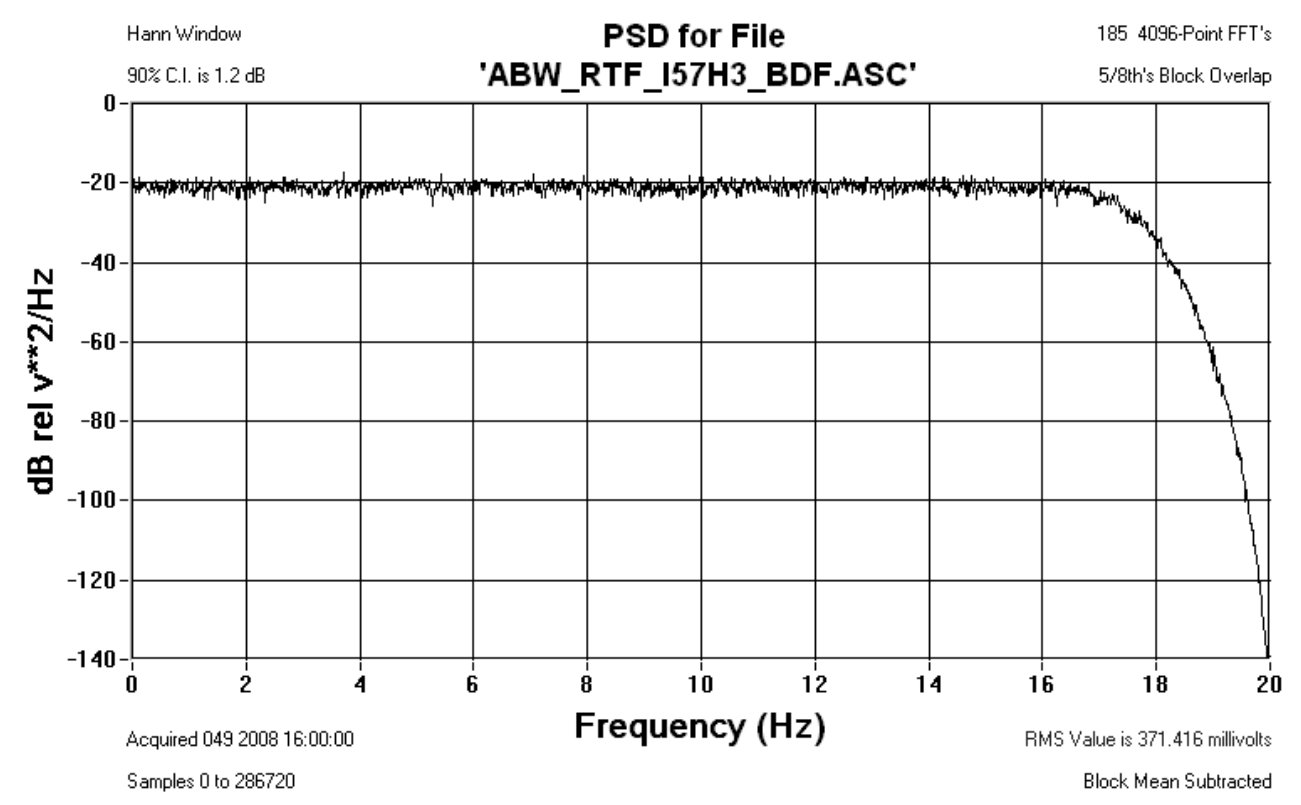

Figure 6.7.3 Response of the SMART24 to Broadband Noise

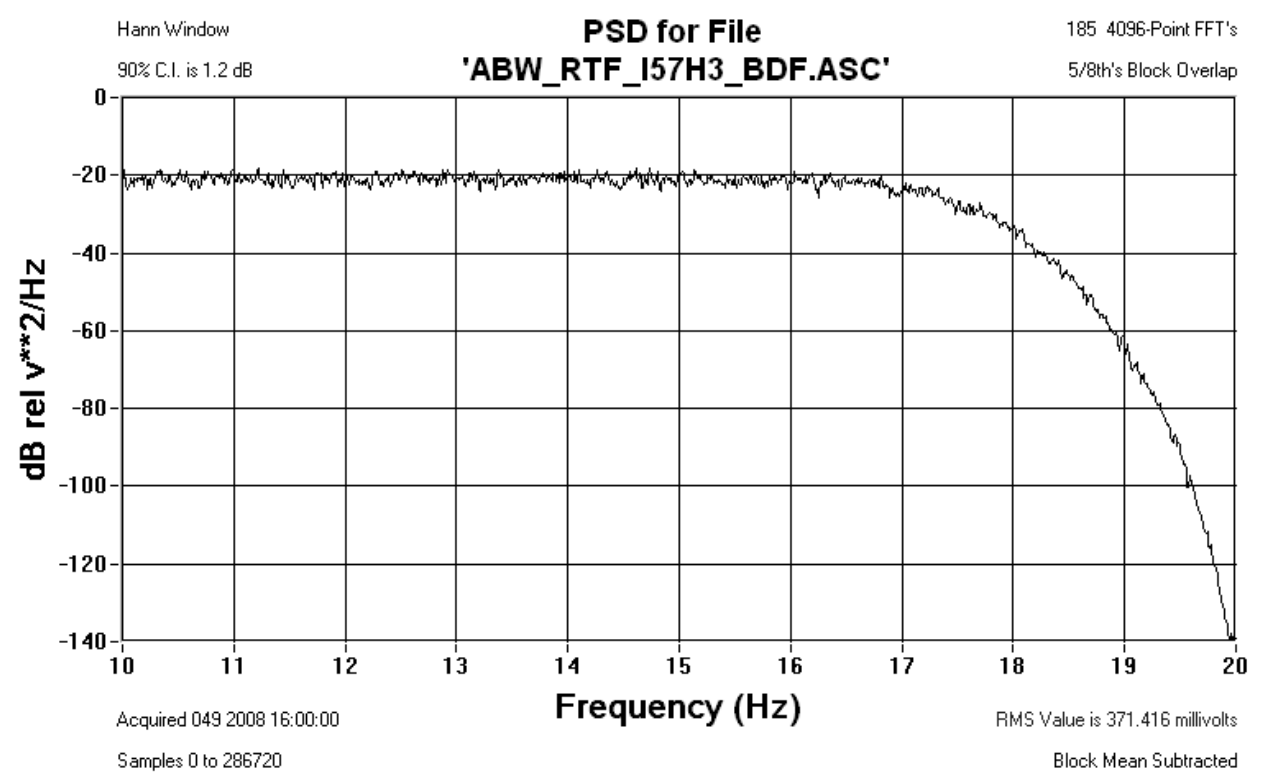

Figure 6.7.4 Response of the SMART24 to Broadband Noise

Test Results: Figures 6.7.1-4 indicates that the SMART24 20 sps $-3 \mathrm{~dB}$ point is at $8.5 \mathrm{~Hz}$ and relative attenuation at the Nyquist is $-112 \mathrm{~dB}$. The SMART24 $40 \mathrm{sps}-3 \mathrm{~dB}$ point is at $17.1 \mathrm{~Hz}$ and relative attenuation at the Nyquist is $-117 \mathrm{~dB}$. 


\subsection{SMART24 Test Data Sheet: 20 Vpp ADC Test - Timing/TTA}

Smart24 S/N: 1224

Firmware Revision: 1.38

Authentication: Enabled

CH 1-3: Single Three Channel 20 Vpp ADC Board - S/N 1360

Smart24 Sample Rate: 20 sps and 40 sps

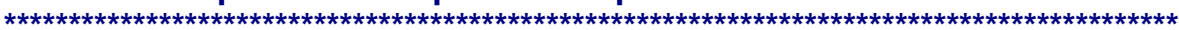

TTA Test Description: Determine the accuracy of the time-tags of the SMART24 data samples.

Time Tag Accuracy for 'TTA_157H3_C1S.ASC' $(20.0 \mathrm{~Hz}$ sampling)

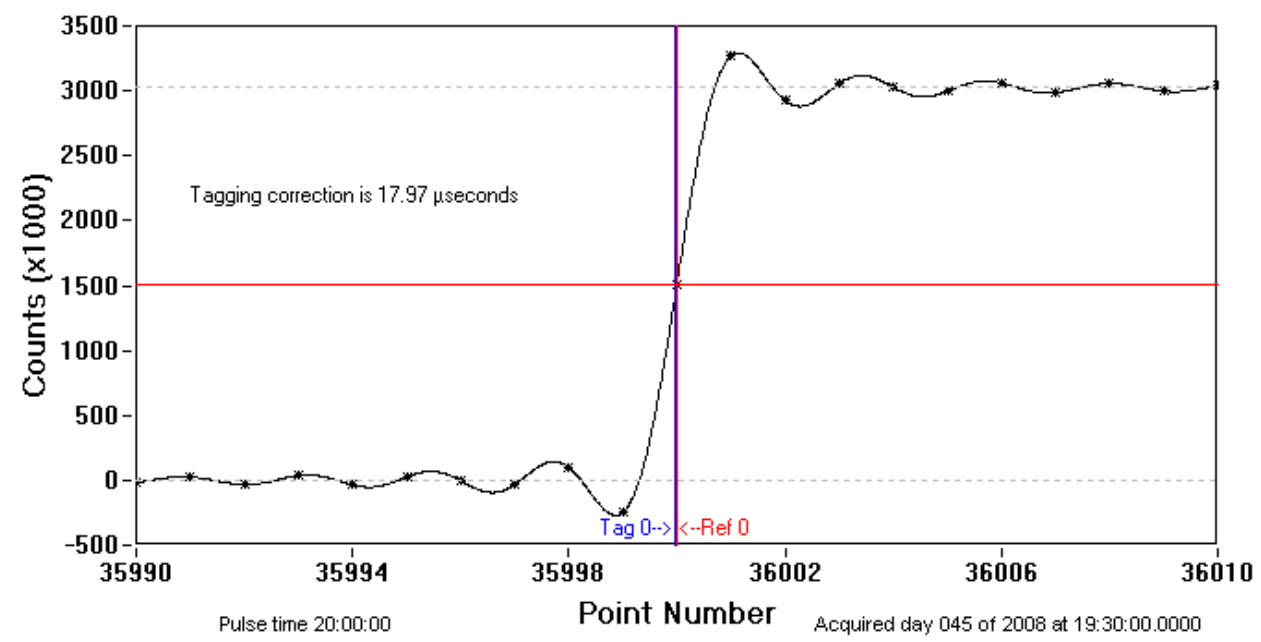

Figure 6.8.1 SMART24 20 sps for Channel C1S Time-Tag Accuracy

\begin{tabular}{|c|c|}
\hline Channel & TTA $\mu$ seconds \\
\hline C1S & 18.0 \\
\hline C $2 \mathrm{~S}$ & 17.7 \\
\hline C3S & 17.0 \\
\hline
\end{tabular}

Table 6.8.1 SMART24 20 sps Time-Tag Accuracy

Test Results: Table 6.8.1 indicates that the SMART24 can time-tag data samples to within 18.0 microseconds. 


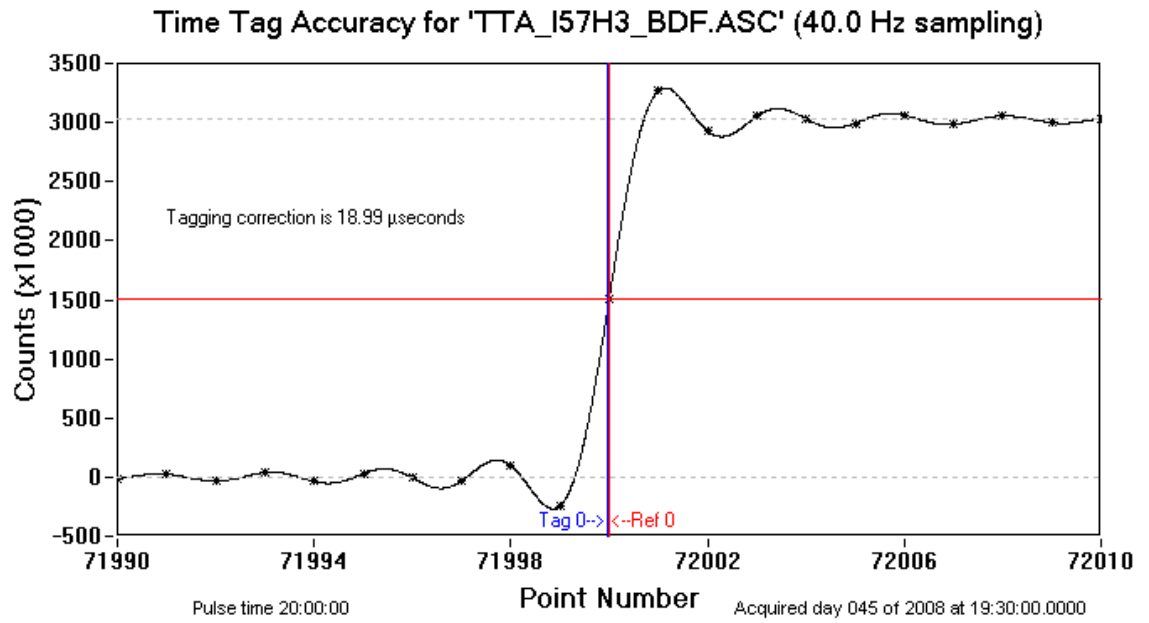

Figure 6.8.2 SMART24 40sps for Channel BDF Time-Tag Accuracy

\begin{tabular}{|c|c|}
\hline Channel & TTA $\mu$ seconds \\
\hline BDF & 19.0 \\
\hline C2P & 18.1 \\
\hline C3P & 18.4 \\
\hline
\end{tabular}

Table 6.8.2 SMART24 Time-Tag Accuracy

Test Results: Table 6.8.2 indicates that the SMART24 can time-tag data samples to within $\mathbf{1 9 . 0}$ microseconds. 


\subsection{SMART24 Test Data Sheet: 20 Vpp ADC Test - Calibrator/CAT/CFT}

Smart24 S/N: 1224

Firmware Revision: 1.38

Authentication: Enabled

CH 1-3: Single Three Channel 20 Vpp ADC Board - S/N 1360

Smart24 Sample Rate: 20 sps

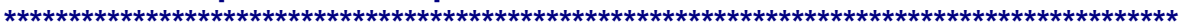

CAT Test Description: Determine accuracy of SMART24 to program correct output amplitude for sensor calibrations.

\begin{tabular}{|c|c|c|c|}
\hline $\begin{array}{c}\text { Programmed } \\
\text { SMART24 output } \\
\text { voltage (V) }\end{array}$ & $\begin{array}{c}\text { Measured } \\
\text { SMART24 } \\
\text { output voltage } \\
(\mathrm{V})\end{array}$ & $\begin{array}{c}\text { Test Frequency } \\
(\mathrm{Hz})\end{array}$ & $\begin{array}{c}\text { \% Deviation from } \\
\text { Nominal }\end{array}$ \\
\hline 5 & 4.985294 & 0.99999 & 0.29 \\
\hline 1 & 1.000102 & 1.00000 & -0.01 \\
\hline 0.5 & 0.499991 & 1.00000 & 0.00 \\
\hline 0.1 & 0.099953 & 1.00000 & 0.05 \\
\hline 0.05 & 0.049976 & 1.00000 & 0.05 \\
\hline
\end{tabular}

Table 6.9.1 SMART24 CAT results

Test Results: Table 6.9.1 indicates that the SMART24 output calibration amplitudes are better than $0.29 \%$ of nominal.

CFT Test Description: Determine accuracy of SMART24 to program correct output frequency for sensor calibrations.

\begin{tabular}{|c|c|c|c|}
\hline $\begin{array}{c}\text { Programmed } \\
\text { SMART24 } \\
\text { Output } \\
\text { Frequency (Hz) }\end{array}$ & $\begin{array}{c}\text { Measured } \\
\text { Frequency (Hz) }\end{array}$ & $\begin{array}{c}\text { Test Output } \\
\text { Voltage (V) }\end{array}$ & $\begin{array}{c}\text { \% Deviation from } \\
\text { Nominal } \\
\text { Frequency }\end{array}$ \\
\hline 5 & 5 & 0.999829 & 0.00000 \\
\hline 1 & 1 & 0.999799 & 0.00000 \\
\hline 0.5 & 0.5 & 0.999904 & 0.00000 \\
\hline 0.1 & 0.1 & 1.000332 & 0.00000 \\
\hline 0.05 & 0.05 & 1.000342 & 0.00000 \\
\hline 0.01 & 0.01 & 1.000037 & 0.00000 \\
\hline
\end{tabular}

Table 6.9.2 SMART24 CFT results

Test Results: Table 6.9.2 indicates that the SMART24 output calibration amplitudes are better than $0.00 \%$ of nominal. 


\subsection{SMART24 Test Data Sheet: 20 Vpp ADC Test - Calibrator/CAT/CFT}

Smart24 S/N: 1224

Firmware Revision: 1.38

Authentication: Enabled

CH 1-3: Single Three Channel 20 Vpp ADC Board - S/N 1360

Smart24 Sample Rate: 40 sps

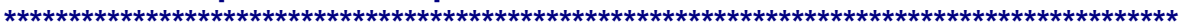

CAT Test Description: Determine accuracy of SMART24 to program correct output amplitude for sensor calibrations.

\begin{tabular}{|c|c|c|c|}
\hline $\begin{array}{c}\text { Programmed } \\
\text { SMART24 output } \\
\text { voltage (V) }\end{array}$ & $\begin{array}{c}\text { Measured } \\
\text { SMART24 } \\
\text { output voltage } \\
(\mathrm{V})\end{array}$ & $\begin{array}{c}\text { Test Frequency } \\
(\mathrm{Hz})\end{array}$ & $\begin{array}{c}\text { \% Deviation from } \\
\text { Nominal }\end{array}$ \\
\hline 5 & 4.983857 & 0.99999 & 0.32 \\
\hline 1 & 0.999814 & 1.00000 & 0.02 \\
\hline 0.5 & 0.499848 & 1.00000 & 0.03 \\
\hline 0.1 & 0.099925 & 1.00000 & 0.08 \\
\hline 0.05 & 0.049963 & 1.00000 & 0.07 \\
\hline
\end{tabular}

Table 6.10.1 SMART24 CAT results

Test Results: Table 6.10.1 indicates that the SMART24 output calibration amplitudes are better than $0.32 \%$ of nominal.

CFT Test Description: Determine accuracy of SMART24 to program correct output frequency for sensor calibrations.

\begin{tabular}{|c|c|c|c|}
\hline $\begin{array}{c}\text { Programmed } \\
\text { SMART24 } \\
\text { Output } \\
\text { Frequency (Hz) }\end{array}$ & $\begin{array}{c}\text { Measured } \\
\text { Frequency (Hz) }\end{array}$ & $\begin{array}{c}\text { Test Output } \\
\text { Voltage (V) }\end{array}$ & $\begin{array}{c}\text { \% Deviation from } \\
\text { Nominal } \\
\text { Frequency }\end{array}$ \\
\hline 5 & 5 & 0.999829 & 0.00000 \\
\hline 1 & 1 & 0.999799 & 0.00000 \\
\hline 0.5 & 0.5 & 0.999904 & 0.00000 \\
\hline 0.1 & 0.1 & 1.000332 & 0.00000 \\
\hline 0.05 & 0.05 & 1.000342 & 0.00000 \\
\hline 0.01 & 0.01 & 1.000037 & 0.00000 \\
\hline
\end{tabular}

Table 6.10.2 SMART24 CFT results

Test Results: Table 6.10.2 indicates that the SMART24 output calibration amplitudes are better than $0.00 \%$ of nominal. 


\subsection{SMART24 Test Data Sheet: 20 Vpp ADC Test - Calibrator/CHD/CLB}

Smart24 S/N: 1224

Firmware Revision: 1.38

Authentication: Enabled

CH 1-3: Single Three Channel 20 Vpp ADC Board - S/N 1360

Smart24 Sample Rate: 20 sps

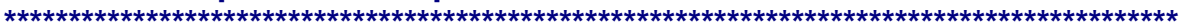

CHD Test Description: Determine linearity of SMART24's sensor calibration generator.

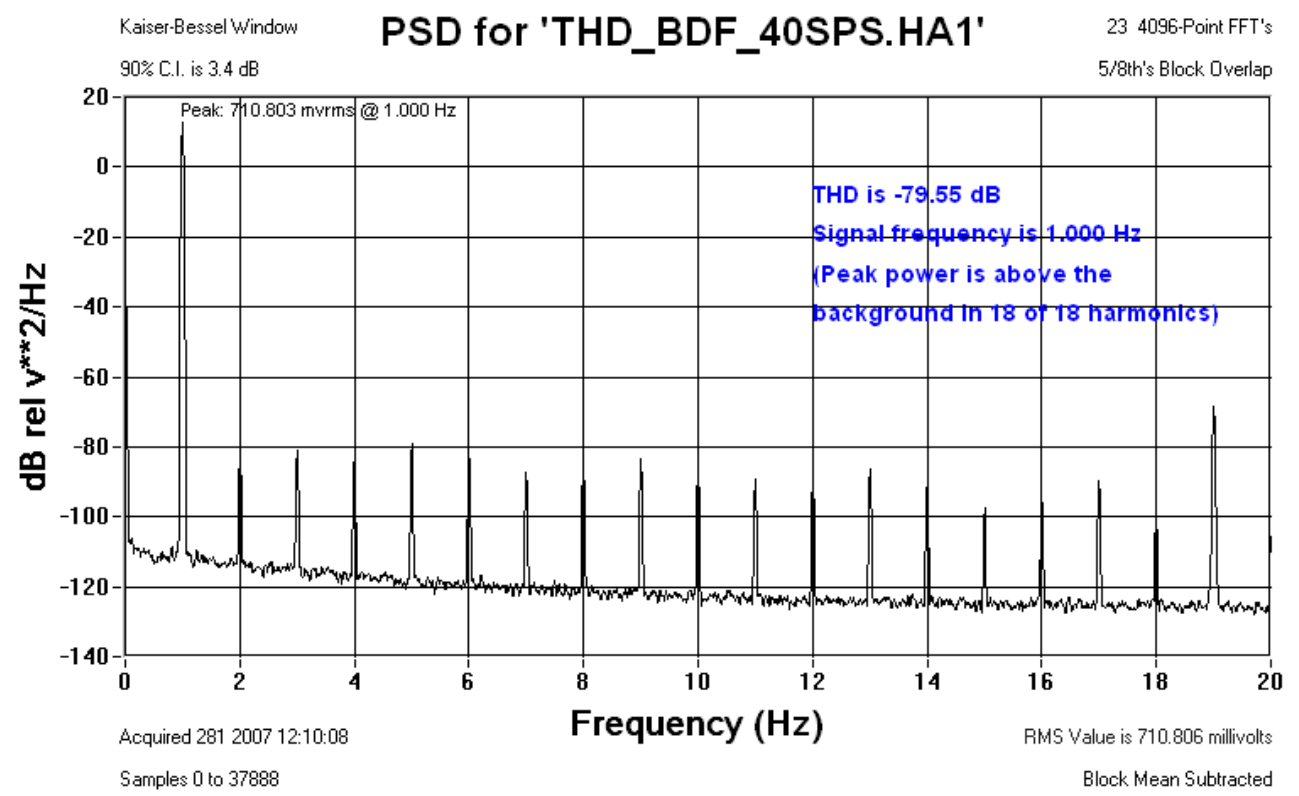

Figure 12.13.1 SMART24 sensor calibration generator's Total Harmonic Distortion for programmed output on channel BDF of 1 volts at $1 \mathrm{~Hz}$.

\begin{tabular}{|c|c|}
\hline Channel & THD \\
\hline$Z$ & $-79.55 \mathrm{~dB}$ \\
\hline
\end{tabular}

Table 12.13.1 SMART24 Sensor Calibration

Generator linearity using THD

Test Results: Table 12.13.1 indicates that the SMART24 Sensor Calibration Generator's Total Harmonic Distortion is better than -79.6 dB.

CLB Test Description: Determine linearity of SMART24's loopback circuit to the sensor calibration generator. 


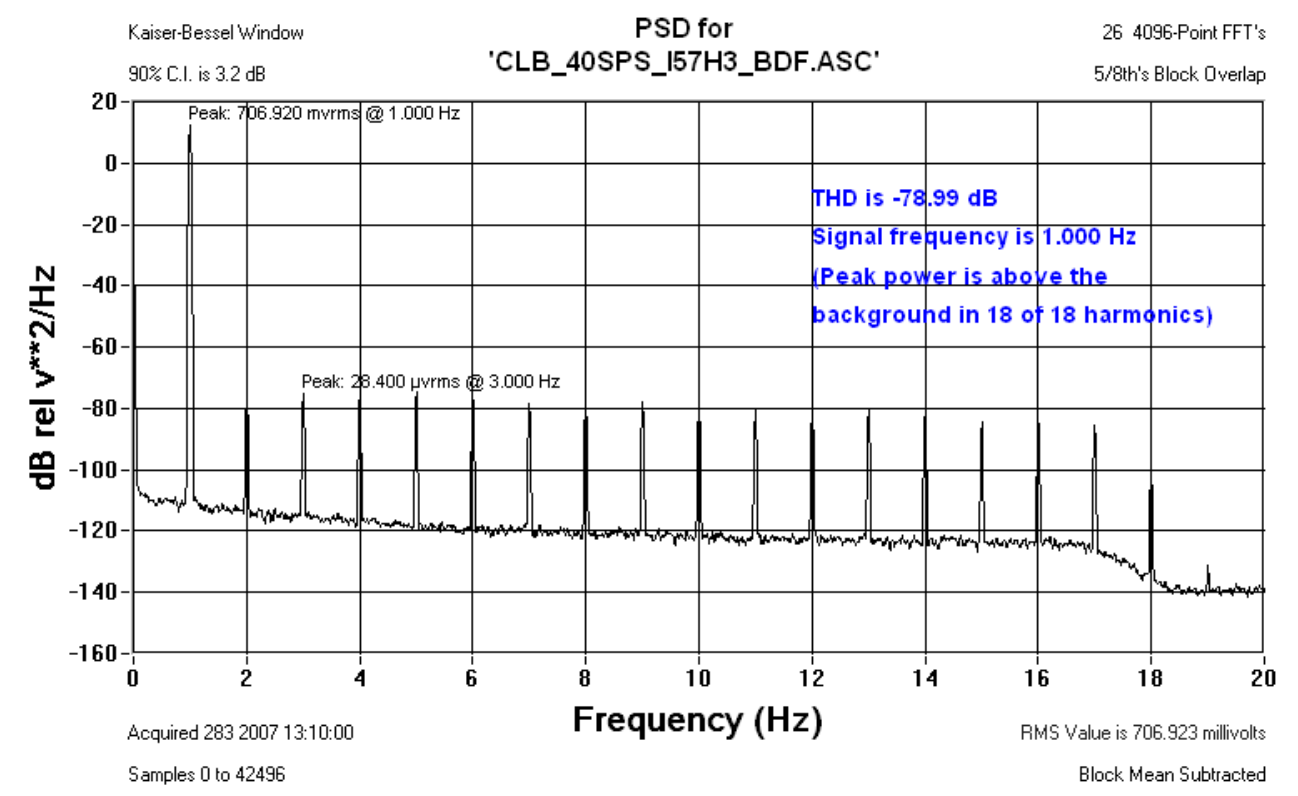

Figure 12.13.2 SMART24 sensor calibration generator's Total Harmonic Distortion loopback circuit for programmed output on channel $\mathrm{Z}$ of 1 volts at $1 \mathrm{~Hz}$.

\begin{tabular}{|c|c|}
\hline Channel & CLB \\
\hline BDF & -78.99 \\
\hline C2P & -78.97 \\
\hline C3P & -78.97 \\
\hline
\end{tabular}

Table 12.13.2 SMART24 Sensor Calibration Generator linearity using loopback controls

Test Results: Table 12.13.2 indicates that the SMART24 Sensor Calibration Generator's Total Harmonic Distortion of the loopback circuit is better than - $79.6 \mathrm{~dB}$ and this CLB was within $0.73 \%$ of the original signal's THD (i.e. - $79.6 \mathrm{~dB}$ ). 


\subsection{SMART24 Test Data Sheet: 20 Vpp ADC Test - Calibrator/CHD/CLB}

Smart24 S/N: 1224

Firmware Revision: 1.38

Authentication: Enabled

CH 1-3: Single Three Channel 20 Vpp ADC Board - S/N 1360

Smart24 Sample Rate: 40 sps

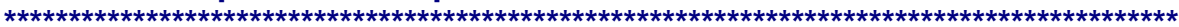

CHD Test Description: Determine linearity of SMART24's sensor calibration generator.

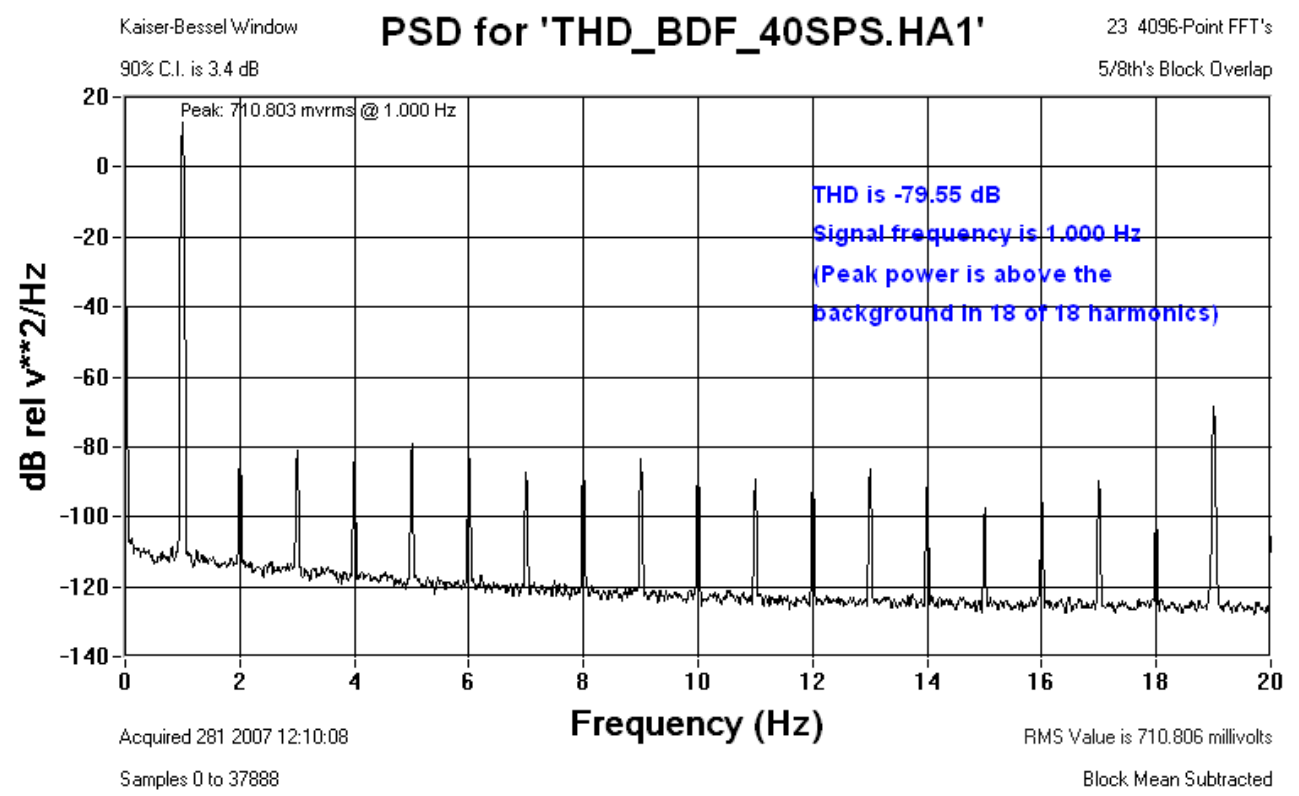

Figure 12.13.1 SMART24 sensor calibration generator's Total Harmonic Distortion for programmed output on channel BDF of 1 volts at $1 \mathrm{~Hz}$.

\begin{tabular}{|c|c|}
\hline Channel & THD \\
\hline$Z$ & $-79.55 \mathrm{~dB}$ \\
\hline
\end{tabular}

Table 12.13.1 SMART24 Sensor Calibration

Generator linearity using THD

Test Results: Table 12.13.1 indicates that the SMART24 Sensor Calibration Generator's Total Harmonic Distortion is better than -79.6 dB.

CLB Test Description: Determine linearity of SMART24's loopback circuit to the sensor calibration generator. 


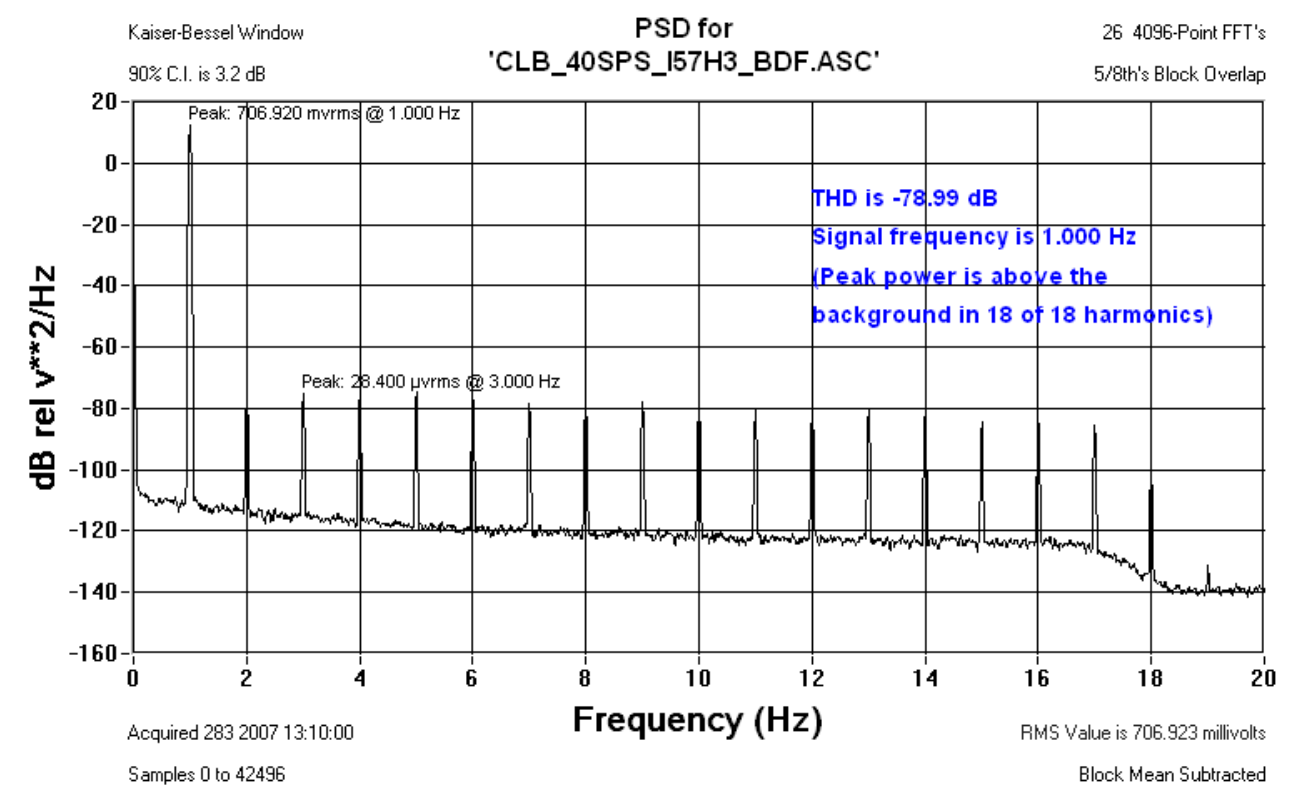

Figure 12.13.2 SMART24 sensor calibration generator's Total Harmonic Distortion loopback circuit for programmed output on channel $\mathrm{Z}$ of 1 volts at $1 \mathrm{~Hz}$.

\begin{tabular}{|c|c|}
\hline Channel & CLB \\
\hline BDF & -78.99 \\
\hline C2P & -78.97 \\
\hline C3P & -78.97 \\
\hline
\end{tabular}

Table 12.13.2 SMART24 Sensor Calibration Generator linearity using loopback controls

Test Results: Table 12.13.2 indicates that the SMART24 Sensor Calibration Generator's Total Harmonic Distortion of the loopback circuit is better than - $79.6 \mathrm{~dB}$ and this CLB was within $0.73 \%$ of the original signal's THD (i.e. - $79.6 \mathrm{~dB}$ ). 


\subsection{SMART24 Test Data Sheet: 40 Vpp ADC Test - Static/DCA}

Smart24 S/N: 1224

Firmware Revision: 1.38

Authentication: Enabled

CH 1-3: Single Three Channel 40 Vpp ADC Board - S/N 1724

Smart24 Sample Rate: 20sps and 40sps

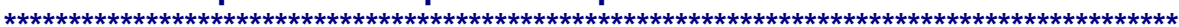

DCA Test Description: Measure DC Accuracy, and DC Full-Scale.

DCA- Manufacture Specified Volts/Count (CH 1-3): $3.2711 \times 10^{-6}$

\begin{tabular}{|c|c|c|c|c|c|c|}
\hline Channel & $\begin{array}{c}\text { Test Input } \\
\text { Volts }\end{array}$ & Counts/Volt & $\begin{array}{c}\mu \text { Volts/Coun } \\
\mathrm{t}\end{array}$ & $\begin{array}{c}\% \text { Deviation } \\
\text { from } \\
\text { Test Input } \\
\text { Voltage }\end{array}$ & $\begin{array}{c}\text { DC Offset } \\
\mu \text { Volts }\end{array}$ & $\begin{array}{c}\% \text { Deviation } \\
\text { from } \\
\text { Manufactures } \\
\text { LSB } \\
\text { Specification } \\
\mathrm{s}\end{array}$ \\
\hline $\mathrm{C} 1 \mathrm{~S}$ & 1.0000 & 305003 & 3.27865 & -0.264 & 6.6 & 0.231 \\
\hline $\mathrm{C} 2 \mathrm{~S}$ & 1.0000 & 305176 & 3.27679 & -0.207 & -3.3 & 0.174 \\
\hline $\mathrm{C} 3 \mathrm{~S}$ & 1.0000 & 304679 & 3.28213 & -0.370 & -98.5 & 0.337 \\
\hline
\end{tabular}

Table 6.13.1 DC Accuracy \pm 1 Volt Results for 20 sps.

\begin{tabular}{|c|c|c|c|c|c|c|}
\hline Channel & $\begin{array}{c}\text { Test Input } \\
\text { Volts }\end{array}$ & Counts/Volt & $\begin{array}{c}\mu \text { Volts/Coun } \\
\mathrm{t}\end{array}$ & $\begin{array}{c}\text { \% Deviation } \\
\text { from } \\
\text { Test Input } \\
\text { Voltage }\end{array}$ & $\begin{array}{c}\text { DC Offset } \\
\mu \text { Volts }\end{array}$ & $\begin{array}{c}\% \text { Deviation } \\
\text { from } \\
\text { Manufactures } \\
\text { LSB } \\
\text { Specification } \\
\mathrm{s}\end{array}$ \\
\hline BDF & 1.0000 & 305004 & 3.27865 & -0.264 & 6.6 & 0.231 \\
\hline C2P & 1.0000 & 305176 & 3.27679 & -0.207 & -3.3 & 0.174 \\
\hline C3P & 1.0000 & 304679 & 3.28213 & -0.370 & -98.5 & 0.337 \\
\hline
\end{tabular}

Table 6.13.2 DC Accuracy \pm 1 Volt Results for 40 sps.

Test Results: Tables 6.13.1-2 indicate that the Smart24 w/Fortezza Card accuracy of the measured LSB to \pm 1 Volt DC input is better than 0.34 of the manufactures specified LSB. 


\subsection{SMART24 Test Data Sheet: 40 Vpp ADC Test - Static/ITN/MPDR}

Smart24 S/N: 1224

Firmware Revision: 1.38

Authentication: Enabled

CH 1-3: Single Three Channel 40 Vpp ADC Board - S/N 1724

Smart24 Sample Rate: 20sps

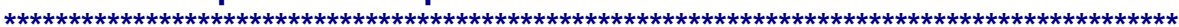

ITN Test Description: Measure Input Terminated Noise.

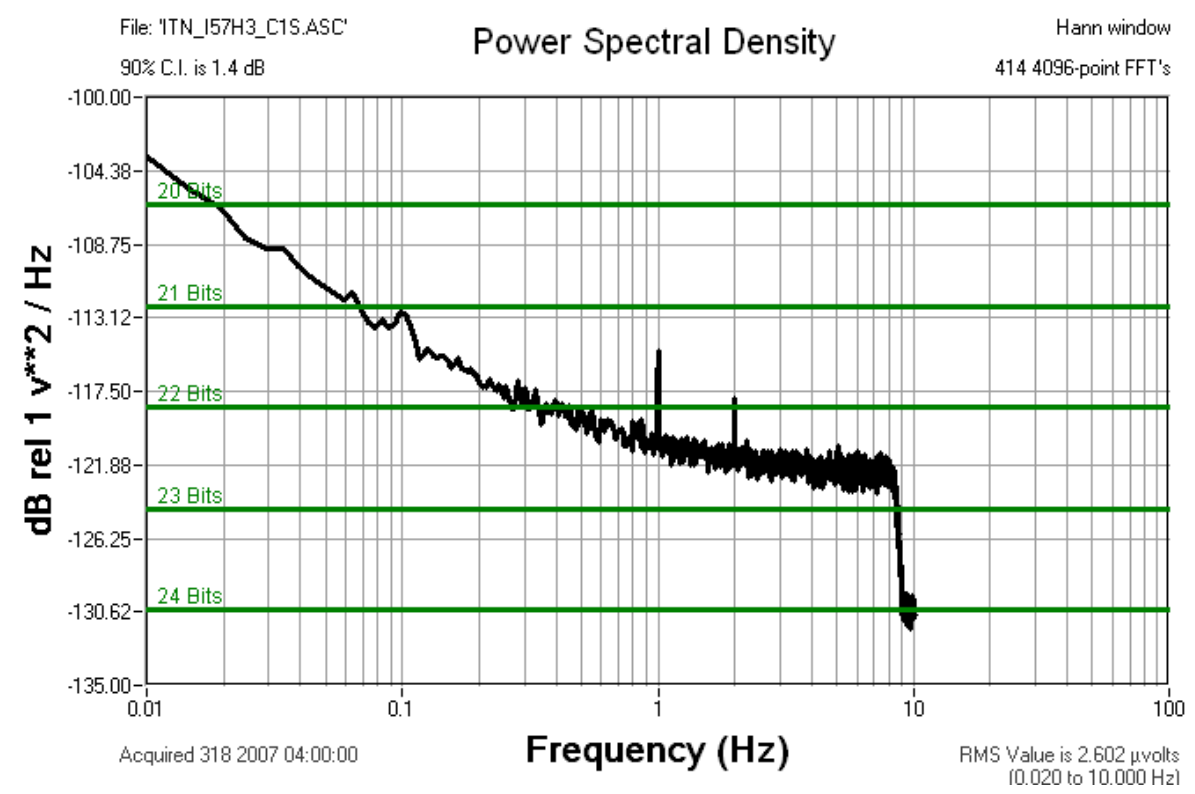

Figure 6.14.1 SMART24 Channel C1S Input Terminated Noise 


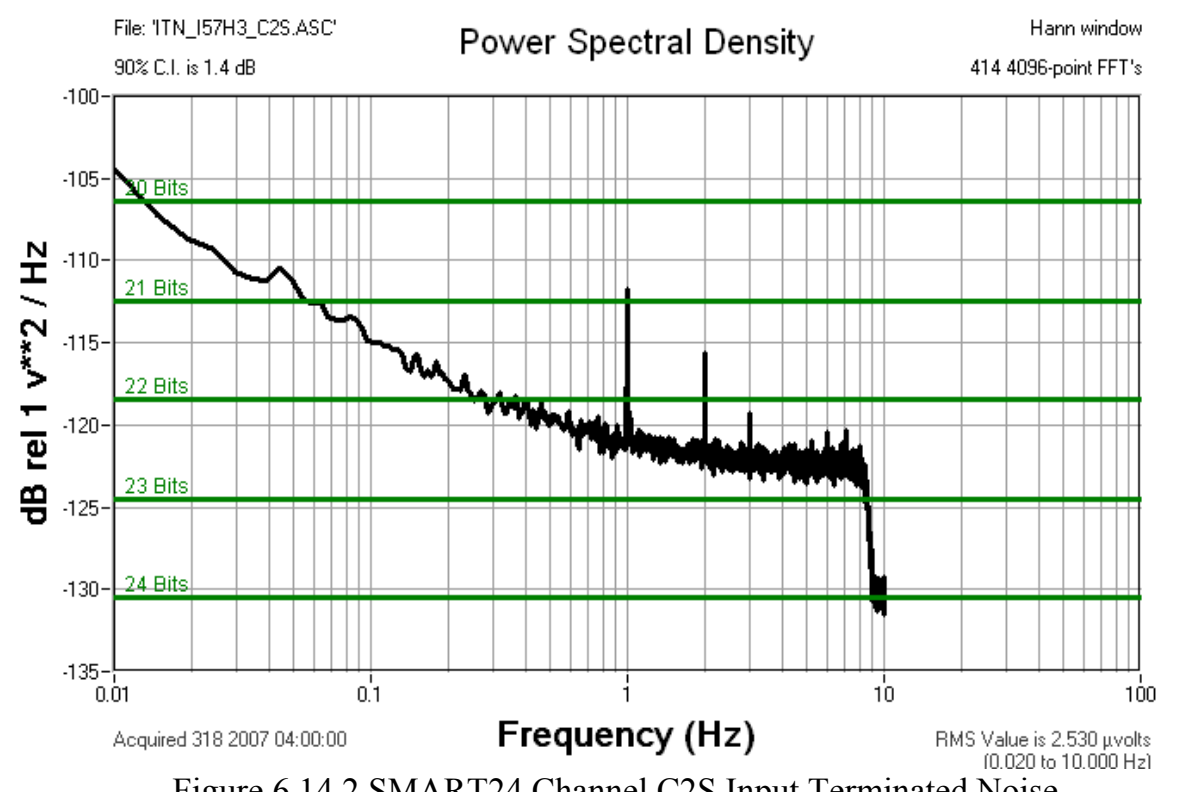

Figure 6.14.2 SMART24 Channel C2S Input Terminated Noise

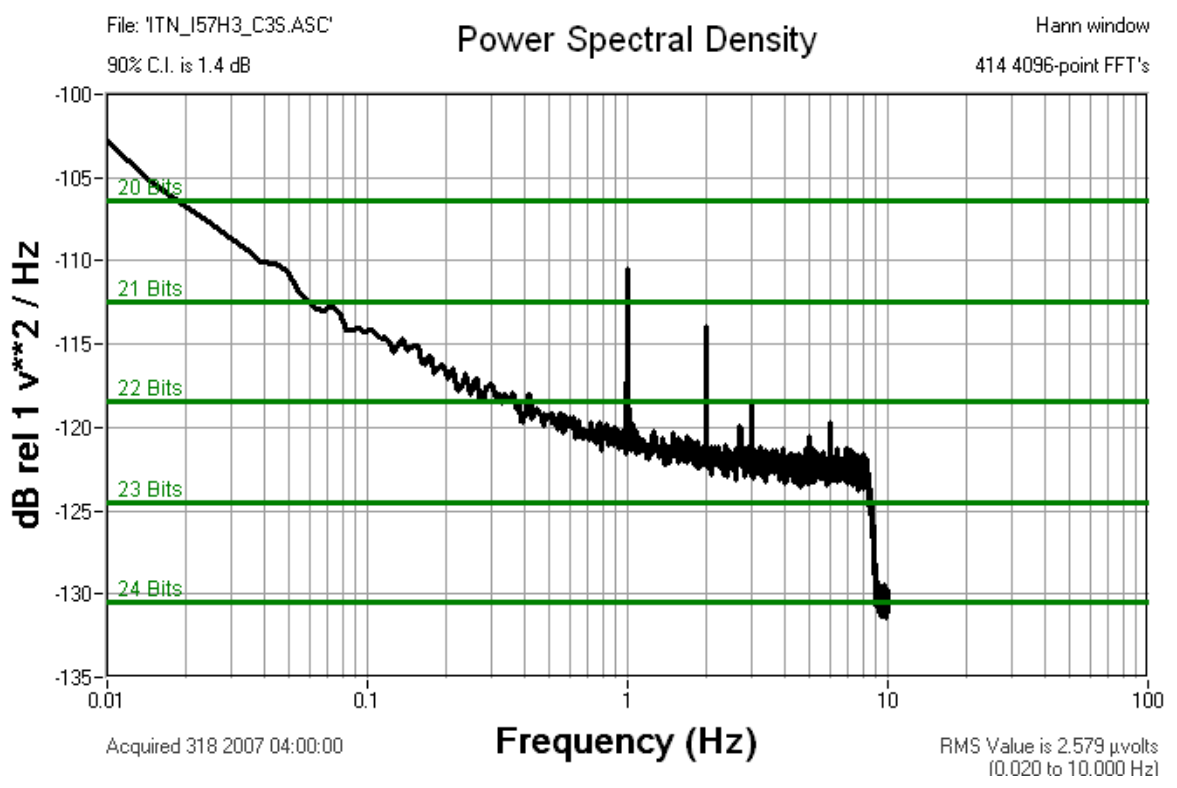

Figure 6.14.3 SMART24 Channel C3S Input Terminated Noise

\begin{tabular}{|c|c|c|}
\hline Channel & $\begin{array}{c}\text { RMS Noise } \mu \mathrm{V} \\
0.02 \text { to } 10 \mathrm{~Hz}\end{array}$ & Counts RMS \\
\hline C1S & 2.602 & 0.794 \\
\hline C2S & 2.530 & 0.772 \\
\hline C3S & 2.579 & 0.786 \\
\hline
\end{tabular}

Table 6.14.1 SMART24 20sps RMS Noise 
Test Results: Figures 6.14.1-3 and Table 6.14.1 indicate that the SMART24 has $<0.80$ counts RMS noise.

MPDR Test Description: Compute Maximum Potential Dynamic Range using data from ITN Test.

\begin{tabular}{|c|c|c|c|}
\hline Channel & $\begin{array}{c}\text { RMS Noise } \mu \mathrm{V} \\
0.02 \text { to } 10 \mathrm{~Hz}\end{array}$ & $\begin{array}{c}\text { RMS } \\
\text { Full-Scale Volts }\end{array}$ & MPDR \\
\hline C1S & 2.602 & 14.14 & 134.7 \\
\hline C2S & 2.530 & 14.14 & 134.9 \\
\hline C3S & 2.579 & 14.14 & 134.8 \\
\hline
\end{tabular}

Table 6.14.2 SMART24 20sps MPDR

Test Results: Table 6.14.2 indicates that the SMART24 Maximum Potential Dynamic Range is greater than $134.7 \mathrm{~dB}$. 


\subsection{SMART24 Test Data Sheet: 40 Vpp ADC Test - Static/ITN/MPDR}

Smart24 S/N: 1224

Firmware Revision: 1.38

Authentication: Enabled

CH 1-3: Single Three Channel 40 Vpp ADC Board - S/N 1724

Smart24 Sample Rate: 40sps

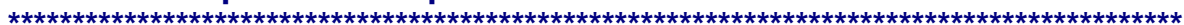

ITN Test Description: Measure Input Terminated Noise.

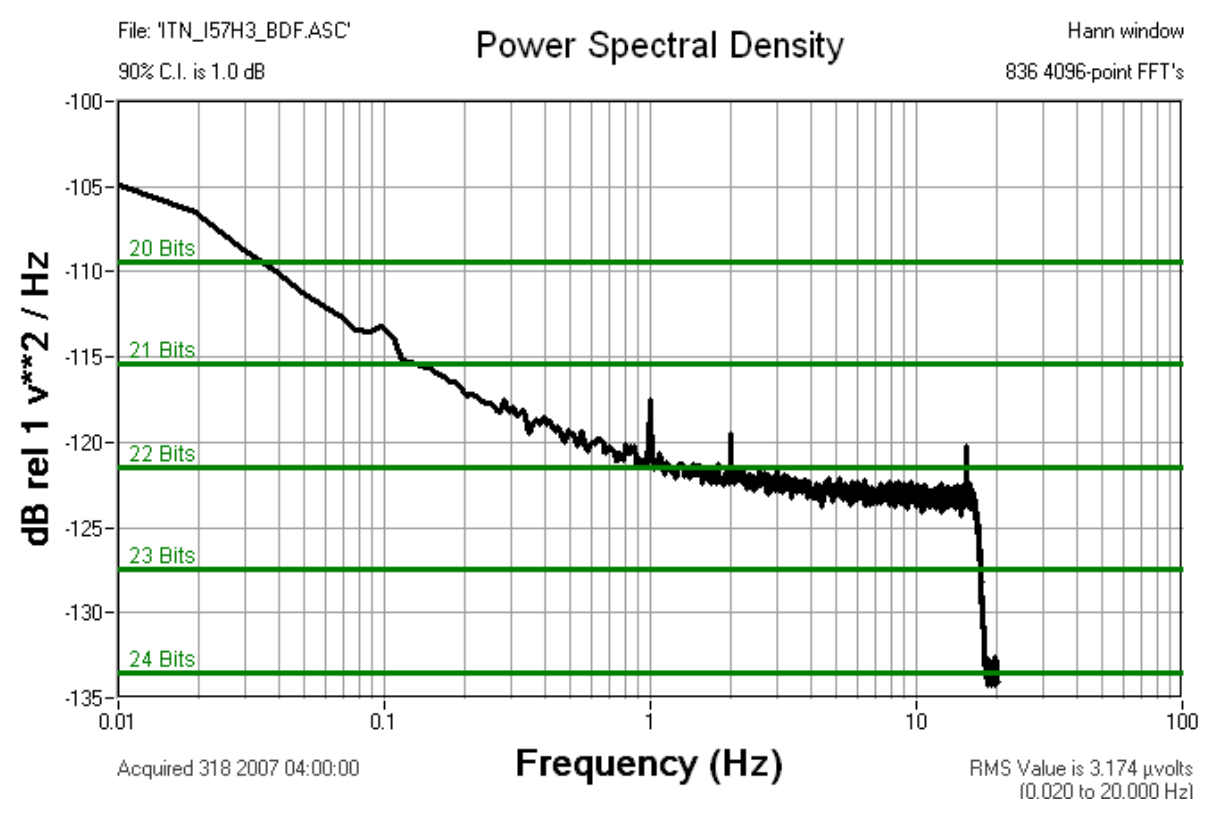

Figure 6.15.1 SMART24 Channel BDF Input Terminated Noise 


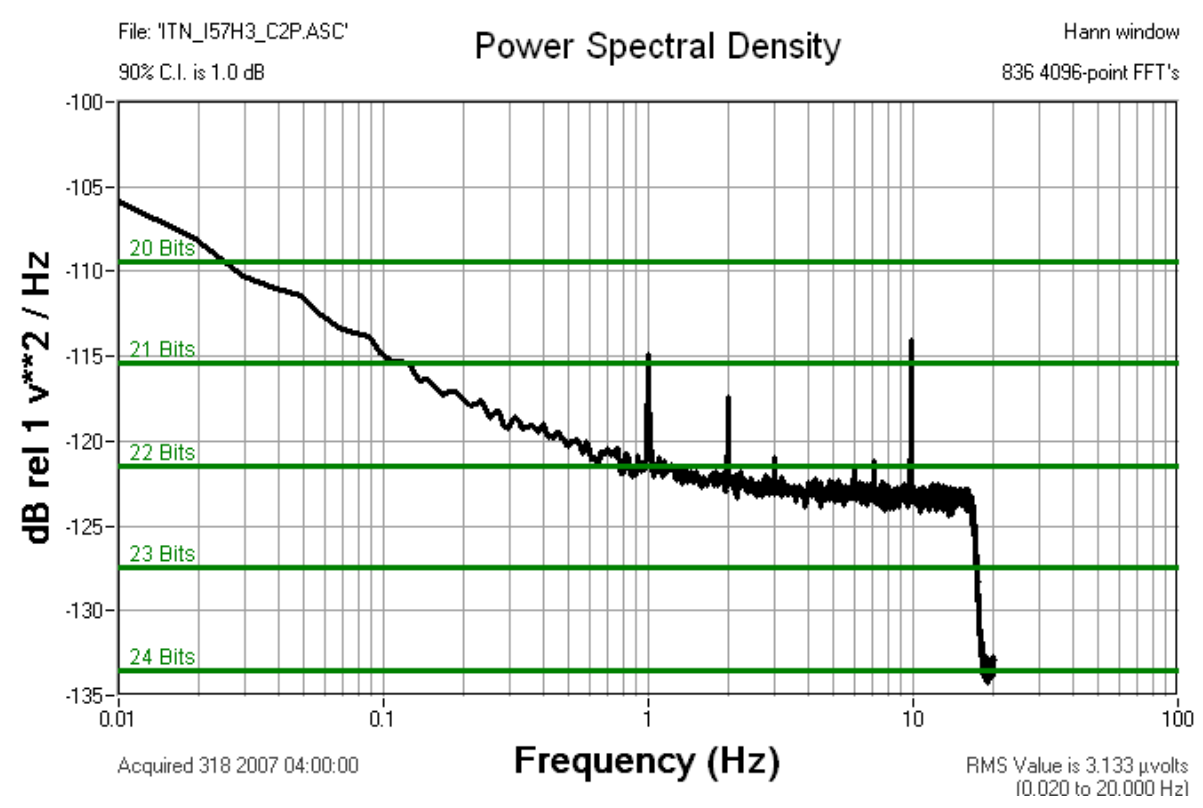

Figure 6.15.2 SMART24 Channel C2P Input Terminated Noise

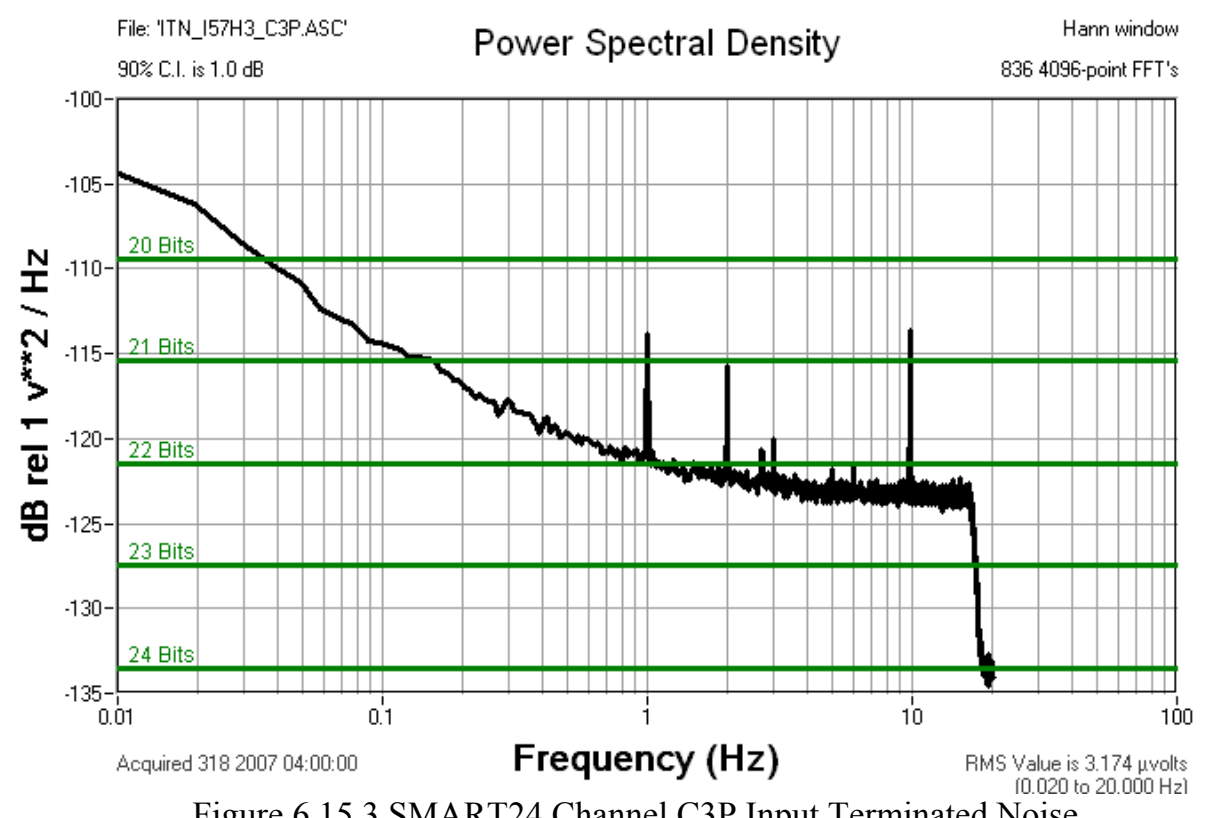

Figure 6.15.3 SMART24 Channel C3P Input Terminated Noise

\begin{tabular}{|c|c|c|}
\hline Channel & $\begin{array}{c}\text { RMS Noise } \mu \mathrm{V} \\
0.02 \text { to } 20 \mathrm{~Hz}\end{array}$ & Counts RMS \\
\hline BDF & 3.174 & 0.968 \\
\hline C2P & 3.133 & 0.956 \\
\hline C3P & 3.174 & 0.967 \\
\hline
\end{tabular}

Table 6.15.1 SMART24 40sps RMS Noise 
Test Results: Figures 6.15.1-3 and Table 6.15.1 indicate that the SMART24 has $<0.97$ counts RMS noise.

MPDR Test Description: Compute Maximum Potential Dynamic Range using data from ITN Test.

\begin{tabular}{|c|c|c|c|}
\hline Channel & $\begin{array}{c}\text { RMS Noise } \mu \mathrm{V} \\
0.02 \text { to } 20 \mathrm{~Hz}\end{array}$ & $\begin{array}{c}\text { RMS } \\
\text { Full-Scale Volts }\end{array}$ & MPDR \\
\hline BDF & 3.174 & 14.14 & 133.0 \\
\hline C2P & 3.133 & 14.14 & 133.1 \\
\hline C3P & 3.174 & 14.14 & 133.0 \\
\hline
\end{tabular}

Table 6.15.2 SMART24 40sps MPDR

Test Results: Table 6.15.2 indicates that the SMART24 Maximum Potential Dynamic Range is greater than $133.0 \mathrm{~dB}$. 


\subsection{SMART24 Test Data Sheet: 40 Vpp ADC Test - Dynamic Tonal/THD}

Smart24 S/N: 1224

Firmware Revision: 1.38

Authentication: Enabled

CH 1-3: Single Three Channel 40 Vpp ADC Board - S/N 1724

Smart24 Sample Rate: 20 sps and 40 sps

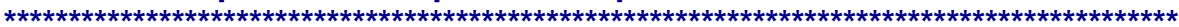

THD Test Description: Measure the linearity of the SMART24 using Total Harmonic Distortion.

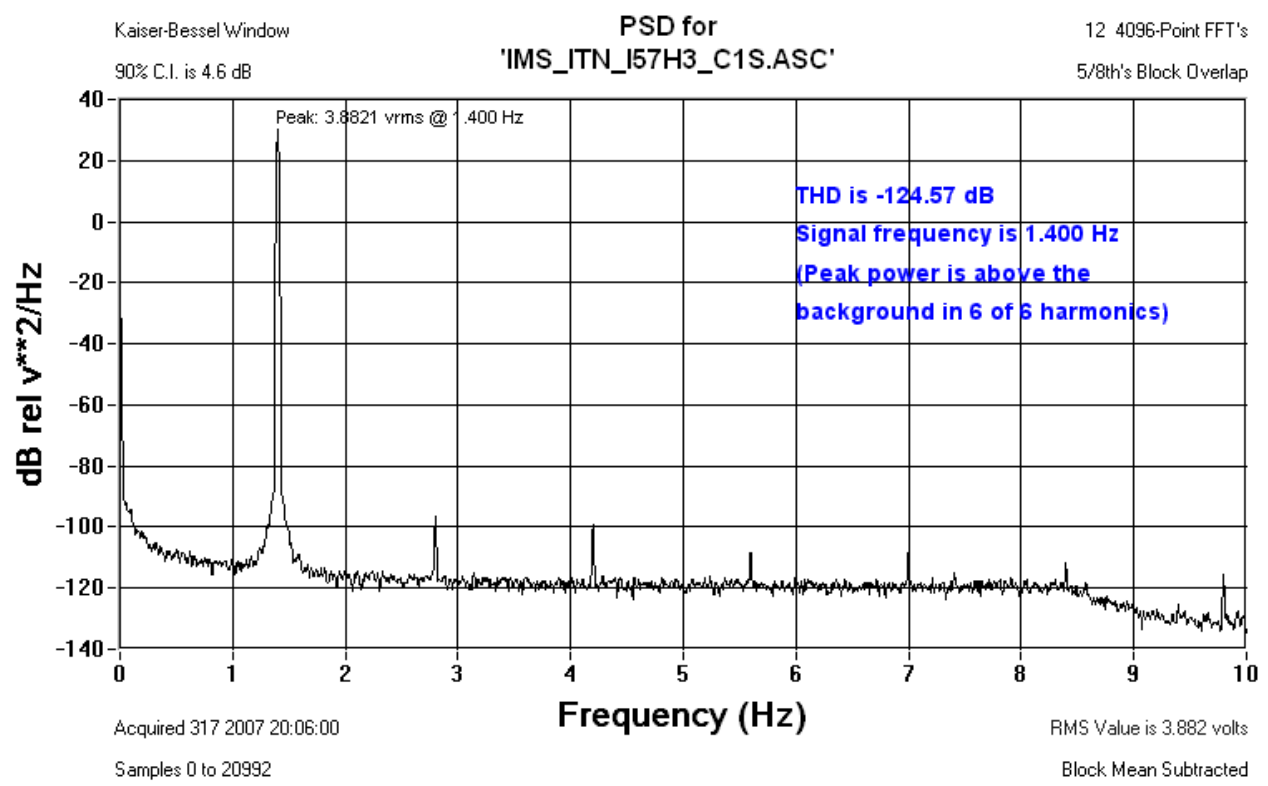

Figure 6.16.1 SMART24 20sps Total Harmonic Distortion

\begin{tabular}{|c|c|}
\hline Channel & THD (dB) \\
\hline C1S & -124.57 \\
\hline C2S & -132.87 \\
\hline C3S & -134.19 \\
\hline
\end{tabular}

Table 6.16.1 SMART24 THD

Test Results: Table 6.161 indicates that the SMART24 Total Harmonic Distortion is better than 124.6 dB for 20 sps acquisition rate. 


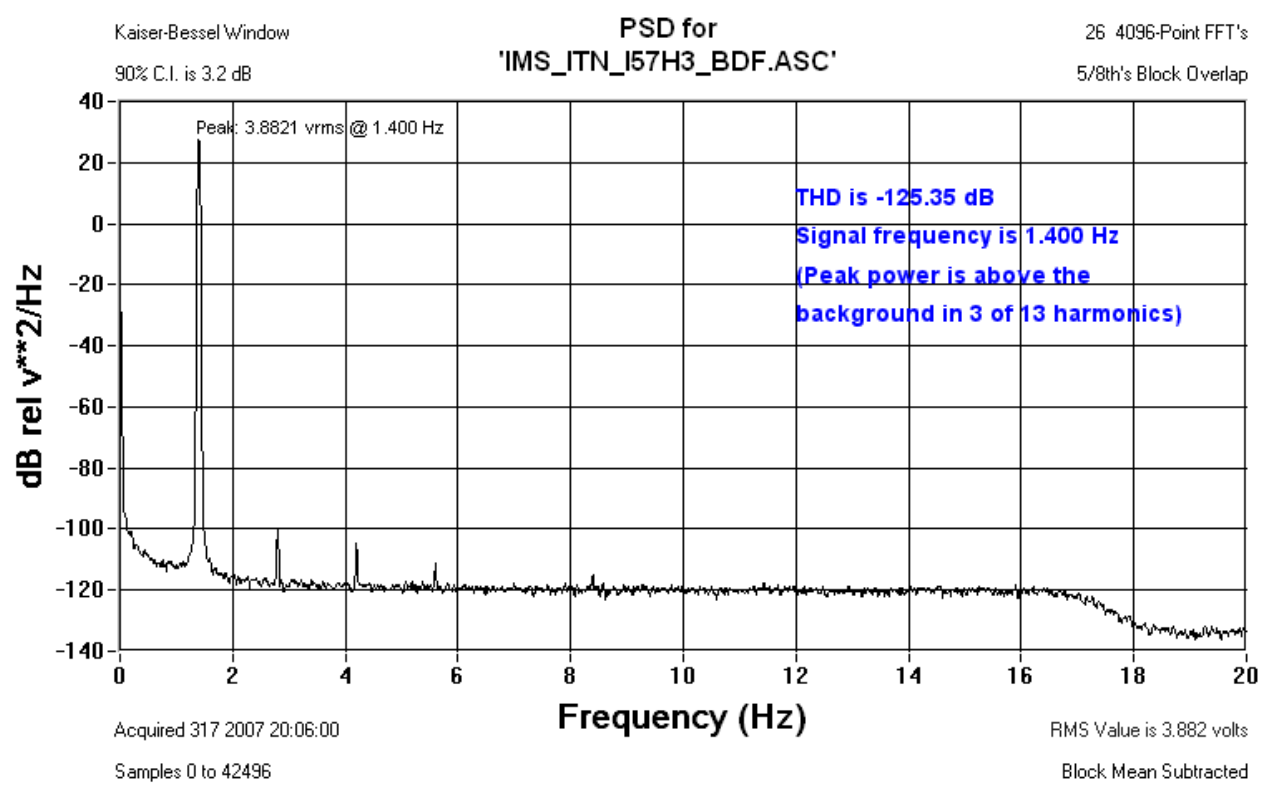

Figure 6.16.2 SMART24 40sps Total Harmonic Distortion

\begin{tabular}{|c|c|}
\hline Channel & THD (dB) \\
\hline BDF & -125.35 \\
\hline C2P & -131.74 \\
\hline C3P & -135.24 \\
\hline
\end{tabular}

Table 6.16.2 SMART24 40sps THD

Test Results: Table 6.16.2 indicates that the SMART24 Total Harmonic Distortion is better than $125.4 \mathrm{~dB}$ for 40 sps acquisition rate. 


\subsection{SMART24 Test Data Sheet: 40 Vpp ADC Test - Dynamic Tonal/CTK}

Smart24 S/N: 1224

Firmware Revision: 1.38

Authentication: Enabled

CH 1-3: Single Three Channel 40 Vpp ADC Board - S/N 1724

Smart24 Sample Rate: 20 sps and 40 sps

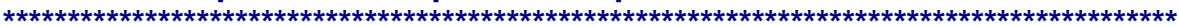

CTK Test Description: Measure the amount of SMART24 channel-to-channel crosstalk.

\begin{tabular}{|c|c|c|c|}
\hline Channel & $\begin{array}{c}\text { RMS Input } \\
(\mathrm{V})\end{array}$ & $\begin{array}{c}\text { RMS Crosstalk } \\
(\mu \mathrm{V})\end{array}$ & $\begin{array}{c}\text { Crosstalk } \\
(\mathrm{dB})\end{array}$ \\
\hline $\mathrm{C} 1 \mathrm{~S}$ & 3.88 & 2.83 & -122.7 \\
\hline $\mathrm{C} 2 \mathrm{~S}$ & 3.87 & 2.73 & -123.0 \\
\hline $\mathrm{C} 3 \mathrm{~S}$ & 3.88 & 2.66 & -123.3 \\
\hline
\end{tabular}

Table 6.17.1 SMART24 20 sps Crosstalk

\begin{tabular}{|c|c|c|c|}
\hline Channel & RMS Input & RMS Crosstalk & $\begin{array}{c}\text { Crosstalk } \\
(\mathrm{dB})\end{array}$ \\
\hline BDF & 3.88 & 3.30 & -121.4 \\
\hline C2P & 3.87 & 3.17 & -121.7 \\
\hline C3P & 3.88 & 3.20 & -121.7 \\
\hline
\end{tabular}

Table 6.17.2 SMART24 40 sps Crosstalk

Test Results: Tables 6.17.1-2 indicates that the SMART24 20sps crosstalk is better than $\mathbf{- 1 2 2 . 7} \mathrm{dB}$ and the Smart24 40sps is better than -121.4 dB. 


\subsection{SMART24 Test Data Sheet: 40 Vpp ADC Test - Dynamic Broadband/RTFIABW}

Smart24 S/N: 1224

Firmware Revision: 1.38

Authentication: Enabled

CH 1-3: Single Three Channel 40 Vpp ADC Board - S/N 1724

Smart24 Sample Rate: 20 sps and 40 sps

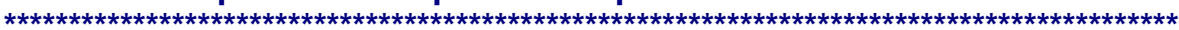

RTF/ABW Test Description: Measure SMART24 channel-to-channel relative phase and compute channel skew. Measure the bandwidth/corner frequency ( $-3 \mathrm{~dB}$ point) and attenuation at the Nyquist $(20 \mathrm{~Hz})$.
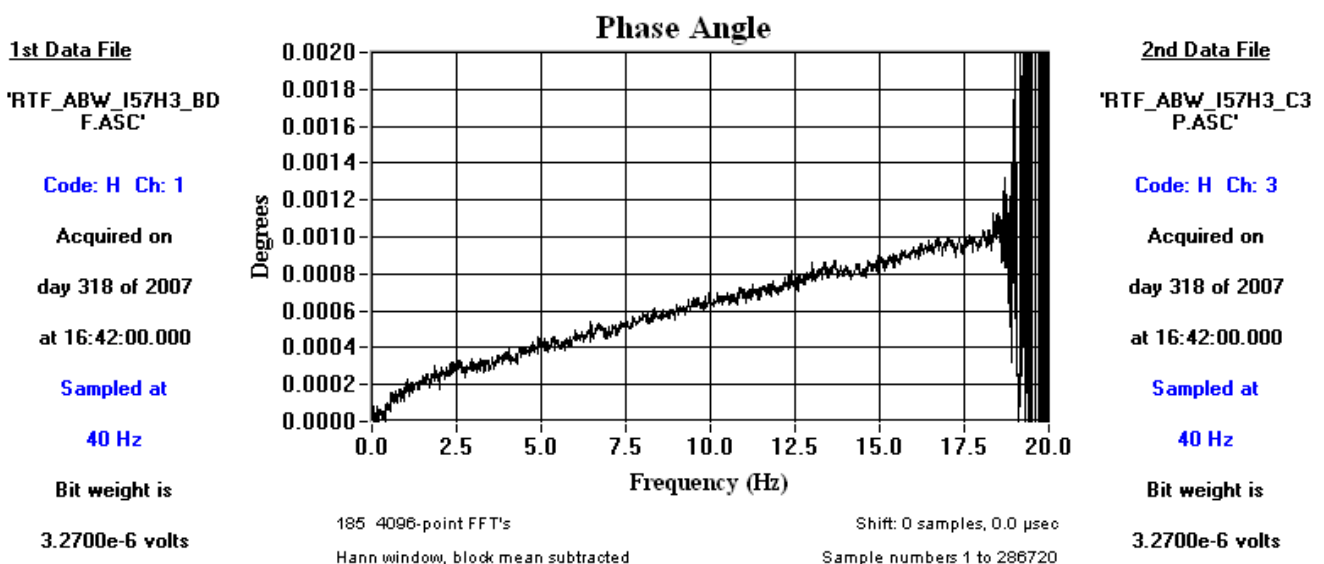

Table 6.18.1 Coherence analysis results for SMART24 40 sps Channel Relative Phase/Skew

\begin{tabular}{|c|c|c|}
\hline Channel & $\begin{array}{c}\text { Relative Phase } \\
\text { (degrees) } \\
@, 5 \mathrm{~Hz}\end{array}$ & $\begin{array}{c}\text { Channel Skew } \\
\text { (Microseconds) }\end{array}$ \\
\hline C1S-C2S & -0.004 & -2.22 \\
\hline C1S-C3S & 0.004 & 2.22 \\
\hline C2S-C3S & 0.008 & 4.44 \\
\hline
\end{tabular}

Table 6.18.1 SMART24 20 sps Channel Relative Phase/Skew

\begin{tabular}{|c|c|c|}
\hline Channel & $\begin{array}{c}\text { Relative Phase } \\
\text { (degrees) } \\
\text { @ } 10 \mathrm{~Hz}\end{array}$ & $\begin{array}{c}\text { Channel Skew } \\
\text { (Microseconds) }\end{array}$ \\
\hline $\begin{array}{c}\text { BDF- } \\
\text { C2P }\end{array}$ & 0.0008 & 0.22 \\
\hline $\begin{array}{c}\text { BDF- } \\
\text { C3P }\end{array}$ & 0.0004 & 0.18 \\
\hline C2P-C3P & 0.00147 & 0.41 \\
\hline
\end{tabular}

Table 6.18.2 SMART24 40 sps Channel Relative Phase/Skew

Test Results: Table 6.18.1-2 indicates that the SMART24 has better than 5 microseconds channel-tochannel skew at 20 sps and better than 0.41 microseconds channel-to-channel skew at 40 sps. 


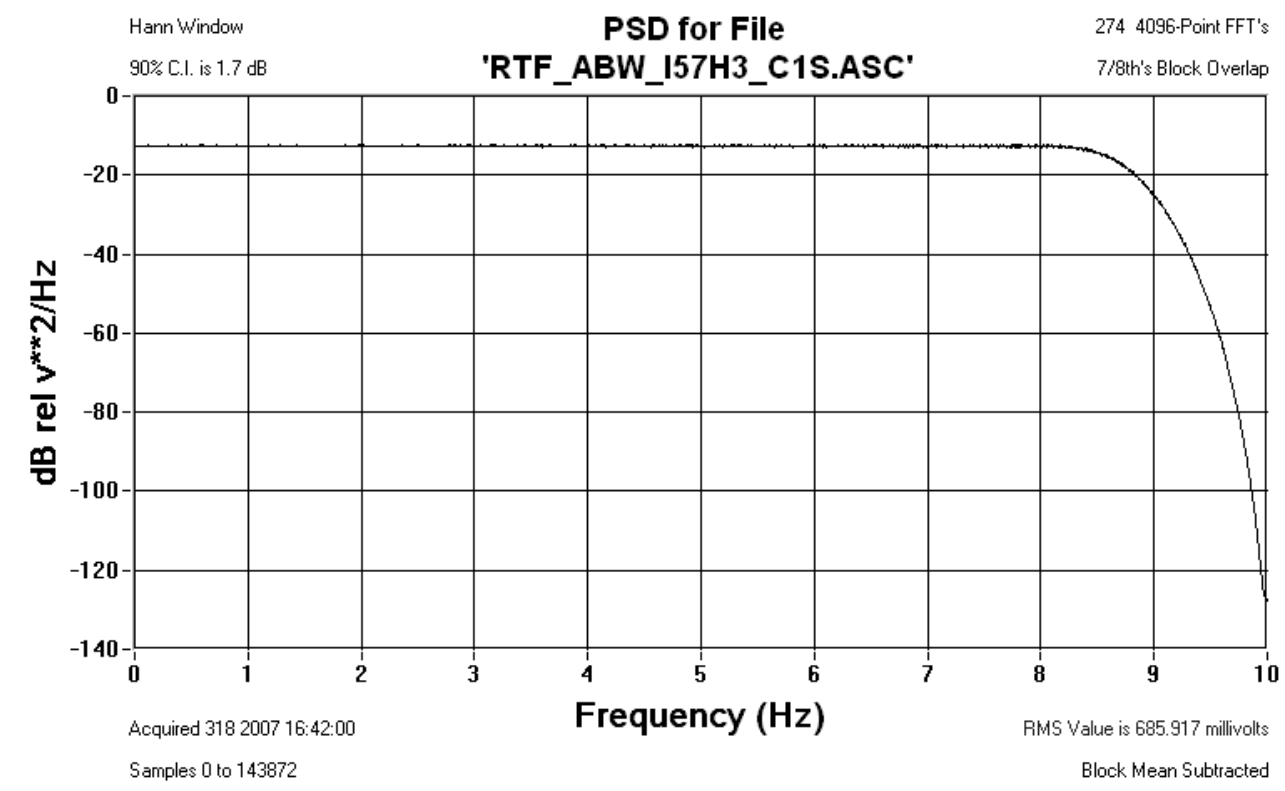

Figure 6.18.1 Response of the SMART24 to Broadband Noise

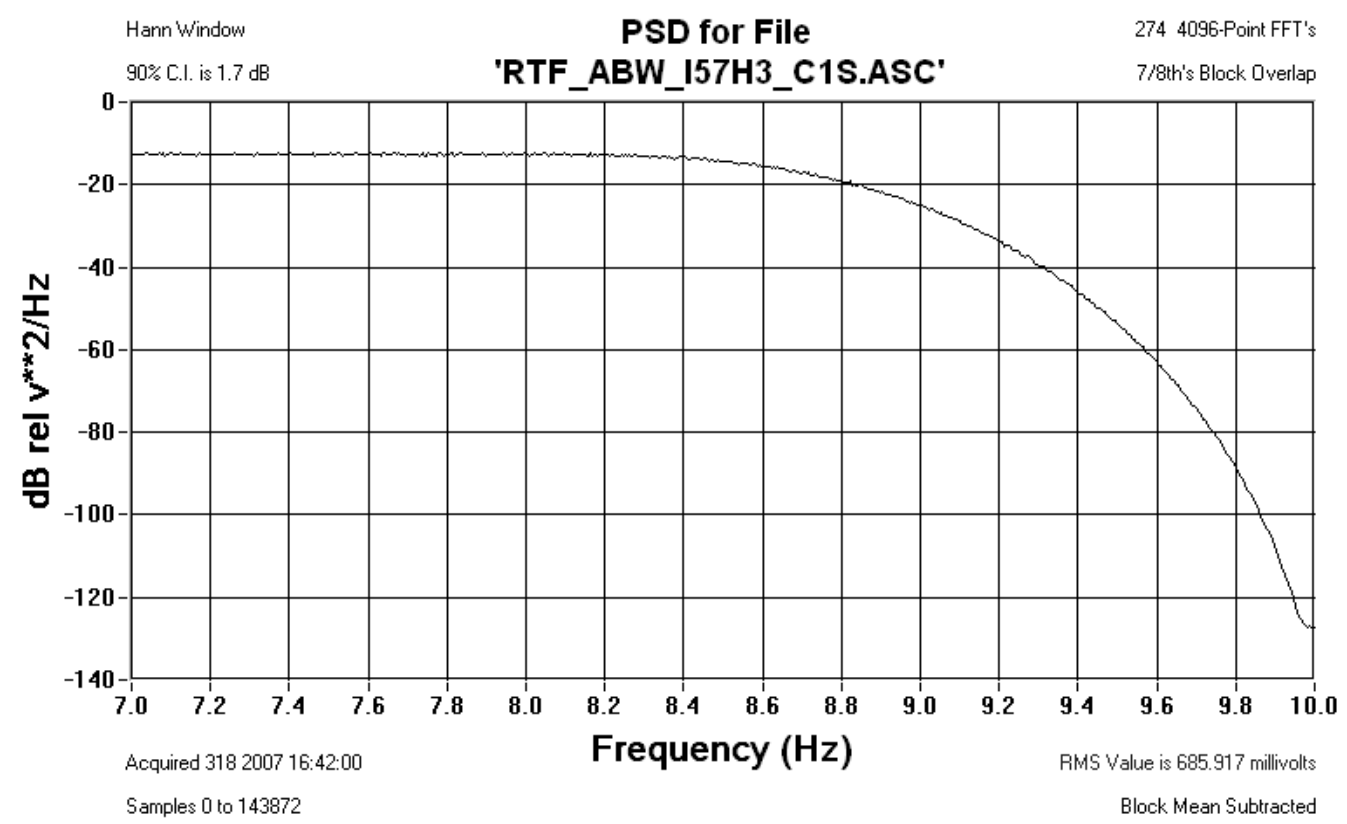

Figure 6.18.2 Response of the SMART24 to Broadband Noise 


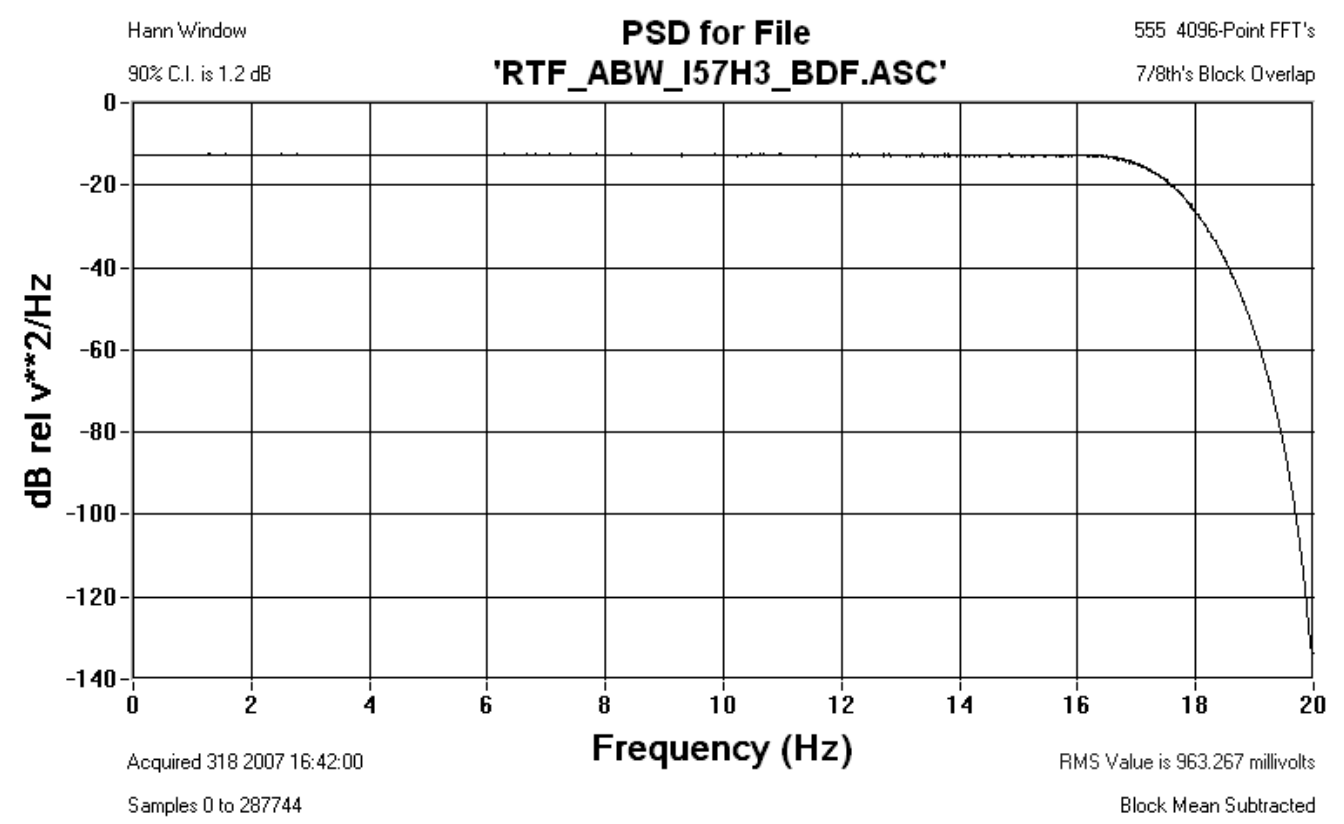

Figure 6.18.3 Response of the SMART24 to Broadband Noise

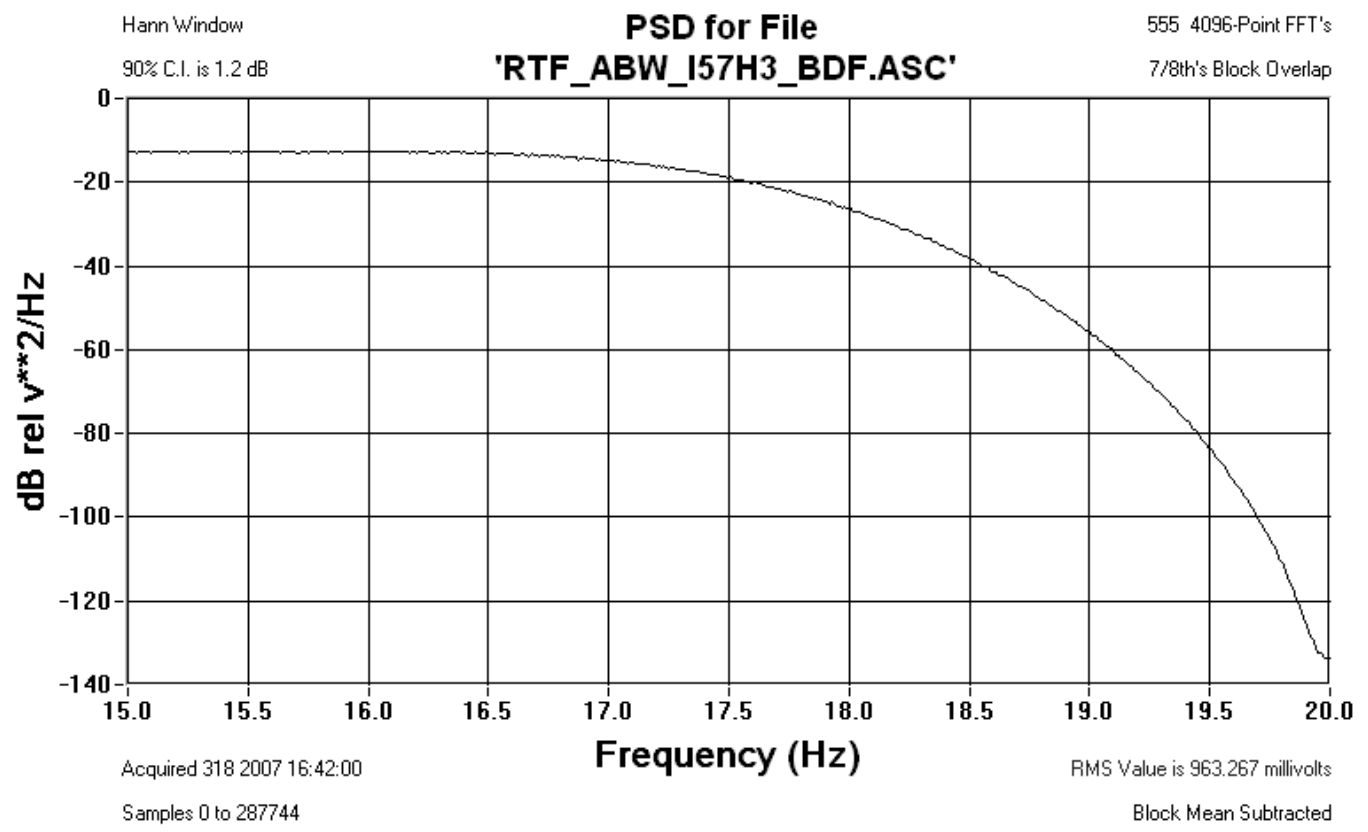

Figure 6.18.4 Response of the SMART24 to Broadband Noise

Test Results: Figures 6.18.1-4 indicates that the SMART24 20 sps -3dB point is at $8.6 \mathrm{~Hz}$ and relative attenuation at the Nyquist is $-113 \mathrm{~dB}$. The SMART24 40 sps $-3 \mathrm{~dB}$ point is at $17.1 \mathrm{~Hz}$ and relative attenuation at the Nyquist is $-121 \mathrm{~dB}$. 


\subsection{SMART24 Test Data Sheet: 40 Vpp ADC Test - Timing/TTA}

Smart24 S/N: 1224

Firmware Revision: 1.38

Authentication: Enabled

CH 1-3: Single Three Channel 40 Vpp ADC Board - S/N 1724

Smart24 Sample Rate: 20 sps and 40 sps

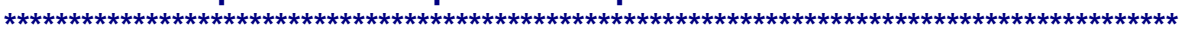

TTA Test Description: Determine the accuracy of the time-tags of the SMART24 data samples.

Time Tag Accuracy for 'TTA_157H3_C1S.ASC' $(20.0 \mathrm{~Hz}$ sampling)

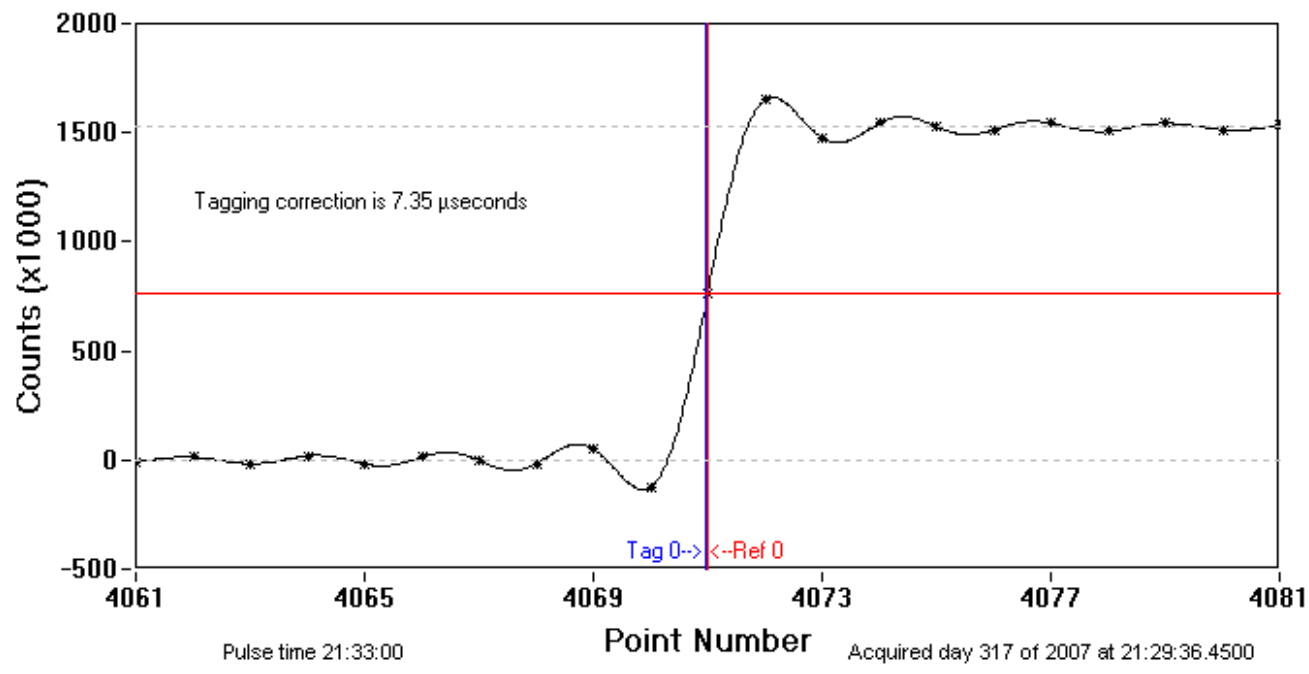

Figure 6.19.1 SMART24 20 sps for Channel C1S Time-Tag Accuracy

\begin{tabular}{|c|c|}
\hline Channel & TTA $\mu$ seconds \\
\hline C1S & 7.35 \\
\hline C2S & 7.74 \\
\hline C3S & 7.11 \\
\hline
\end{tabular}

Table 6.19.1 SMART24 20 sps Time-Tag Accuracy

Test Results: Table 6.19.1 indicates that the SMART24 can time-tag data samples to within 8 microseconds. 


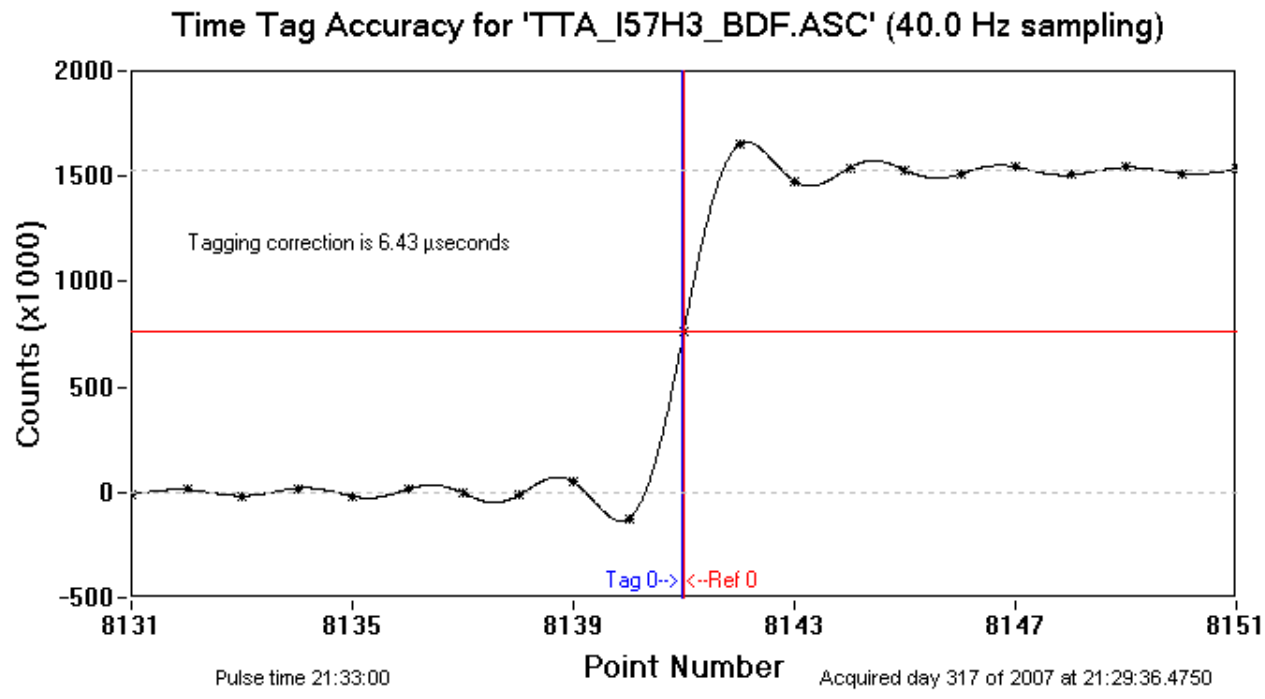

Figure 6.19.2 SMART24 40sps for Channel BDF Time-Tag Accuracy

\begin{tabular}{|c|c|}
\hline Channel & TTA $\mu$ seconds \\
\hline BDF & 6.43 \\
\hline C2P & 6.85 \\
\hline C3P & 4.99 \\
\hline
\end{tabular}

Table 6.19.2 SMART24 Time-Tag Accuracy

Test Results: Table 6.18.2 indicates that the SMART24 can time-tag data samples to within 7 microseconds. 


\subsection{SMART24 Test Data Sheet: 40 Vpp ADC Test - Calibrator/CAT/CFT}

Smart24 S/N: 1224

Firmware Revision: 1.38

Authentication: Enabled

CH 1-3: Single Three Channel 40 Vpp ADC Board - S/N 1724

Smart24 Sample Rate: 20 sps

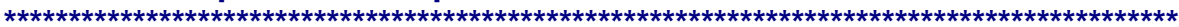

CAT Test Description: Determine accuracy of SMART24 to program correct output amplitude for sensor calibrations.

\begin{tabular}{|c|c|c|c|}
\hline $\begin{array}{c}\text { Programmed } \\
\text { SMART24 output } \\
\text { voltage (V) }\end{array}$ & $\begin{array}{c}\text { Measured } \\
\text { SMART24 } \\
\text { output voltage } \\
(\mathrm{V})\end{array}$ & $\begin{array}{c}\text { Test Frequency } \\
(\mathrm{Hz})\end{array}$ & $\begin{array}{c}\text { \% Deviation from } \\
\text { Nominal }\end{array}$ \\
\hline 5 & 4.985294 & 0.9999 & 0.29 \\
\hline 1 & 1.000102 & 1.0000 & -0.01 \\
\hline 0.5 & 0.499991 & 1.0000 & 0.00 \\
\hline 0.1 & 0.099953 & 1.0000 & 0.05 \\
\hline 0.05 & 0.049976 & 1.0000 & 0.05 \\
\hline
\end{tabular}

Table 6.20.1 SMART24 CAT results

Test Results: Table 6.20.1 indicates that the SMART24 output calibration amplitudes are better than $0.29 \%$ of nominal.

CFT Test Description: Determine accuracy of SMART24 to program correct output frequency for sensor calibrations.

\begin{tabular}{|c|c|c|c|}
\hline $\begin{array}{c}\text { Programmed } \\
\text { SMART24 } \\
\text { Output } \\
\text { Frequency (Hz) }\end{array}$ & $\begin{array}{c}\text { Measured } \\
\text { Frequency (Hz) }\end{array}$ & $\begin{array}{c}\text { Test Output } \\
\text { Voltage (V) }\end{array}$ & $\begin{array}{c}\text { \% Deviation from } \\
\text { Nominal } \\
\text { Frequency }\end{array}$ \\
\hline 5 & 5 & 1.000126 & 0.00000 \\
\hline 1 & 1 & 1.000087 & 0.00000 \\
\hline 0.5 & 0.5 & 1.000154 & 0.00000 \\
\hline 0.1 & 0.1 & 1.00039 & 0.00000 \\
\hline 0.05 & 0.05 & 1.000356 & 0.00000 \\
\hline 0.01 & 0.01 & 1.000368 & 0.00000 \\
\hline
\end{tabular}

Table 6.20.2 SMART24 CFT results

Test Results: Table 6.20.2 indicates that the SMART24 output calibration amplitudes are better than $0.00 \%$ of nominal. 


\subsection{SMART24 Test Data Sheet: 40 Vpp ADC Test - Calibrator/CAT/CFT}

Smart24 S/N: 1224

Firmware Revision: 1.38

Authentication: Enabled

CH 1-3: Single Three Channel 40 Vpp ADC Board - S/N 1724

Smart24 Sample Rate: 40 sps

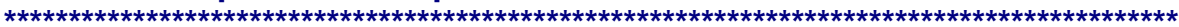

CAT Test Description: Determine accuracy of SMART24 to program correct output amplitude for sensor calibrations.

\begin{tabular}{|c|c|c|c|}
\hline $\begin{array}{c}\text { Programmed } \\
\text { SMART24 output } \\
\text { voltage (V) }\end{array}$ & $\begin{array}{c}\text { Measured } \\
\text { SMART24 } \\
\text { output voltage } \\
(\mathrm{V})\end{array}$ & $\begin{array}{c}\text { Test Frequency } \\
(\mathrm{Hz})\end{array}$ & $\begin{array}{c}\text { \% Deviation from } \\
\text { Nominal }\end{array}$ \\
\hline 5 & 5.008596 & 0.999992 & -0.17 \\
\hline 1 & 1.004836 & 0.999996 & -0.48 \\
\hline 0.5 & 0.502367 & 0.999996 & -0.47 \\
\hline 0.1 & 0.100433 & 0.999995 & -0.43 \\
\hline 0.05 & 0.050215 & 0.999998 & -0.43 \\
\hline
\end{tabular}

Table 6.21.1 SMART24 CAT results

Test Results: Table 6.21.1 indicates that the SMART24 output calibration amplitudes are better than $0.48 \%$ of nominal.

CFT Test Description: Determine accuracy of SMART24 to program correct output frequency for sensor calibrations.

\begin{tabular}{|c|c|c|c|}
\hline $\begin{array}{c}\text { Programmed } \\
\text { SMART24 } \\
\text { Output } \\
\text { Frequency (Hz) }\end{array}$ & $\begin{array}{c}\text { Measured } \\
\text { Frequency (Hz) }\end{array}$ & $\begin{array}{c}\text { Test Output } \\
\text { Voltage (V) }\end{array}$ & $\begin{array}{c}\text { \% Deviation from } \\
\text { Nominal } \\
\text { Frequency }\end{array}$ \\
\hline 5 & 4.999978 & 0.99371 & 0.00044 \\
\hline 1 & 0.999996 & 1.00486 & 0.00040 \\
\hline 0.5 & 0.499998 & 1.00521 & 0.00040 \\
\hline 0.1 & 0.100000 & 1.00531 & 0.00000 \\
\hline 0.05 & 0.050000 & 1.00533 & 0.00000 \\
\hline 0.01 & 0.010000 & 1.00534 & 0.00000 \\
\hline
\end{tabular}

Table 6.21.2 SMART24 CFT results

Test Results: Table 6.21.2 indicates that the SMART24 output calibration amplitudes are better than $0.00044 \%$ of nominal. 


\subsection{SMART24 Test Data Sheet: 40 Vpp ADC Test - Calibrator/CHD/CLB}

Smart24 S/N: 1224

Firmware Revision: 1.38

Authentication: Enabled

CH 1-3: Single Three Channel 40 Vpp ADC Board - S/N 1724

Smart24 Sample Rate: 20 sps

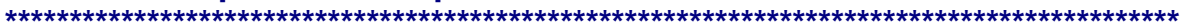

CHD Test Description: Determine linearity of SMART24's sensor calibration generator.

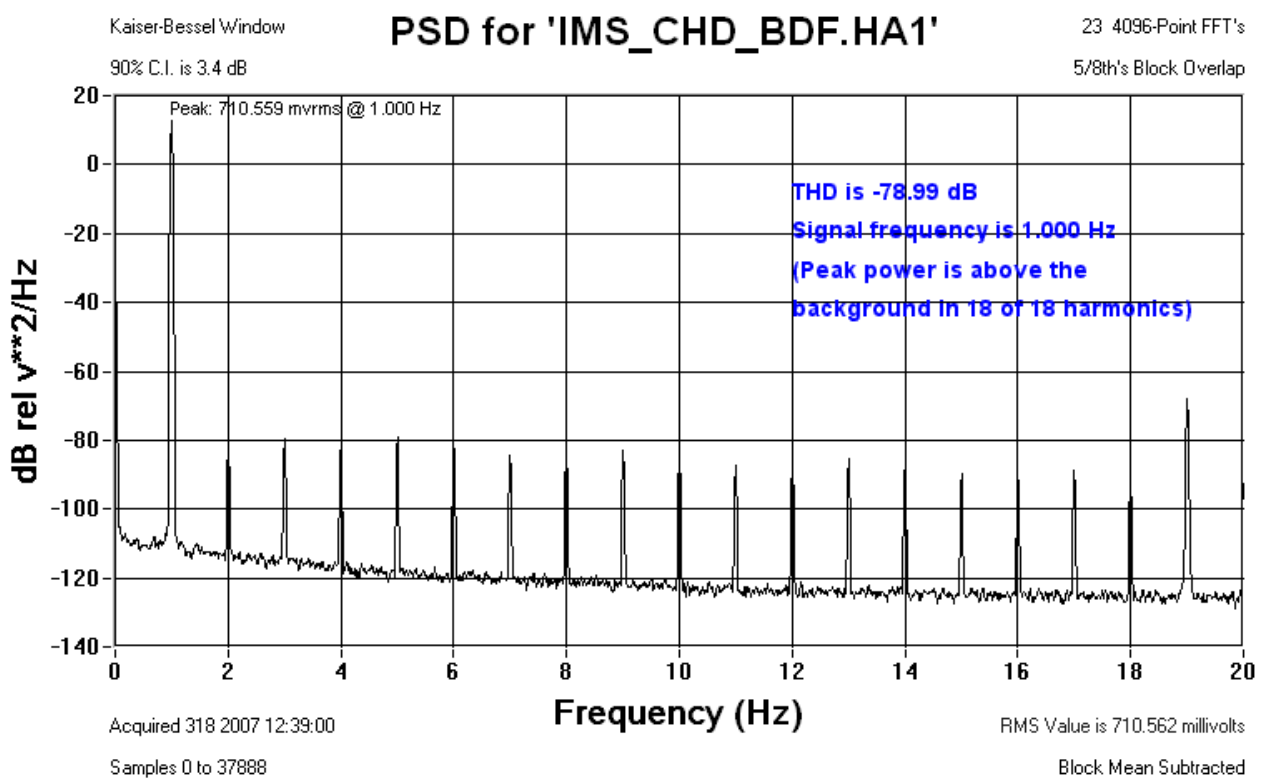

Figure 6.22.1 SMART24 sensor calibration generator's Total Harmonic Distortion for programmed output on channel BDF of 1 volts at $1 \mathrm{~Hz}$.

\begin{tabular}{|c|c|}
\hline Channel & THD \\
\hline BDF & $-78.99 \mathrm{~dB}$ \\
\hline
\end{tabular}

Table 6.22.1 SMART24 Sensor Calibration

Generator linearity using THD

Test Results: Table 6.22.1 indicates that the SMART24 Sensor Calibration Generator's Total Harmonic Distortion is better than -79 dB.

CLB Test Description: Determine linearity of SMART24's loopback circuit to the sensor calibration generator. 


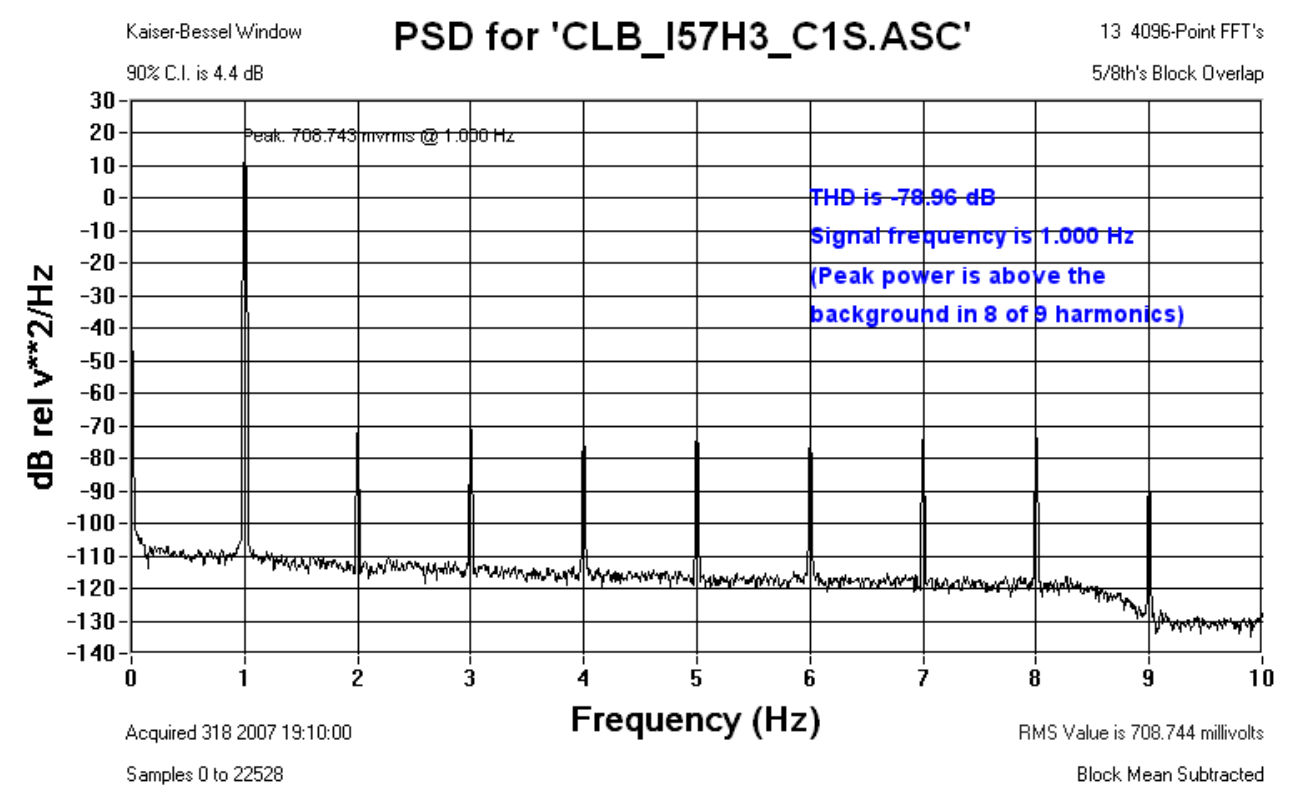

Figure 6.22.2 SMART24 sensor calibration generator's Total Harmonic Distortion loopback circuit for programmed output on channel $\mathrm{Z}$ of 1 volts at $1 \mathrm{~Hz}$.

\begin{tabular}{|c|c|}
\hline Channel & CLB \\
\hline BDF & -78.90 \\
\hline C2P & -78.96 \\
\hline C3P & -78.92 \\
\hline
\end{tabular}

Table 6.22.2 SMART24 Sensor Calibration

Generator linearity using loopback controls

Test Results: Table 6.22.2 indicates that the SMART24 Sensor Calibration Generator's Total Harmonic Distortion of the loopback circuit is better than $-79.92 \mathrm{~dB}$ and this CLB was within $0.11 \%$ of the original signal's THD (i.e. -78.99 dB). 


\subsection{SMART24 Test Data Sheet: 40 Vpp ADC Test - Calibrator/CHD/CLB}

Smart24 S/N: 1224

Firmware Revision: 1.38

Authentication: Enabled

CH 1-3: Single Three Channel 40 Vpp ADC Board - S/N 1724

Smart24 Sample Rate: $\mathbf{4 0}$ sps

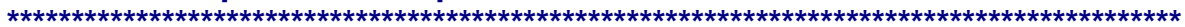

CHD Test Description: Determine linearity of SMART24's sensor calibration generator.

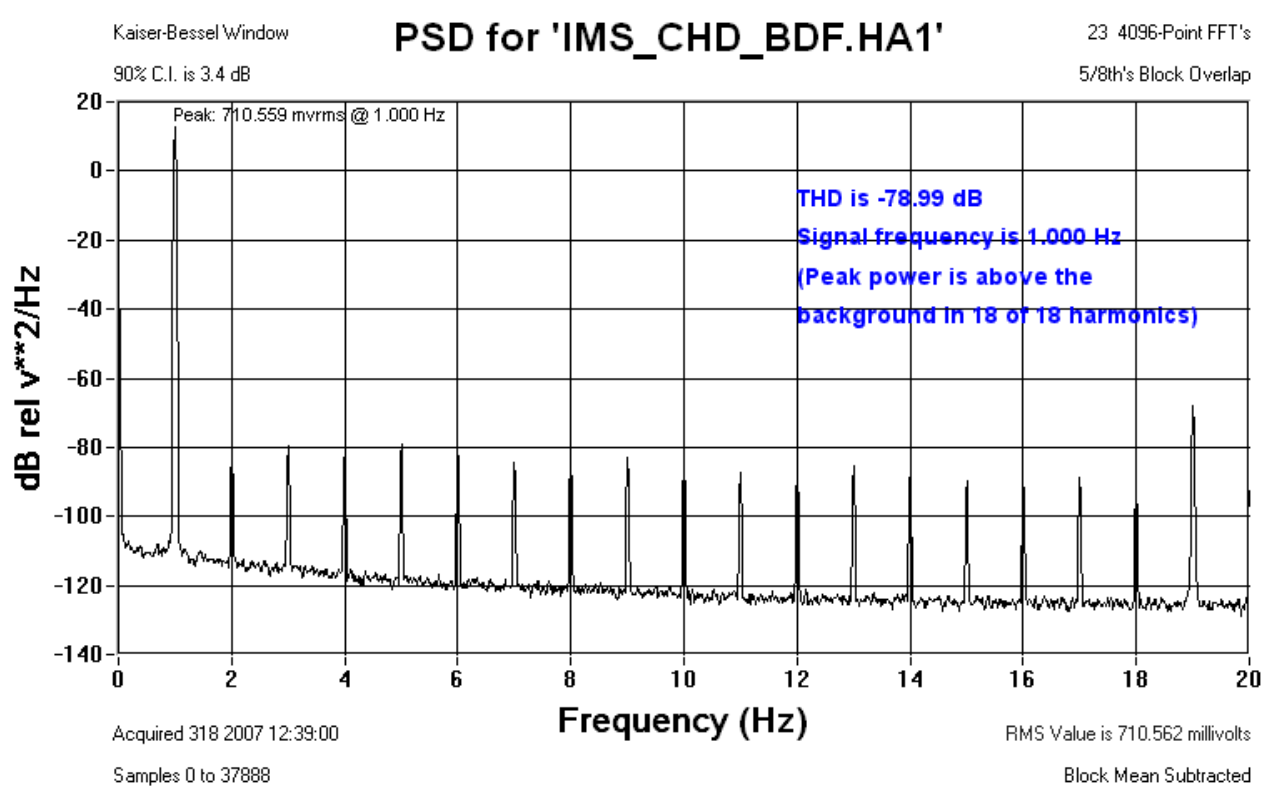

Figure 6.23.1 SMART24 sensor calibration generator's Total Harmonic Distortion for programmed output on channel BDF of 1 volts at $1 \mathrm{~Hz}$.

\begin{tabular}{|c|c|}
\hline Channel & THD \\
\hline BDF & $-78.99 \mathrm{~dB}$ \\
\hline
\end{tabular}

Table 6.23.1 SMART24 Sensor Calibration

Generator linearity using THD

Test Results: Table 6.23.1 indicates that the SMART24 Sensor Calibration Generator's Total Harmonic Distortion is better than -78.99 dB.

CLB Test Description: Determine linearity of SMART24's loopback circuit to the sensor calibration generator. 


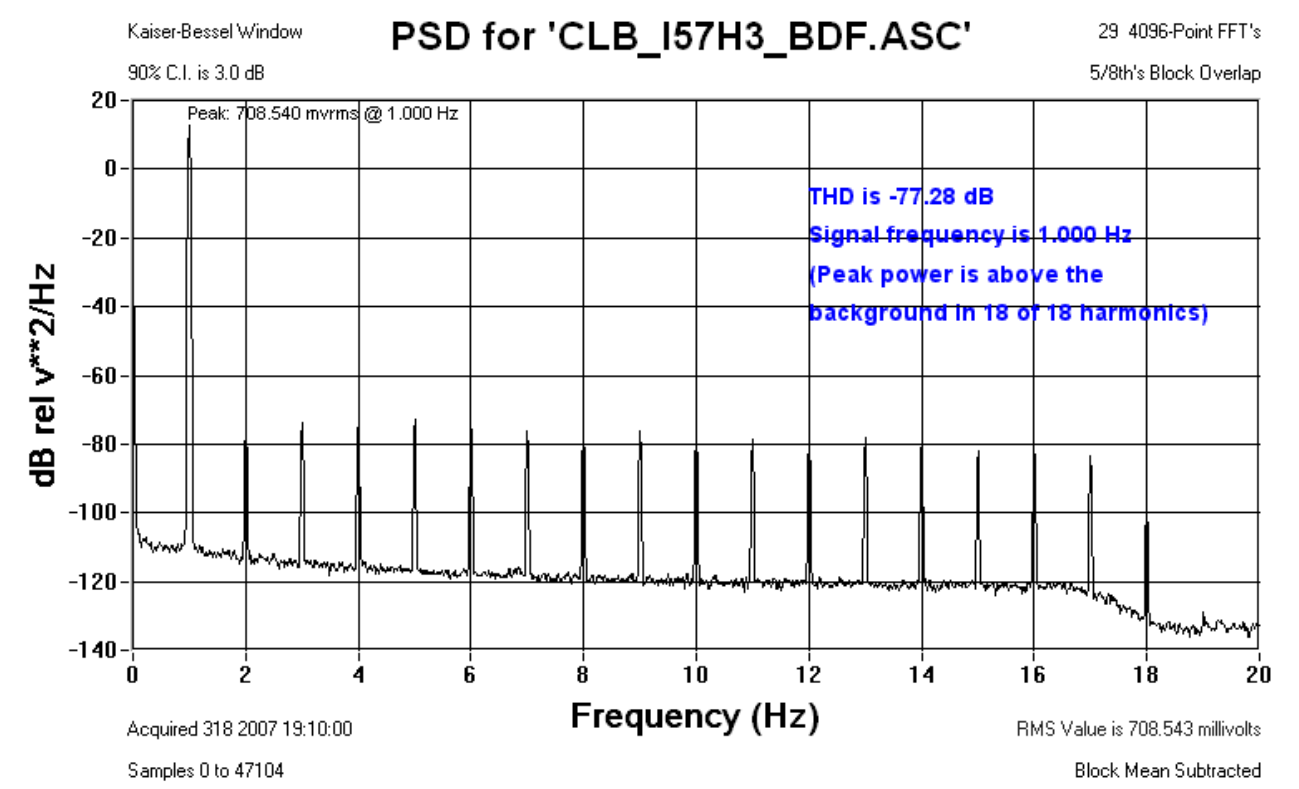

Figure 6.23.2 SMART24 sensor calibration generator's Total Harmonic Distortion loopback circuit for programmed output on channel $\mathrm{Z}$ of 1 volts at $1 \mathrm{~Hz}$.

\begin{tabular}{|c|c|}
\hline Channel & CLB \\
\hline BDF & -77.28 \\
\hline C2P & -77.26 \\
\hline C3P & -77.24 \\
\hline
\end{tabular}

Table 6.23.2 SMART24 Sensor Calibration Generator linearity using loopback controls

Test Results: Table 6.23.2 indicates that the SMART24 Sensor Calibration Generator's Total Harmonic Distortion of the loopback circuit is better than $-77.2 \mathrm{~dB}$ and this CLB was within $2.2 \%$ of the original signal's THD (i.e. $-\mathbf{7 8 . 9 9} \mathrm{dB}$ ). 


\section{DISTRIBUTION}

1 Leslie Casey

NNSA Office of Nonproliferation Research and Development/NA-22

1000 Independence Avenue SW

Washington, DC 20585

1 Dr. Lani Oncescu

Geotech Instruments, LLC

10755 Sanden Drive

Dallas, TX 75238-1336

1 Joe Schrodt

Air Force Technical Applications Center/TTR

1030 South Highway A1A

Patrick AFB, FL 32925-3002

$1 \quad$ MS0404 Bobby Corbell 05736

1 MS0404 Mark Harris 05736

1 MS0404 Darren Hart 05736

1 MS0404 John Merchant 05736

1 MS0404 Randy Rembold 05736

$1 \quad$ MS0899 Technical Library $\quad 9536$ 